Cochrane Database of Systematic Reviews

\title{
Antibiotics for acute rhinosinusitis in adults (Review)
}

Lemiengre MB, van Driel ML, Merenstein D, Liira H, Mäkelä M, De Sutter AIM

Lemiengre MB, van Driel ML, Merenstein D, Liira H, Mäkelä M, De Sutter AIM. Antibiotics for acute rhinosinusitis in adults.

Cochrane Database of Systematic Reviews 2018, Issue 9. Art. No.: CD006089. DOI: 10.1002/14651858.CD006089.pub5. 
TABLE OF CONTENTS

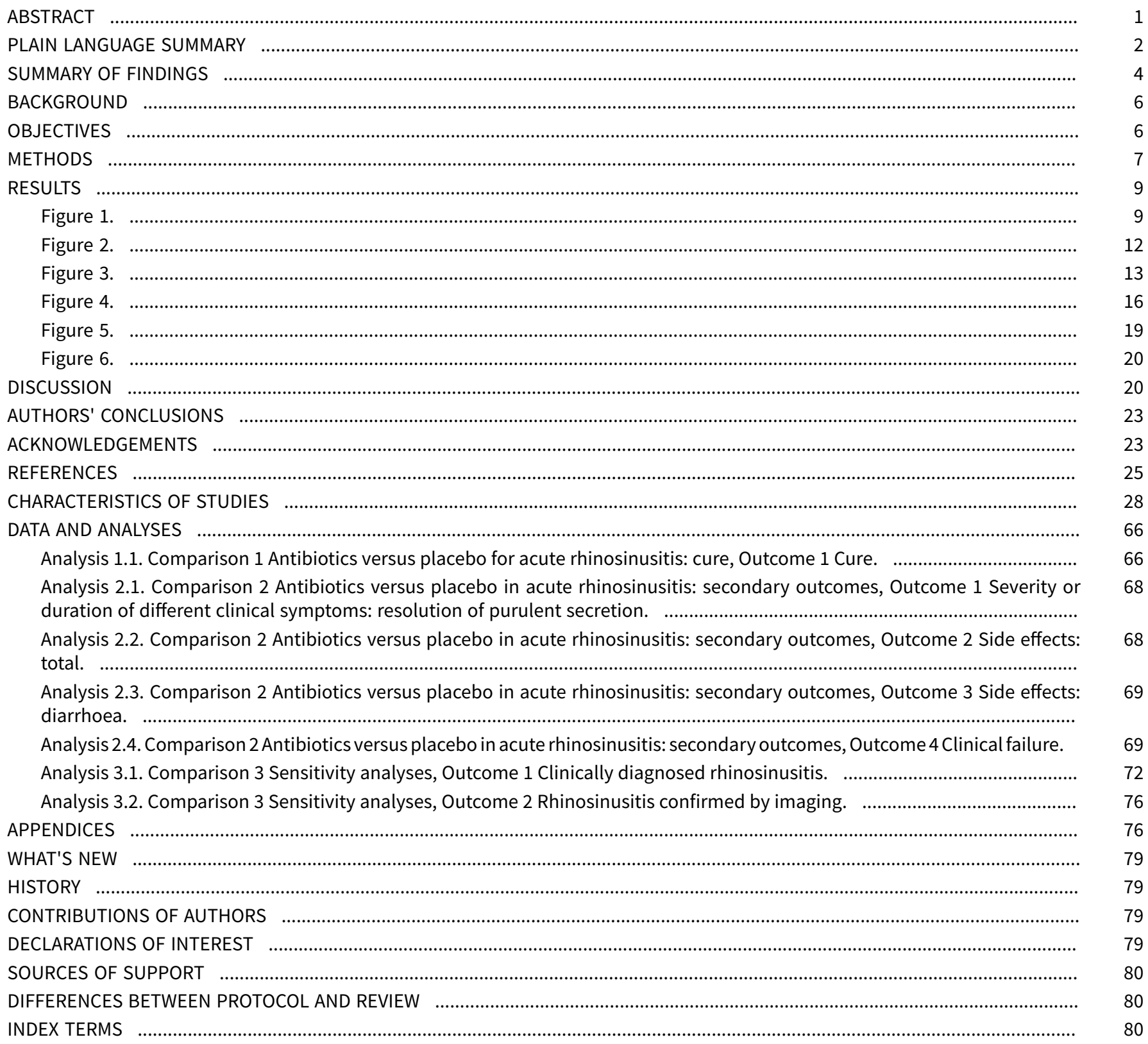


[Intervention Review]

\section{Antibiotics for acute rhinosinusitis in adults}

Marieke B Lemiengreㄹ, Mieke L van Driel1,2,3, Dan Merenstein4, Helena Liira5 ${ }^{5}$, Marjukka Mäkelä6,7, An IM De Sutter ${ }^{1}$

1Department of Family Medicine and Primary Health Care, Ghent University, Ghent, Belgium. ${ }^{2}$ Centre for Research in Evidence-Based Practice (CREBP), Bond University, Gold Coast, Australia. 3Primary Care Clinical Unit, Faculty of Medicine, The University of Queensland, Brisbane, Australia. ${ }^{4}$ Department of Family Medicine, Georgetown University Medical Center, Washington, DC, USA. ${ }^{5}$ University of Helsinki, Helsinki, Finland. ${ }^{6}$ THL (National Institute for Health and Welfare), Helsinki, Finland. ${ }^{7}$ Department of Public Health / Unit of General Practice, University of Copenhagen, DK-1014 Copenhagen, Denmark

Contact: Marieke B Lemiengre, Department of Family Medicine and Primary Health Care, Ghent University, Campus UZ 6K3, Corneel Heymanslaan 10, Ghent, 9000, Belgium. marieke.lemiengre@ugent.be.

Editorial group: Cochrane Acute Respiratory Infections Group.

Publication status and date: New search for studies and content updated (no change to conclusions), published in Issue 9, 2018.

Citation: Lemiengre MB, van Driel ML, Merenstein D, Liira H, Mäkelä M, De Sutter AIM. Antibiotics for acute rhinosinusitis in adults. Cochrane Database of Systematic Reviews 2018, Issue 9. Art. No.: CD006089. DOI: 10.1002/14651858.CD006089.pub5.

Copyright ( 2018 The Cochrane Collaboration. Published by John Wiley \& Sons, Ltd.

\section{A B S T R A C T}

\section{Background}

Acute rhinosinusitis is an acute infection of the nasal passages and paranasal sinuses that lasts less than four weeks. Diagnosis of acute rhinosinusitis is generally based on clinical signs and symptoms in ambulatory care settings. Technical investigations are not routinely performed, nor are they recommended in most countries. Some trials show a trend in favour of antibiotics, but the balance of benefit versus harm is unclear.

We merged two Cochrane Reviews for this update, which comprised different approaches with overlapping populations, resulting in different conclusions. For this review update, we maintained the distinction between populations diagnosed by clinical signs and symptoms, or imaging.

\section{Objectives}

To assess the effects of antibiotics versus placebo or no treatment in adults with acute rhinosinusitis in ambulatory care settings.

\section{Search methods}

We searched CENTRAL (2017, Issue 12), which contains the Cochrane Acute Respiratory Infections Group's Specialised Register, MEDLINE (January 1950 to January 2018), Embase (January 1974 to January 2018), and two trials registers (January 2018). We also checked references from identified trials, systematic reviews, and relevant guidelines.

\section{Selection criteria}

Randomised controlled trials of antibiotics versus placebo or no treatment in people with rhinosinusitis-like signs or symptoms or sinusitis confirmed by imaging.

\section{Data collection and analysis}

Two review authors independently extracted data about cure and side effects and assessed the risk of bias. We contacted trial authors for additional information as required.

\section{Main results}

We included 15 trials involving 3057 participants. Of the 15 included trials, 10 appeared in our 2012 review, and five (631 participants) are legacy trials from merging two reviews. No new studies were included from searches for this update. Overall, risk of bias was low. Without 
antibiotics, $46 \%$ of participants with rhinosinusitis, whether or not confirmed by radiography, were cured after 1 week and $64 \%$ after 14 days. Antibiotics can shorten time to cure, but only 5 to 11 more people per 100 will be cured faster if they receive antibiotics instead of placebo or no treatment: clinical diagnosis (odds ratio (OR) 1.25, 95\% confidence interval $(\mathrm{Cl}) 1.02$ to 1.54 ; number needed to treat for an additional beneficial outcome (NNTB) $19,95 \% \mathrm{Cl} 10$ to $205 ; \mathrm{I}^{2}=0 \% ; 8$ trials; high-quality evidence) and diagnosis confirmed by radiography (OR 1.57, 95\% Cl 1.03 to 2.39 ; NNTB 10, 95\% $\mathrm{Cl} 5$ to $136 ; \mathrm{I}^{2}=0 \%$; 3 trials; moderate-quality evidence). Cure rates with antibiotics were higher when a fluid level or total opacification in any sinus was found on computed tomography (OR 4.89, 95\% $\mathrm{Cl} 1.75$ to 13.72 ; NNTB $4,95 \%$ $\mathrm{Cl} 2$ to 15; 1 trial; moderate-quality evidence). Purulent secretion resolved faster with antibiotics (OR 1.58, 95\% Cl 1.13 to 2.22; NNTB 10, $95 \% \mathrm{Cl} 6$ to $35 ;\left.\right|^{2}=0 \% ; 3$ trials; high-quality evidence). However, 13 more people experienced side effects with antibiotics compared to placebo or no treatment (OR 2.21, $95 \% \mathrm{Cl} 1.74$ to 2.82; number needed to treat for an additional harmful outcome (NNTH) $8,95 \% \mathrm{Cl} 6$ to $12 ; I^{2}=16 \% ; 10$ trials; high-quality evidence). Five fewer people per 100 will experience clinical failure if they receive antibiotics instead of placebo or no treatment (Peto OR $0.48,95 \% \mathrm{Cl} 0.36$ to 0.63 ; NNTH $19,95 \% \mathrm{Cl} 15$ to $27 ; \mathrm{I}^{2}=21 \%$; 12 trials; high-quality evidence). A diseaserelated complication (brain abscess) occurred in one participant (of 3057) one week after receiving open antibiotic therapy (clinical failure, control group).

\section{Authors' conclusions}

The potential benefit of antibiotics to treat acute rhinosinusitis diagnosed either clinically (low risk of bias, high-quality evidence) or confirmed by imaging (low to unclear risk of bias, moderate-quality evidence) is marginal and needs to be seen in the context of the risk of adverse effects. Considering antibiotic resistance, and the very low incidence of serious complications, we conclude there is no place for antibiotics for people with uncomplicated acute rhinosinusitis. We could not draw conclusions about children, people with suppressed immune systems, and those with severe sinusitis, because these populations were not included in the available trials.

\section{PLAIN LANGUAGE SUMMARY}

\section{Antibiotics for sinus infection of short duration in adults}

\section{Review question}

Do antibiotics cure sinus infection faster than no antibiotics in adults?

\section{Background}

A sinus is a cavity situated in the head. Adults with short-duration sinus infection experience stuffy nose and thick, yellow discharge from the nose. People with sinus infection can feel slime in the back of the throat, facial pain, pain when bending forward, and pain in the upper teeth or when chewing. A short-duration sinus infection may be suspected following physical examination and questions about symptoms. Blood examination or images of the sinuses can support diagnosis, but are not routinely recommended in most countries. Short-duration sinus infections are mostly caused by viruses. Nevertheless, physicians tend to prescribe antibiotics, which should only be used to treat bacterial infections. Taking antibiotics unnecessarily results in antibiotic resistance against bacterial infections. We investigated whether antibiotics cure adults with short-duration sinus infection faster than a dummy drug (placebo) or no treatment.

\section{Search date}

18 January 2018.

\section{Study characteristics}

We included 15 studies in which adults with short-duration sinus infection, whether or not confirmed by imaging, randomly received antibiotics, or a dummy drug or no treatment, in ambulatory care settings. The studies included a total of 3057 adults whose average age was 36 years; about $60 \%$ were female. Participants were followed until they were cured. Trial duration ranged from 8 to 28 days.

\section{Study funding sources}

Seven studies received financial support from government or academic institutions; six received grants from the pharmaceutical industry; and five did not state sources of support.

\section{Key results}

Without antibiotics, almost half of all participants were cured after one week, and two out of three were cured after 14 days. Five (diagnosis based on symptoms described to a doctor) to 11 (diagnosis confirmed by x-ray) more people per 100 were cured faster with antibiotics. A computed tomography (CT) scan could better predict who would benefit from antibiotics, but routine use would cause health problems related to radiation exposure. Ten more people per 100 were relieved faster of thick, yellow discharge from the nose with antibiotics compared to a dummy drug or no treatment. Thirteen more people per 100 experienced side effects (mostly concerning stomach or intestines) with antibiotics compared to a dummy drug or no treatment. Compared with people who initially started antibiotics, five more people per 100 in the dummy drug or no treatment group had to start antibiotics because their condition worsened. Serious complications (e.g. brain abscess) were rare. 
We found that antibiotics are not a first-choice treatment for adults with short-duration sinus infection. We found no evidence relating to adults with severe sinusitis or with reduced immunity, or to children.

\section{Quality of evidence}

We found high-quality evidence when the diagnosis was based on symptoms described to a doctor. We downgraded evidence quality to moderate when diagnosis was confirmed by x-ray or CT scan because the number of participants was small, which makes the estimates less reliable. 
SUMMARY OF FINDINGS

Summary of findings for the main comparison. Antibiotics compared to placebo for acute rhinosinusitis in adults

Antbiotics compared to placebo for acute rhinosinusitis in adults

Patient or population: acute rhinosinusitis in adults, whether clinically diagnosed or confirmed by imaging

Settings: general practice (11 studies), otolaryngology outpatient clinics of university hospitals ( 2 studies), medical centre (1 study), unknown ( 2 studies)

Intervention: antibiotics

Comparison: placebo

\begin{tabular}{|c|c|c|c|c|c|c|}
\hline \multirow[t]{3}{*}{ Outcomes } & \multicolumn{2}{|c|}{$\begin{array}{l}\text { Illustrative comparative risks }{ }^{\star} \\
(95 \% \mathrm{CI})\end{array}$} & \multirow[t]{3}{*}{$\begin{array}{l}\text { Relative effect } \\
(95 \% \mathrm{Cl})\end{array}$} & \multirow{3}{*}{$\begin{array}{l}\text { No. of partici- } \\
\text { pants } \\
\text { (studies) }\end{array}$} & \multirow{3}{*}{$\begin{array}{l}\text { Quality of the } \\
\text { evidence } \\
\text { (GRADE) }\end{array}$} & \multirow[t]{3}{*}{ Comments } \\
\hline & Assumed risk & $\begin{array}{l}\text { Corresponding } \\
\text { risk }\end{array}$ & & & & \\
\hline & Placebo & Antibiotics & & & & \\
\hline $\begin{array}{l}\text { Cure in adults with } \\
\text { clinically diagnosed } \\
\text { acute rhinosinusitis }\end{array}$ & 55 per 100 & $\begin{array}{l}60 \text { per } 100 \\
(56 \text { to } 65)\end{array}$ & $\begin{array}{l}\text { OR } 1.25 \\
(1.02 \text { to } 1.54)\end{array}$ & $\begin{array}{l}1687 \\
\text { (8 studies) }\end{array}$ & $\begin{array}{l}\oplus \oplus \oplus \oplus \\
\text { High }\end{array}$ & $\begin{array}{l}\text { Combination of sinusitis-like symptoms. Most } \\
\text { frequently used clinical symptoms: nasal dis- } \\
\text { charge, facial pain, and common cold or upper } \\
\text { respiratory tract infection. } \\
\text { NNTB } 19 \text { (95\% Cl } 10 \text { to } 205)\end{array}$ \\
\hline $\begin{array}{l}\text { Cure in adults with } \\
\text { acute rhinosinusitis } \\
\text { confirmed by radiogra- } \\
\text { phy } 1\end{array}$ & 51 per 100 & $\begin{array}{l}62 \text { per } 100 \\
(52 \text { to } 72)\end{array}$ & $\begin{array}{l}\text { OR } 1.57 \\
\text { (1.03 to } 2.39 \text { ) }\end{array}$ & $\begin{array}{l}394 \\
\text { (3 studies) }\end{array}$ & $\begin{array}{l}\oplus \oplus \oplus \ominus \\
\text { Moderate } 2,3\end{array}$ & $\begin{array}{l}\text { Clinical suspicion + radiography, using various } \\
\text { criteria: } \\
\text { - confirmed secretion; } \\
\text { - > } 5 \mathrm{~mm} \text { mucosal thickening, opacity or fluid } \\
\text { level; or } \\
\text { - the presence in at least } 1 \text { sinus of an air-fluid } \\
\text { level, a complete opacity, or a mucosal thick- } \\
\text { ening of } 10 \mathrm{~mL} \text {. } \\
\text { NNTB } 10 \text { ( } 95 \% \mathrm{Cl} 5 \text { to } 136)\end{array}$ \\
\hline $\begin{array}{l}\text { Cure in adults with } \\
\text { acute rhinosinusitis } \\
\text { confirmed by comput- } \\
\text { ed tomography } 1,4\end{array}$ & 11 per 100 & $\begin{array}{l}39 \text { per } 100 \\
(18 \text { to } 64)\end{array}$ & $\begin{array}{l}\text { OR } 4.89 \\
\text { (1.75 to } 13.72)\end{array}$ & $\begin{array}{l}127 \\
\text { (1 study) }\end{array}$ & $\begin{array}{l}\oplus \oplus \oplus \ominus \\
\text { Moderate }^{5}\end{array}$ & $\begin{array}{l}\text { Clinical suspicion + computed tomography, us- } \\
\text { ing as a criterion presence of fluid level or total } \\
\text { opacification in any sinus } \\
\text { NNTB } 4(95 \% \mathrm{Cl} 2 \text { to } 15)\end{array}$ \\
\hline
\end{tabular}




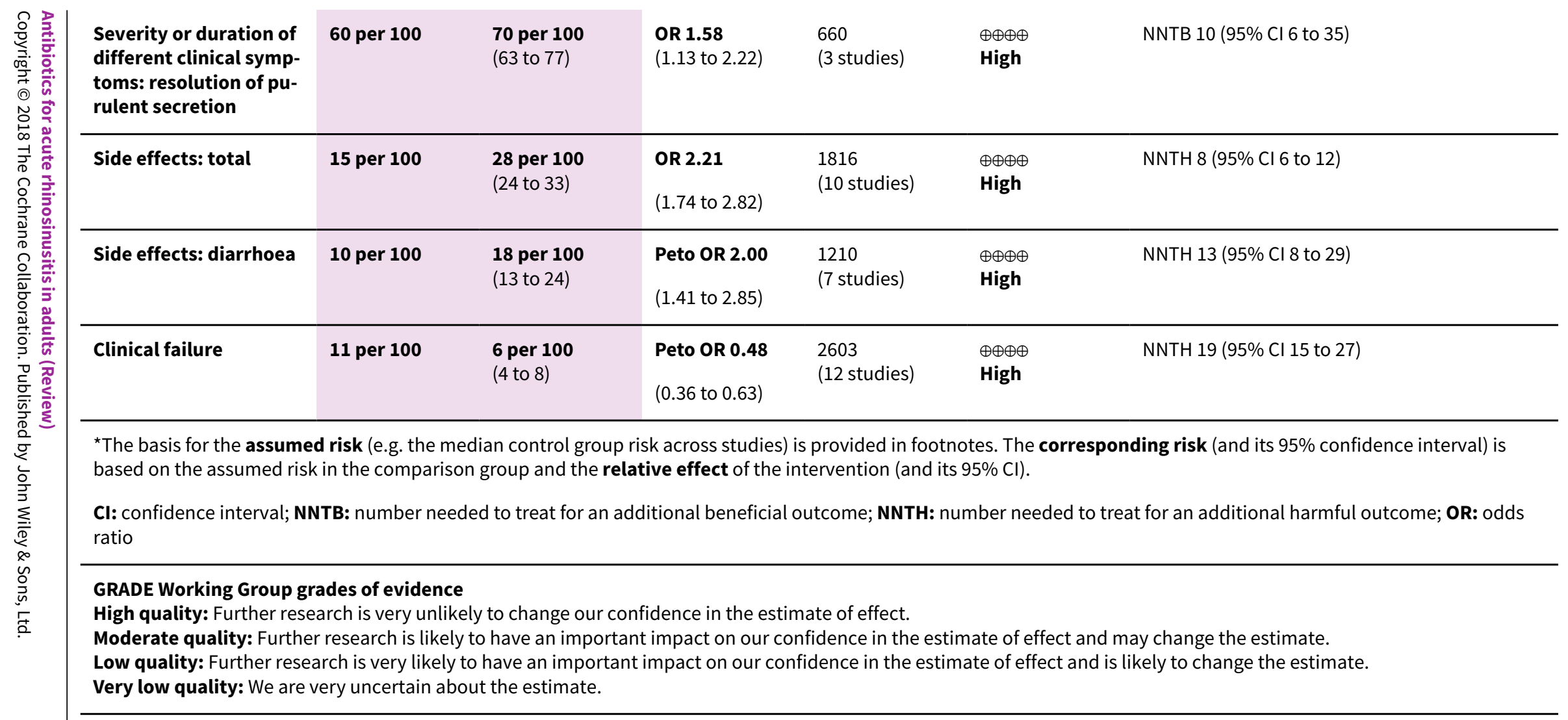

Only outcomes that could be pooled were presented.

1 High heterogeneity $\left(\mathrm{I}^{2}=41 \%\right)$ for the outcome of cure in adults with acute rhinosinusitis confirmed by imaging led us to split the outcome into cure in adults with acute rhinosinusitis confirmed by radiography and cure in adults with acute rhinosinusitis confirmed by computed tomography.

2There was a high risk of blinding bias in Axelsson 1970. Blinding was not reported and was probably not applied. Placebo group participants did not receive tablets, only nose drops. It was not possible to blind sinus irrigation as an intervention. Only group 2 participants underwent radiological evaluation every second day. Group 3 participants received a longer course of tablets than group 4. For this reason, we downgraded the quality of evidence from high to moderate. Omitting this trial from the meta-analysis did not substantially change the overall result; therefore, we did not downgrade the quality of the evidence further.

3Three trials reported cure in adults with acute rhinosinusitis confirmed by radiography, and confidence intervals were wide. We downgraded the quality of the evidence to moderate.

4 Lindbaek 1996 and Lindbaek 1998 presented study results from two distinct groups (those with fluid level or total opacification in any sinus on computed tomography and those with only mucosal thickening on computed tomography, respectively). Consequently, the results of the two trials were very different $\left(I^{2}=84 \%\right)$. We opted to report only the results from Lindbaek 1996 because the beneficial effect of antibiotics was clearly present only in this subgroup.

5 Only one trial $(\mathrm{N}=127)$ reported on cure in adults with acute rhinosinusitis confirmed by computed tomography. We downgraded the quality of the evidence to moderate because of the low number of participants despite this being a well-conducted trial. 


\section{B A C K G R O U N D}

We merged two Cochrane Reviews for this update (De Sutter 2012; Ahovuo-Saloranta 2014).

\section{Description of the condition}

Acute rhinosinusitis is defined as an acute infection of the nasal passages and the paranasal sinuses lasting fewer than four weeks (Ah-See 2007; Lanza 1997). It is one of the most common diagnoses made in ambulatory care and continues to be a clinical challenge (Blackwell 2014; Lethbridge-Cejku 2006; McCaig 1995; Okkes 2005; Schappert 1998; Willet 1994). Although guidelines have long recommended restricted use of antibiotics for rhinosinusitis, antibiotics continue to be prescribed for $67 \%$ to $100 \%$ of people with suspected acute rhinosinusitis (Gulliford 2014 (UK); Rún 2015 (Denmark, Iceland); Fleming-Dutra 2016 (USA)).

Rhinosinusitis is a more exact term than sinusitis since it takes into account that inflammation of the sinuses is unlikely to occur without inflammation of the mucous membranes of the nose. In this review, the term 'sinusitis' was used when inflammation of a specific sinus (confirmed by radiology or ultrasound) was mentioned (e.g. maxillary sinusitis). Sinusitis was often used in older studies when referring to rhinosinusitis.

Typical signs and symptoms of acute rhinosinusitis include purulent nasal discharge, postnasal drip, sinus pain at palpation, unilateral facial pain, and maxillary toothache (Autio 2015; Axelsson 1972; Williams 1993). However, there is no convincing evidence that people with these clinical findings would benefit from antibiotic treatment (Young 2008). Bacterial infections can also be self limiting. Imaging investigations, such as $\mathrm{x}$-ray and computed tomography (CT), have been used to demonstrate fluid in the sinuses (air-fluid level or total opacity). Sinus ultrasound has also been used for this purpose in Scandinavia (Varonen 2000). However, radiological methods cause radiation, are not readily available in ambulatory care settings, and cannot differentiate between viral and bacterial infections. Rhinosinusitis could be confirmed by sinus puncture (Lindbaek 2002), but this is not a feasible ambulatory care method. Acute rhinosinusitis remains a clinical diagnosis with a non-specific clinical picture.

\section{Description of the intervention}

We investigated the effectiveness of antibiotics versus placebo or no treatment in adults with acute rhinosinusitis, whether diagnosed clinically or by imaging.

Two previous Cochrane Reviews ('Antibiotics for acute maxillary sinusitis in adults' and 'Antibiotics for clinically diagnosed acute rhinosinusitis in adults') described the effect of antibiotics for acute rhinosinusitis (Ahovuo-Saloranta 2014; De Sutter 2012). The reviews studied the same condition but looked at different populations: people diagnosed by imaging versus people diagnosed clinically according to their signs and symptoms (Ahovuo-Saloranta 2014; De Sutter 2012). As different approaches resulted in different conclusions, we therefore merged these reviews while maintaining the relevant distinction between the two populations. We omitted comparison between antibiotics, as assessed by Ahovuo-Saloranta 2014. Rather than clinical trials, local up-to-date antibiotic resistance patterns should guide clinicians in making the best choice of a particular antibiotic and dose in the subgroup of people with suspected bacterial rhinosinusitis.

Two other Cochrane Reviews focused on antibiotic treatment for people with acute infections of the nose, sinuses, or both (Kenealy 2013; Morris 2002). Kenealy and colleagues looked at the effect of antibiotics in people with symptoms of acute upper respiratory tract infection lasting less than seven days, or acute purulent rhinitis of less than 10 days duration (Kenealy 2013). The authors concluded that there was insufficient evidence to warrant the use of antibiotics for common cold or for persisting acute purulent rhinitis in children or adults (Kenealy 2013). Morris and colleagues considered antibiotic treatment in children with persistent nasal discharge (Morris 2002). The authors concluded that antibiotics have some benefit in the short and medium term in children with purulent rhinorrhoea for more than 10 days, or in older children with radiologically confirmed rhinosinusitis (Morris 2002).

\section{How the intervention might work}

Acute rhinosinusitis can be caused by viral or bacterial infections. Acute viral rhinosinusitis is a viral upper respiratory tract infection (or common cold) which, in most cases, also involves the sinuses. Gwaltney 1994 showed that $87 \%$ of people with a common cold also have sinus abnormalities on CT scan. Antibiotics are unnecessary in viral rhinosinusitis (Hickner 2001), and people prescribed an antibiotic can develop bacterial resistance to that antibiotic (Costelloe 2010).

Few people $(0.5 \%$ to $2 \%)$ develop bacterial rhinosinusitis (Berg 1986; Gwaltney 1996). Antibiotics may be indicated for bacterial rhinosinusitis to speed up recovery or to prevent suppurative complications. Identifying people with bacterial rhinosinusitis on a clinical basis is challenging (Ebell 2017; Lindbaek 2002). Bacterial origin may be more likely if symptoms last for more than a week (Gwaltney 2005). Consequently, the notions of 'viral' and 'bacterial' are not very workable in daily practice, and there is a pressing need to identify who would benefit from antibiotics (Lanza 1997).

\section{Why it is important to do this review}

Diagnosis of most people with acute rhinosinusitis who present in ambulatory care settings is based on clinical signs and symptoms. In most countries, technical investigations are not routinely performed, nor are they recommended (Brazzelli 2003; Hickner 2001; Low 1997). Except for the Cochrane Reviews that are part of this amalgamation (Ahovuo-Saloranta 2014; De Sutter 2012), two other previously published Cochrane Reviews did not focus exclusively on adults or people with suspected rhinosinusitis (Kenealy 2013; Morris 2002). Results from those reviews could therefore not indicate if this population should be treated with antibiotics. Individual trials show a trend in favour of antibiotics for this population, but the balance of benefit versus harm is unclear.

\section{O B JECTIVES}

To assess the effects of antibiotics versus placebo in adults with acute rhinosinusitis in ambulatory care settings. 


\section{METHODS}

\section{Criteria for considering studies for this review}

\section{Types of studies}

We included randomised controlled trials (RCTs) comparing antibiotics with placebo or no treatment in participants with rhinosinusitis-like signs or symptoms, whether confirmed by imaging or not. We considered trials including participants with an upper respiratory tract infection or common cold if most participants had rhinosinusitis-like symptoms, or if participants with rhinosinusitis-like symptoms could be analysed separately.

We excluded the following studies.

1. Trials in which participants were included on the basis of a laboratory investigations such as measurement of Creactive protein (CRP) or erythrocyte sedimentation rate (ESR), bacteriological or cytological investigations.

2. Studies comparing one antibiotic with another and trials comparing antibiotics versus other medications.

3. Trials in which more than $50 \%$ of participants were considered to have a common cold.

4. Trials in which participants had signs and symptoms for more than 30 days.

5. Trials in which participants were not randomised, or trials that did not include a placebo arm.

\section{Types of participants}

We considered all trials in which adults with acute rhinosinusitis, whether clinically diagnosed or confirmed by imaging, were randomly assigned to treatment with an antibiotic, placebo, or no treatment. The clinical diagnosis of acute rhinosinusitis was based on the presence of clinical signs or symptoms that are associated with the presence of fluid in the sinuses in diagnostic studies or that are mentioned in clinical practice guidelines as indicating rhinosinusitis. These included: started with a common cold or experienced both phases of the illness (i.e. catches a cold, feels better after a few days, then feels worse again), purulent nasal discharge, unilateral maxillary pain, pain in the upper teeth, pain when chewing, postnasal drip, pain on bending forward, and duration of symptoms for more than seven days.

We limited participants to adults (aged 18 years or over); the Cochrane Review by Morris 2002 reviewed studies on children. We limited the duration of symptoms to 30 days or less to exclude participants with subacute or chronic rhinosinusitis, where the infection was probably not the primary cause of inflammation (Bachert 2003).

\section{Types of interventions}

We included only RCTs that compared antibiotic therapy versus placebo or no treatment. We included trials that permitted concurrent use of other medications if participants were allowed equal access in both the antibiotic and placebo groups.

\section{Types of outcome measures}

\section{Primary outcomes}

1. Cure in people with:

a. clinically diagnosed rhinosinusitis;

b. rhinosinusitis confirmed by imaging.

\section{Secondary outcomes}

1. Ratings of measures of overall well-being.

2. Severity or duration of different clinical symptoms:
a. resolution of purulent secretion;
b. resolution of pain;
c. illness duration;
d. restriction of daily activities.

3. Use of concomitant medications:
a. analgesics;
b. nasal decongestants.

4. Side effects.

5. Clinical failure.

6. Serious adverse events.

\section{Search methods for identification of studies}

\section{Electronic searches}

We searched the following databases up to 18 January 2018 for this update:

1. the Cochrane Central Register of Controlled Trials (CENTRAL; 2017, Issue 12), which contains the Cochrane Acute Respiratory Infections Group's Specialised Register, in the Cochrane Library using the strategy in Appendix 1;

2. MEDLINE via Ovid (from January 1950 to January 2018) using the strategy in Appendix 1; and

3. Embase via Elsevier (from January 1974 to January 2018) using the strategy in Appendix 2.

We searched the following trials registries on 18 January 2018:

1. the World Health Organization International Clinical Trials Registry Platform (WHO ICTRP) (apps.who.int/trialsearch) (Appendix 3); and

2. ClinicalTrials.gov (clinicaltrials.gov) (Appendix 4).

We did not restrict the results by language or publication status.

\section{Searching other resources}

We scrutinised the reference lists of identified trials, systematic reviews, and relevant guidelines for other eligible trials.

\section{Data collection and analysis}

\section{Selection of studies}

Two review authors (ML, ADS) independently screened titles and abstracts of all studies identified as a result of the search for studies that were potentially eligible for inclusion in the review. We retrieved the full-text study reports, and two review authors (ML, ADS) independently screened the full texts to identify studies for inclusion, and identify and record reasons for exclusion of ineligible studies. Any disagreements were resolved through discussion or by consulting a third review author (MVD) where necessary. We 
identified and excluded duplicates and collated multiple reports of the same study so that each study, rather than each report, was the unit of interest in the review. We recorded the selection process in sufficient detail to complete a PRISMA flow diagram and Characteristics of excluded studies table (Moher 2009). We did not impose any language restrictions.

\section{Data extraction and management}

We used a data collection form for study characteristics and outcome data that had been piloted on at least one study in the review. Two review authors (ML, ADS) extracted the following study characteristics from the included studies.

1. Methods: study design, total duration of study, details of any 'run in' period, number of study centres and location, study setting, withdrawals, and date of study.

2. Participants: N, mean age, age range, gender, severity of condition, diagnostic criteria, baseline lung function, smoking history, inclusion criteria, and exclusion criteria.

3. Interventions: intervention, comparison, concomitant medications, and excluded medications.

4. Outcomes: primary and secondary outcomes specified and collected, and time points reported.

5. Notes: funding for trial, and notable conflicts of interest of trial authors.

Two review authors (ML, ADS) independently extracted outcome data from the included studies. We noted in the Characteristics of included studies table if outcome data were not reported in a usable way. There were no disagreements. One review author $(\mathrm{ML})$ transferred data into the Review Manager 5 file (Review Manager 2014). We double-checked that data were entered correctly by comparing the data presented in the systematic review with the study reports. A second review author (ADS) spot-checked study characteristics for accuracy against the trial report.

\section{Assessment of risk of bias in included studies}

Two review authors (ML, ADS) independently assessed risk of bias for each study using the criteria outlined in the Cochrane Handbook for Systematic Reviews of Interventions (Higgins 2011a). Any disagreements were resolved by discussion. We assessed the risk of bias according to the following domains.

1. Random sequence generation.

2. Allocation concealment.

3. Blinding of participants and personnel.

4. Blinding of outcome assessment.

5. Incomplete outcome data.

6. Selective outcome reporting.

7. Other bias.

We graded each potential source of bias as high, low, or unclear and provided a quote from the study report together with a justification for our judgement in the 'Risk of bias' table. We summarised the 'Risk of bias' judgements across different studies for each of the domains listed. We considered blinding separately for different key outcomes, where necessary. Where information on risk of bias related to unpublished data or correspondence with a trialist, we planned to note this in the 'Risk of bias' table.
When considering treatment effects, we took into account the risk of bias for the studies that contributed to that outcome.

\section{Assessment of bias in conducting the systematic review}

We conducted the review according to the published protocol and reported any deviations from it in the Differences between protocol and review section. We ensured that current Cochrane methods were applied.

\section{Measures of treatment effect}

We entered outcome data for each study into the data tables in Review Manager 5 to calculate the treatment effects (Review Manager 2014). We used odds ratio for dichotomous outcomes, and mean differences or standardised mean differences for continuous outcomes.

We conducted meta-analyses only where this was meaningful, that is the treatments, participants, and the underlying clinical question were similar enough for pooling to make sense.

\section{Unit of analysis issues}

In trials with multiple treatment groups, we compared event rates in the antibiotic treatment arms (intervention) with placebo event rates (control). We did not include cluster-RCTs.

\section{Dealing with missing data}

Where numerical outcome data were missing and could not be obtained from the authors, these were calculated from other available statistics, according to the methods described in the Cochrane Handbook for Systematic Reviews of Interventions (Higgins 2011b).

\section{Assessment of heterogeneity}

We assessed variability among studies for statistical heterogeneity using Cochran's test for heterogeneity and the $1^{2}$ statistic. The $I^{2}$ statistic describes the percentage of variability in effect estimates that is due to heterogeneity rather than to sampling error. We considered a value greater than $50 \%$ to represent substantial heterogeneity, in which case we used a random-effects model.

\section{Assessment of reporting biases}

We planned to construct funnel plots to assess the likelihood of publication bias if 10 studies or more were available for analysis.

\section{Data synthesis}

We pooled data from studies judged to be clinically homogeneous using Review Manager 5 software (Review Manager 2014). If more than one study provided usable data in any single comparison, we performed a meta-analysis.

\section{GRADE and 'Summary of findings' table}

We created Summary of findings for the main comparison using the following outcomes.

1. Cure in adults with clinically diagnosed rhinosinusitis.

2. Cure in adults with rhinosinusitis confirmed by radiography.

3. Cure in adults with rhinosinusitis confirmed by CT scan.

4. Resolution of purulent secretion.

5. Side effects: general. 
6. Side effects: diarrhoea.

7. Clinical failure.

We used the five GRADE considerations (study limitations, consistency of effect, imprecision, indirectness, and publication bias) to assess the quality of a body of evidence as it relates to the studies that contributed data to the meta-analyses for the prespecified outcomes (Atkins 2004). We used methods and recommendations described in Section 8.5 and Chapter 12 of the Cochrane Handbook for Systematic Reviews of Interventions (Higgins 2011b), using GRADEpro GDT software (GRADEpro GDT 2015). We justified all decisions to down- or upgrade the quality of studies using footnotes, and made comments to aid the reader's understanding of the review where necessary.

\section{Subgroup analysis and investigation of heterogeneity}

We planned to carry out the following subgroup analyses.

1. Clinically diagnosed rhinosinusitis.

2. Rhinosinusitis confirmed by imaging.

We used the $\mathrm{Chi}^{2}$ test to test for subgroup interactions using Review Manager 5 software (Review Manager 2014).

\section{Figure 1. Study flow diagram.}

Search yield
Database searches
After removal of duplicates, 409 records
identified through database searching
Trials registers searches
After removal of duplicates, 115 records
identified through trials registers searching
(WHO ICTRP, ClinicalTrials.gov)

\section{Sensitivity analysis}

We carried out the following sensitivity analyses.

1. Excluding studies at higher risk of bias.

2. Assessing the influence of missing data: adding dropouts as failures, successes or as having the same cure rate as control group.

3. Adding participants who were 'improved' to those who were cured.

\section{RESULTS}

\section{Description of studies}

See Characteristics of included studies and Characteristics of excluded studies tables.

\section{Results of the search}

For the 2018 update, after deleting duplicates, we identified 524 new records from electronic searches. We rejected 354 records on the basis of title or keyword assessment, 52 records after assessing abstracts, and three records following full-text record assessment. We rejected 115 trials based on information from trials registers (WHO ICTRP or ClinicalTrials.gov). No new studies were added for this update as a result of 2018 searches (Figure 1).

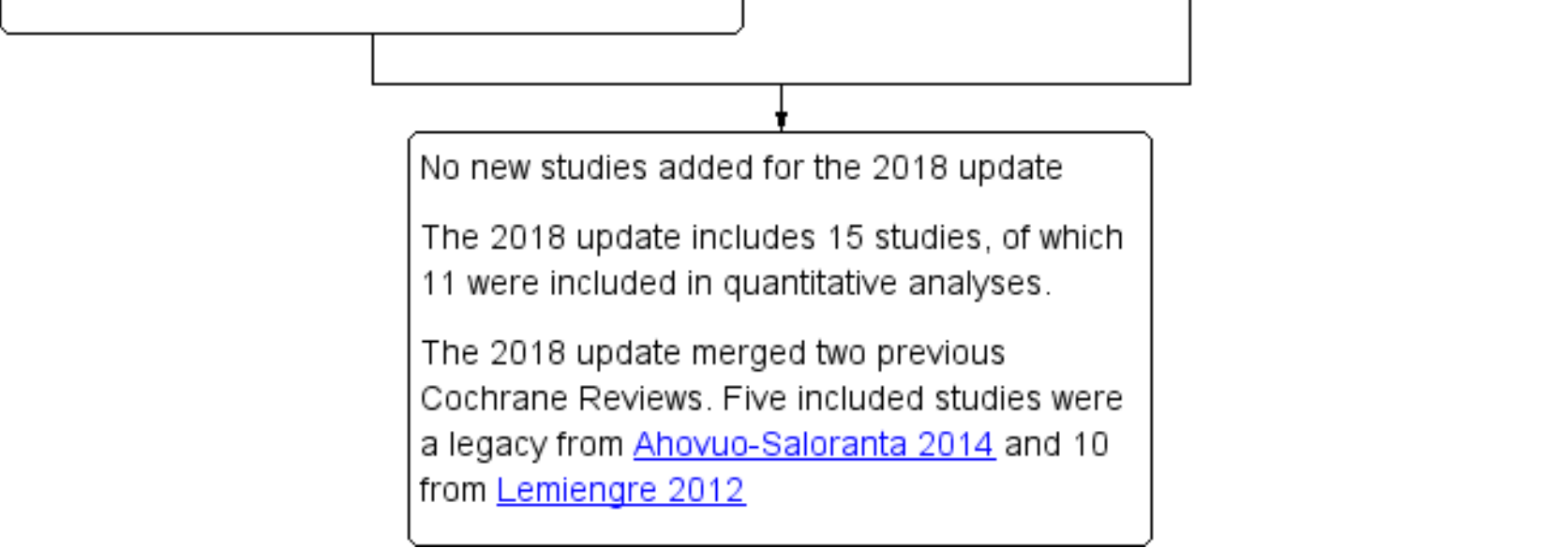

\section{Included studies}

Because we merged two Cochrane Reviews (Ahovuo-Saloranta 2014; De Sutter 2012), we revised search results from De Sutter

\section{Exclusions}

354 records excluded (title, keywords)

52 records excluded (abstract)

3 records excluded (full text)

115 records excluded (information available on WHO ICTRP or ClinicalTrials.gov) 
Buchem 1997b was a Dutch translation of Van Buchem 1997a; we used data from Van Buchem 1997a). We retained 10 trials (2450 participants) that were included in De Sutter 2012 (Bucher 2003; De Sutter 2002; Garbutt 2012; Kaiser 2001; Meltzer 2005; Merenstein 2005; Norrelund 1978; Stalman 1997; Varonen 2003; Williamson 2007).

We included 15 trials involving a total of 3057 participants for this update.

\section{Design}

With one exception, all included trials were randomised controlled trials (RCTs) that compared an antibiotic with a placebo. Axelsson 1970 (most probably) compared antibiotic treatment to no treatment.

\section{Sample sizes}

Ten trials involving 2450 participants concerned clinically diagnosed rhinosinusitis (Bucher 2003; De Sutter 2002; Garbutt 2012; Kaiser 2001; Meltzer 2005; Merenstein 2005; Norrelund 1978; Stalman 1997; Varonen 2003; Williamson 2007).

Five trials involving 631 participants concerned rhinosinusitis confirmed by imaging (radiology investigation: 431 participants (Axelsson 1970; Rantanen 1973; Van Buchem 1997a); CT scan: 200 participants (Lindbaek 1996; Lindbaek 1998)). In addition, Kaiser 2001 identified a subgroup of 82 participants in which rhinosinusitis was confirmed by radiography.

\section{Setting}

Eleven trials recruited participants from ambulatory care settings (Bucher 2003; De Sutter 2002; Garbutt 2012; Lindbaek 1996; Lindbaek 1998; Merenstein 2005; Norrelund 1978; Stalman 1997; Van Buchem 1997a; Varonen 2003; Williamson 2007). One trial also enrolled walk-in and non-referred participants from otolaryngology outpatient clinics of the university hospital (Bucher 2003). Kaiser 2001 recruited participants from an outpatient clinic of a university hospital. Meltzer 2005 enrolled participants from 14 medical centres worldwide, but settings were not described. Axelsson 1970 and Rantanen 1973 did not describe study settings.

\section{Participants}

\section{Inclusion criteria}

All included studies used clinical signs and symptoms to enrol participants. The three most common inclusion criteria were nasal discharge (Bucher 2003; De Sutter 2002; Garbutt 2012; Kaiser 2001; Meltzer 2005; Merenstein 2005; Norrelund 1978; Stalman 1997; Varonen 2003; Williamson 2007), facial pain (Bucher 2003; Garbutt 2012; Meltzer 2005; Merenstein 2005; Norrelund 1978; Stalman 1997; Varonen 2003; Williamson 2007), and common cold or upper respiratory tract infection (De Sutter 2002; Kaiser 2001; Stalman 1997; Varonen 2003). Two studies included participants with pus in the nasal cavity on rhinoscopy (Bucher 2003; Kaiser 2001), but this symptom was a clinical criterion for inclusion in three trials (Merenstein 2005; Varonen 2003; Williamson 2007).

Five studies used imaging criteria to include participants: confirmed secretion on radiography (Axelsson 1970), homogenous shadows in the sinuses or a fluid level on radiography (Rantanen 1973), more than $5 \mathrm{~mm}$ mucosal thickening, opacity or fluid level on radiography (Van Buchem 1997a), presence of fluid level or total opacification in any sinus on CT (Lindbaek 1996), and presence of mucosal thickening without fluid levels or total opacification on CT (Lindbaek 1998). In these trials, participants were preselected on clinical suspicion of having sinusitis. No further details about the clinical criteria used to select participants were provided. Kaiser 2001 used the presence, in at least one sinus, of an air-fluid level, a complete opacity, or a mucosal thickening of $10 \mathrm{~mm}$ as a criterion to identify participants for their subgroup of participants with radiologically confirmed maxillary sinusitis.

\section{Exclusion criteria}

Common exclusion criteria were recent antibiotic use (Axelsson 1970; Bucher 2003; De Sutter 2002; Garbutt 2012; Kaiser 2001; Lindbaek 1996; Lindbaek 1998; Merenstein 2005; Rantanen 1973; Stalman 1997; Van Buchem 1997a; Varonen 2003; Williamson 2007), severe illness (Kaiser 2001; Lindbaek 1996; Lindbaek 1998; Meltzer 2005; Stalman 1997), symptoms of complicated rhinosinusitis (De Sutter 2002; Garbutt 2012; Varonen 2003), long-lasting symptoms before inclusion (Bucher 2003; De Sutter 2002; Lindbaek 1996; Lindbaek 1998; Stalman 1997; Van Buchem 1997a; Varonen 2003), chronic ear, nose, and throat disease (Bucher 2003; Kaiser 2001; Meltzer 2005; Van Buchem 1997a; Varonen 2003; Williamson 2007), comorbidity (De Sutter 2002; Kaiser 2001; Lindbaek 1996; Lindbaek 1998; Merenstein 2005; Stalman 1997; Van Buchem 1997a; Williamson 2007), previous sinus surgery (Lindbaek 1996; Lindbaek 1998; Merenstein 2005; Varonen 2003), immune deficiency (Bucher 2003; De Sutter 2002; Garbutt 2012; Kaiser 2001; Merenstein 2005), allergy for study medication (Bucher 2003; De Sutter 2002; Garbutt 2012; Kaiser 2001; Meltzer 2005; Merenstein 2005; Norrelund 1978; Stalman 1997; Van Buchem 1997a; Varonen 2003; Williamson 2007), pregnancy or lactation (Bucher 2003; De Sutter 2002; Norrelund 1978; Stalman 1997; Varonen 2003; Williamson 2007), and inability to follow the protocol (language or mental problems) (Bucher 2003; De Sutter 2002; Garbutt 2012; Stalman 1997; Van Buchem 1997a). Due to the occurrence of a brain abscess in a placebo group participant, after 2000, Bucher 2003 excluded people with CRP levels greater than $100 \mathrm{mg} / \mathrm{L}$ or between 50 and $99 \mathrm{mg} /$ $L$ as a safety measure is there was clinical deterioration or CRP increase greater than $100 \mathrm{mg} / \mathrm{L}$ within three days of inclusion. No participants had to be excluded due to this new exclusion criterion. Axelsson 1970 excluded participants who were recently treated with nasal decongestants. Kaiser 2001 excluded participants with a positive pharyngeal culture for Streptococcus pyogenes. Lindbaek and colleagues excluded participants who misused alcohol or narcotics and those who had rheumatic disease (Lindbaek 1996; Lindbaek 1998). Garbutt 2012 excluded participants who rated their symptoms as very mild or mild. Stalman 1997 excluded participants who used xylometazoline nose drops for more than seven days, received antacid or iron treatment, or were referred to an ear, nose, and throat specialist.

\section{Characteristics of the participants}

The average age of participants was approximately 36 years. Norrelund 1978 did not report participants' mean age, but we calculated a median age of between 30 and 39 years. Axelsson 1970, Lindbaek 1996, and Lindbaek 1998 permitted younger participants, but the mean age of the study population was comparable to the average (33 years in Axelsson 1970, 38.6 years in Lindbaek 1996, and 39.7 years in Lindbaek 1998).

The male-to-female ratio was about 5:8. 
The mean duration of symptoms before inclusion was around or at least seven days in seven trials (De Sutter 2002; Lindbaek 1996; Lindbaek 1998; Meltzer 2005; Merenstein 2005; Stalman 1997; Williamson 2007). Participants had symptoms for about four to five days before inclusion in two trials (Bucher 2003; Kaiser 2001). The mean duration of symptoms at baseline was longer in two studies (11 days in Garbutt 2012 and 15.4 days in Van Buchem 1997a). Axelsson 1970, Norrelund 1978, Rantanen 1973, and Varonen 2003 did not report the mean duration of symptoms before inclusion.

\section{Interventions}

\section{Treatment group}

Nine studies compared amoxicillin to placebo (De Sutter 2002; Garbutt 2012; Lindbaek 1996; Lindbaek 1998; Meltzer 2005; Merenstein 2005; Van Buchem 1997a; Varonen 2003; Williamson 2007). Of these nine studies, five had more than one treatment arm, and three compared several antibiotic courses to placebo (penicillin V and amoxicillin (Lindbaek 1996; Lindbaek 1998); amoxicillin, penicillin V, and doxycycline (Varonen 2003)).

Two studies compared an antibiotic course and/or corticosteroid spray to placebo (Meltzer 2005; Williamson 2007) Meltzer 2005 compared mometasone furoate nasal spray once daily only, mometasone furoate nasal spray twice daily only, and amoxicillin only. Williamson 2007 compared budesonide nasal spray only, amoxicillin only, budesonide nasal spray and amoxicillin.

Norrelund 1978 compared pivampicillin to placebo; Kaiser 2001 compared azithromycin to placebo; Rantanen 1973 and Stalman 1997 compared doxycycline to placebo; and Bucher 2003 compared amoxicillin/clavulanic acid to placebo. Axelsson 1970 compared irrigation, phenoxymethylpenicillin and lincomycin to no treatment.

Treatment arms without antibiotic treatment were excluded from analyses (irrigation arm (44 participants) in Axelsson 1970; mometasone furoate nasal spray once daily only (243 participants), mometasone furoate nasal spray twice daily (235 participants) in Meltzer 2005).

All antibiotics were administered orally.

\section{Co-interventions}

Ten studies permitted nasal decongestants and analgesics (Bucher 2003; De Sutter 2002; Garbutt 2012; Kaiser 2001; Lindbaek 1996; Lindbaek 1998; Norrelund 1978; Stalman 1997; Van Buchem 1997a; Varonen 2003). Meltzer 2005 did not permit use of nasal decongestants. Six studies prescribed nasal decongestants for all participants (Axelsson 1970; Bucher 2003; Garbutt 2012; Norrelund 1978; Rantanen 1973; Van Buchem 1997a). Two studies did not describe use of nasal decongestants (Merenstein 2005; Williamson 2007). Four studies did not describe use of analgesics (Axelsson 1970; Merenstein 2005; Rantanen 1973; Williamson 2007). One study prescribed cough syrup (dextromethorphan hydrobromide or guaifenesin) for all participants (Garbutt 2012).

\section{Outcomes}

\section{Primary outcome: cure}

Definitions of cure and time of evaluation varied among trials that used cure as primary outcome (Axelsson 1970; Bucher 2003; De Sutter 2002; Kaiser 2001; Lindbaek 1996; Lindbaek 1998; Merenstein
2005; Norrelund 1978; Rantanen 1973; Stalman 1997; Van Buchem 1997a; Varonen 2003; Williamson 2007). This was reflected in variations in cure rates in placebo groups (clinical diagnosis: $30 \%$ to $74 \%$; diagnosis confirmed by imaging: $11 \%$ to $59 \%$ ).

\section{Clinically diagnosed rhinosinusitis}

Eight trials defined cure or improvement as primary outcome (Bucher 2003; De Sutter 2002; Kaiser 2001; Merenstein 2005; Norrelund 1978; Stalman 1997; Varonen 2003; Williamson 2007). The common denominator of all definitions was the resolution or improvement of major symptoms, evaluated only by the participant (Bucher 2003; De Sutter 2002; Merenstein 2005; Varonen 2003; Williamson 2007), or by the participant and the investigator (Kaiser 2001; Norrelund 1978; Stalman 1997).

The two remaining trials used change on a symptom score as the main outcome measure: Garbutt 2012 used the mean change in Sino-Nasal Outcome Test-16 score, a validated and responsive measure, to assess the effect of treatment on disease-specific quality of life at day 3, and Meltzer 2005 used the mean AM/PM major symptom score (sum of scores for rhinorrhoea, postnasal drip, nasal decongestion/stuffiness, sinus headache, and facial pain/pressure/tenderness on palpation over the paranasal sinuses) over days 2 to 15 of the treatment phase as a primary outcome measure.

\section{Rhinosinusitis confirmed by imaging}

Six studies defined cure as primary outcome (Axelsson 1970; Kaiser 2001 (subgroup of participants with radiologically confirmed maxillary sinusitis); Lindbaek 1996; Lindbaek 1998; Rantanen 1973; Van Buchem 1997a). The common denominator in all definitions was resolution or improvement of major symptoms, evaluated by the participant alone (Axelsson 1970; Lindbaek 1996; Lindbaek 1998; Van Buchem 1997a), or by the participant and the investigator (Kaiser 2001; Rantanen 1973). However, Rantanen 1973 evaluated sinus recovery rather than participants.

\section{Secondary outcomes}

Some trials provided information on effects on purulent secretion (Bucher 2003; De Sutter 2002; Meltzer 2005; Norrelund 1978; Stalman 1997), pain (De Sutter 2002; Meltzer 2005; Stalman 1997; Van Buchem 1997a; Williamson 2007), malaise (De Sutter 2002; Merenstein 2005; Van Buchem 1997a; Williamson 2007), illness duration (Lindbaek 1996; Lindbaek 1998; Merenstein 2005; Norrelund 1978; Varonen 2003; Williamson 2007), restriction of daily activities (Bucher 2003; De Sutter 2002; Garbutt 2012; Stalman 1997; Williamson 2007), intake of analgesics (De Sutter 2002; Norrelund 1978; Stalman 1997; Varonen 2003), intake of nasal decongestants (Stalman 1997; Varonen 2003), side effects (Axelsson 1970; Bucher 2003; De Sutter 2002; Garbutt 2012; Kaiser 2001; Lindbaek 1996; Meltzer 2005; Merenstein 2005; Norrelund 1978; Stalman 1997; Van Buchem 1997a; Varonen 2003), clinical failure (Bucher 2003; De Sutter 2002; Garbutt 2012; Kaiser 2001; Lindbaek 1996; Lindbaek 1998; Meltzer 2005; Stalman 1997; Van Buchem 1997a; Varonen 2003; Williamson 2007), and serious adverse events (Bucher 2003; Garbutt 2012; Williamson 2007).

Seven studies collected laboratory samples (Bucher 2003; Kaiser 2001; Lindbaek 1996; Lindbaek 1998; Rantanen 1973; Van Buchem 1997a; Varonen 2003). Four studies obtained nasopharyngeal secretions for culture (Kaiser 2001; Lindbaek 1996; Lindbaek 1998; Varonen 2003). Rantanen 1973 performed a sinus puncture. Two 
studies measured CRP, leukocytes and neutrophils (Bucher 2003; Van Buchem 1997a). Only Kaiser 2001 reported interaction between culture result, cure and treatment group. Kaiser 2001 found that participants in the antibiotic group with positive culture had lower symptom scores $(P=0.002)$ and a higher rate of symptom resolution on day $7(73 \%$ versus $47 \% ; P=0.007)$ and a higher cure rate on day 8 (65\% versus $41 \% ; P=0.032)$ compared to placebo group participants. There was no significant difference in symptom resolution on day 7 in the culture-negative group between antibiotic and placebo group participants $(63 \%$ versus $69 \% ; P=0.75)$.

See Characteristics of included studies.

\section{Excluded studies}

We had previously excluded five studies. Three RCTs included participants with clinical symptoms of acute rhinosinusitis and specific bacteriological criteria (Gananca 1973; Gananca 1977; Hadley 2010). One excluded study had included participants with clinical symptoms (maxillary pain) and raised values of either Creactive protein (CRP) or erythrocyte sedimentation rate (ESR) (Hansen 2000a; Hanssen 2000b was a Danish translation of Hansen 2000a). Haye 1998 was excluded because participants with empyema (defined as complete opacity or an air-fluid level, or a mucosal thickness of $6 \mathrm{~mm}$ or more measured at the upper lateral border of the maxillary sinus) were withheld. See Characteristics of excluded studies.

\section{Risk of bias in included studies}

'Risk of bias' assessments are reported in Characteristics of included studies and graphically presented in Figure 2 and Figure 3.

Figure 2. Risk of bias graph: review authors' judgements about each risk of bias item presented as percentages across all included studies.

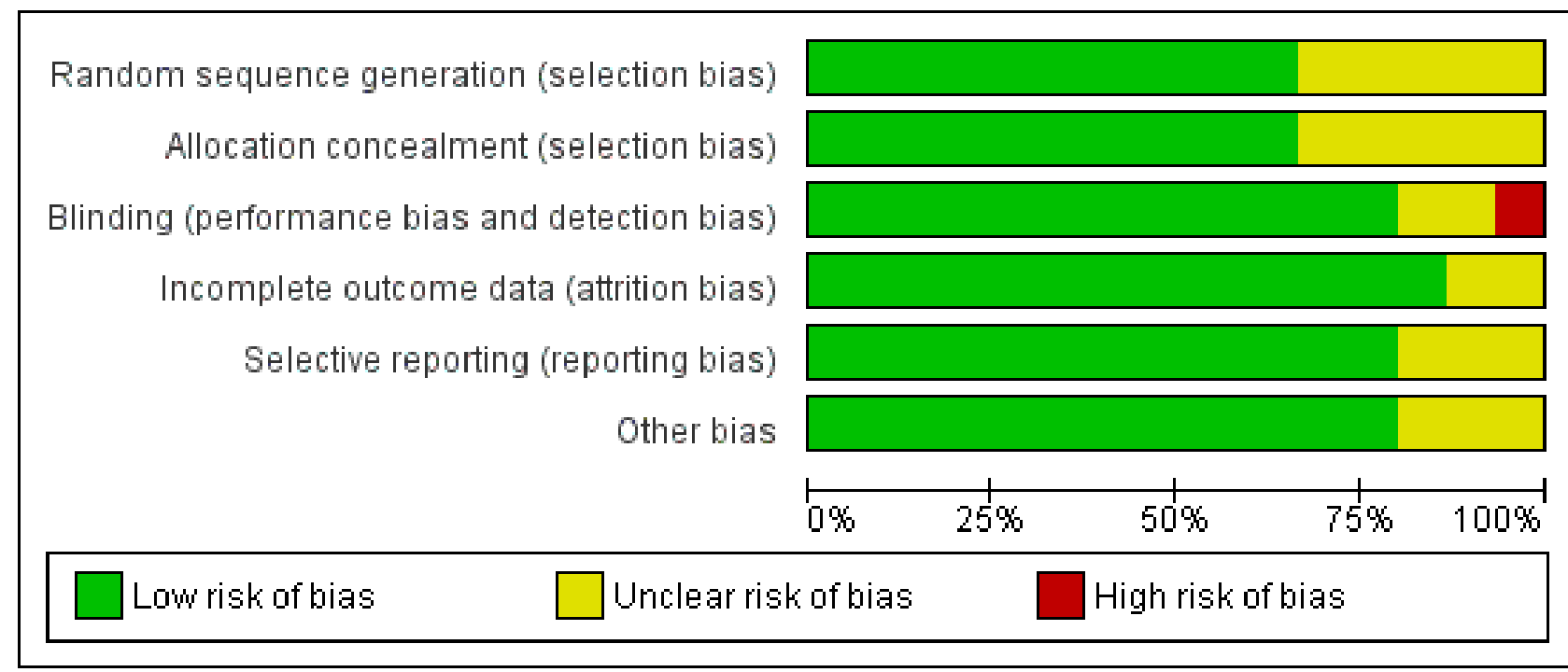


Figure 3. Risk of bias summary: review authors' judgements about each risk of bias item for each included study.

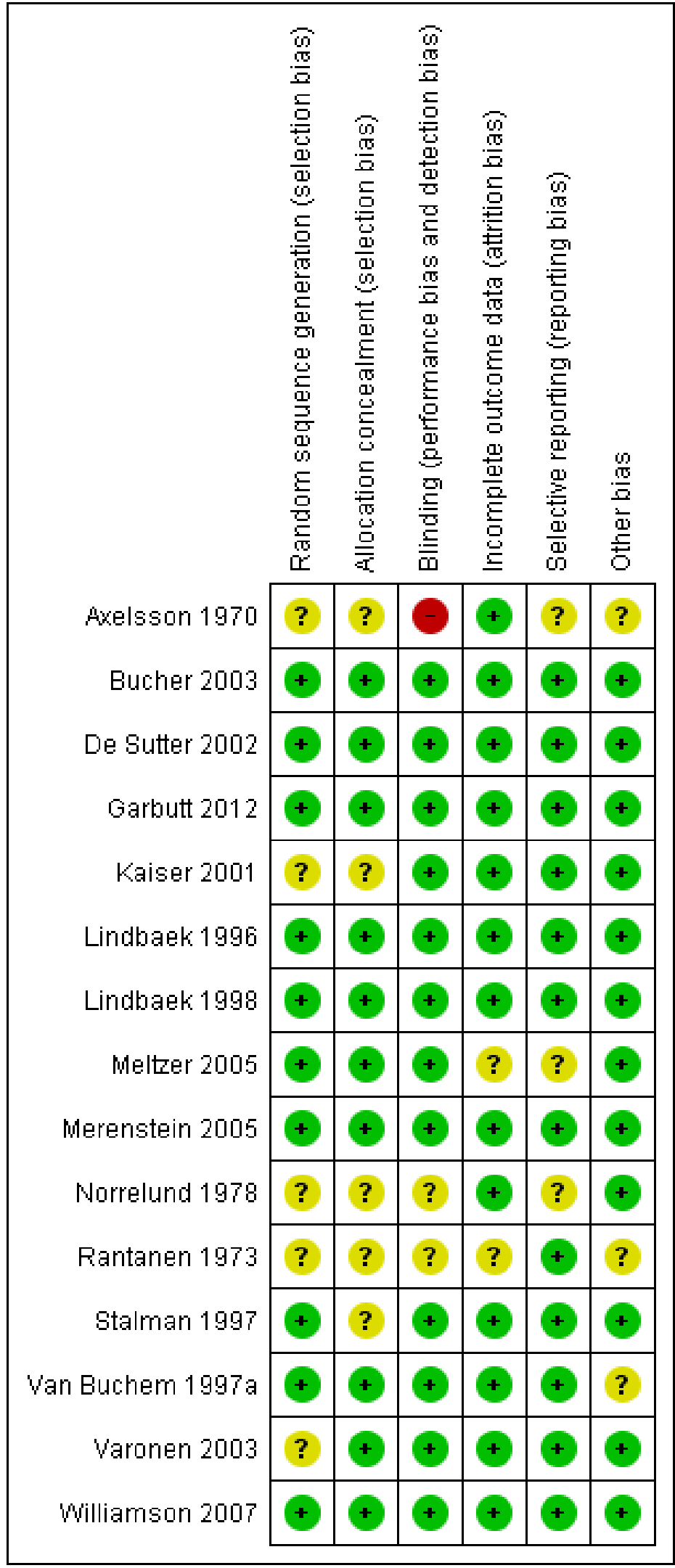




\section{Allocation}

The risk of selection bias was low in nine studies (Bucher 2003; De Sutter 2002; Garbutt 2012; Lindbaek 1996; Lindbaek 1998; Meltzer 2005; Merenstein 2005; Van Buchem 1997a; Williamson 2007), and unclear in four studies (Axelsson 1970; Kaiser 2001; Norrelund 1978; Rantanen 1973; Stalman 1997; Varonen 2003).

Ten studies reported adequate allocation sequencing (Bucher 2003; De Sutter 2002; Garbutt 2012; Lindbaek 1996; Lindbaek 1998; Meltzer 2005; Merenstein 2005; Stalman 1997; Van Buchem 1997a; Williamson 2007). Four studies used block randomisation (Garbutt 2012; Merenstein 2005; Stalman 1997; Williamson 2007); two used unrestricted randomisation (De Sutter 2002; Van Buchem 1997a); and four studies combined blocked and stratified randomisation (Bucher 2003; Lindbaek 1996; Lindbaek 1998; Meltzer 2005). Six studies used a computerised random number generator (Bucher 2003; De Sutter 2002; Garbutt 2012; Meltzer 2005; Merenstein 2005; Van Buchem 1997a; Stalman 1997). Lindbaek 1996 and Lindbaek 1998 used dice. Williamson 2007 used random number tables to select the blocks. Four studies presented insufficient information about the sequence generation process to inform assessment (Axelsson 1970; Kaiser 2001; Norrelund 1978; Varonen 2003). Axelsson 1970 and Kaiser 2001 reported only random assignment. Two studies reported using a block randomisation procedure but did not specify the process to select blocks (Norrelund 1978; Varonen 2003).

Ten trials concealed allocation adequately (Bucher 2003; De Sutter 2002; Garbutt 2012; Lindbaek 1996; Lindbaek 1998; Meltzer 2005; Merenstein 2005; Van Buchem 1997a; Varonen 2003; Williamson 2007). Four trials did not provide information on methods used to blind participants and investigators enrolling participants (Axelsson 1970; Norrelund 1978; Rantanen 1973; Stalman 1997). One study reported only that the medication boxes or envelopes were identical for drugs and placebo, but did not state use of sequential numbering (Kaiser 2001).

\section{Blinding}

The risk of performance and detection bias was low in 12 studies (Bucher 2003; De Sutter 2002; Garbutt 2012; Kaiser 2001; Lindbaek 1996; Lindbaek 1998; Meltzer 2005; Merenstein 2005; Stalman 1997; Van Buchem 1997a; Varonen 2003; Williamson 2007), unclear in 2 studies (Norrelund 1978; Rantanen 1973), and high in 1 study (Axelsson 1970).

Eleven trials blinded allocated intervention adequately (Bucher 2003; De Sutter 2002; Garbutt 2012; Kaiser 2001; Lindbaek 1996; Lindbaek 1998; Merenstein 2005; Stalman 1997; Van Buchem 1997a; Varonen 2003; Williamson 2007). The intervention and placebo tablets were identical in colour, shape, and taste, and blinding of participants and investigators was assured in these studies. Two studies indicated double-blinding, but did not provide information about the blinding procedure (Norrelund 1978; Rantanen 1973). Meltzer 2005 did not provide precise information on how the randomisation result was concealed, but the method of random sequence generation (computer-randomised code) and information on double-dummy design gave the impression that concealment had been fulfilled (additional information requested but not received from the trial authors). Axelsson 1970 did not mention blinding in the methods section, and close examination of the study design led us to strongly believe that there was no blinding: placebo group participants did not take tablets, only nose drops; it is not possible to blind sinus irrigation as an intervention; only group 1 participants received radiological evaluation every second day; and group 2 participants took a longer course of tablets than group 3. We therefore graded the risk of bias for this domain as high for Axelsson 1970.

\section{Incomplete outcome data}

The risk of attrition bias was low in 13 studies (Axelsson 1970; Bucher 2003; De Sutter 2002; Garbutt 2012; Kaiser 2001; Lindbaek 1996; Lindbaek 1998; Merenstein 2005; Norrelund 1978; Stalman 1997; Van Buchem 1997a; Varonen 2003; Williamson 2007), and unclear in 2 studies (Meltzer 2005; Rantanen 1973).

The overall post-randomisation dropout rate was 5.1\%. Rantanen 1973 did not report post-randomisation dropout rates.

The ratio of participants with missing data to participants with events is a good marker of bias due to incomplete data (Higgins 2011a). In the 13 included studies with cure as the primary outcome, the ratio ranged from 0.01 to 0.33 (Axelsson 1970; Bucher 2003; De Sutter 2002; Kaiser 2001; Lindbaek 1996; Lindbaek 1998; Merenstein 2005; Norrelund 1978; Stalman 1997; Van Buchem 1997a; Varonen 2003; Williamson 2007). However, the ratio was low (0.09) for Garbutt 2012, who reported "significant improvement at day 10." The risk of bias due to dropout was low in these 13 studies. We could not calculate the ratio of participants with missing data to participants with events for Meltzer 2005, because the primary outcome was not cure, but a difference in symptom scores. However, the post-randomisation dropout rate was low (2.6\% at day 15) in Meltzer 2005 and probably did not cause bias.

Two studies performed sensitivity analyses. In De Sutter 2002 and Williamson 2007, different scenarios did not reveal a significant difference in cure rate between the intervention and control group. Garbutt 2012 conducted a sensitivity analysis for participants who completed the study drug and those with symptoms for seven days or more and 28 days or less. Varonen 2003 imputed dropouts as treatment failures.

Ten studies followed the intention-to-treat (ITT) principle for analysis of the main outcome (Bucher 2003; De Sutter 2002; Garbutt 2012; Lindbaek 1996; Lindbaek 1998; Meltzer 2005; Merenstein 2005; Stalman 1997; Van Buchem 1997a; Varonen 2003). Four trials included only participants with complete outcome data (Axelsson 1970; Kaiser 2001; Norrelund 1978; Williamson 2007).

\section{Selective reporting}

The risk of reporting bias was low in 12 studies (Bucher 2003; De Sutter 2002; Garbutt 2012; Kaiser 2001; Lindbaek 1996; Lindbaek 1998; Merenstein 2005; Rantanen 1973; Stalman 1997; Van Buchem 1997a; Varonen 2003; Williamson 2007), and unclear in 3 studies (Axelsson 1970; Meltzer 2005; Norrelund 1978).

Twelve studies predefined primary and secondary endpoints (Bucher 2003; De Sutter 2002; Garbutt 2012; Kaiser 2001; Lindbaek 1996; Lindbaek 1998; Meltzer 2005; Merenstein 2005; Rantanen 1973; Stalman 1997; Varonen 2003; Williamson 2007). Definitions of primary outcomes were unclear in two studies (Axelsson 1970; Norrelund 1978). Norrelund 1978 predefined symptoms, side effects, and medication intake that were to be recorded, but provided the definition of cure for the first time in the results section of the report. Meltzer 2005 reported most outcomes of interest 
incompletely; data could not be pooled with other trials. Young 2008 performed an individual participant data meta-analysis and had the results of an unpublished Schering-Plough trial. This trial had the same design as Meltzer 2005, but had a lower odds ratio. This could suggest selective reporting in Meltzer 2005.

\section{Other potential sources of bias}

The risk of other potential sources of bias was low in 12 studies (Bucher 2003; De Sutter 2002; Garbutt 2012; Kaiser 2001; Lindbaek 1996; Lindbaek 1998; Meltzer 2005; Merenstein 2005; Norrelund 1978; Stalman 1997; Varonen 2003; Williamson 2007), and unclear in 3 studies (Axelsson 1970; Rantanen 1973; Van Buchem 1997a).

No included studies contained design-specific risks of bias or were stopped early. Two studies had small, unimportant imbalances of baseline participant characteristics (Stalman 1997; Williamson 2007). Rantanen 1973 did not describe participants' characteristics at baseline, and Axelsson 1970 provided only limited information about these characteristics. One blinded trial broke blinding 12 times due to side effects ( 3 participants) or clinical failure (9 participants) (Lindbaek 1996). Following the ITT principle, these participants were included in the analyses in the groups to which they were originally randomised (Lindbaek 1996). Van Buchem 1997a possibly selected participants with worse symptoms, since only $20 \%$ of participants with possible maxillary sinusitis entered the trial.

Study protocols for participants in intervention and placebo groups were similar. There was a low risk of bias due to increased or different diagnostic activity.

Seven studies were financially supported by government or academic institutions (Garbutt 2012; Lindbaek 1996; Lindbaek 1998; Merenstein 2005; Stalman 1997; Varonen 2003; Williamson 2007). Researchers in six studies received grants from pharmaceutical industry sources (Bucher 2003; De Sutter 2002; Meltzer 2005; Stalman 1997; Varonen 2003; Williamson 2007). Five studies did not state sources of support (Axelsson 1970; Kaiser 2001; Norrelund 1978; Rantanen 1973; Van Buchem 1997a).

More than 276 practices recruited participants. Two trials recruited participants from one site (Kaiser 2001; Merenstein 2005). Eight trials recruited participants from multiple sites, with an average of 9.9 participants per practice (range 3.6 to 15.8 , 25th percentile $=$
6.5, 75th percentile $=15.5$ ) (Bucher 2003; De Sutter 2002; Garbutt 2012; Meltzer 2005; Norrelund 1978; Stalman 1997; Varonen 2003; Williamson 2007). The number of participating practices was not reported in five trials (Axelsson 1970; Lindbaek 1996; Lindbaek 1998; Rantanen 1973; Van Buchem 1997a).

\section{Effects of interventions}

See: Summary of findings for the main comparison Antibiotics compared to placebo for acute rhinosinusitis in adults

\section{Primary outcome}

\section{Cure}

Without antibiotics, $46 \%$ of participants with rhinosinusitis, whether or not confirmed by radiography, were cured after one week (Bucher 2003; Kaiser 2001; Norrelund 1978; Williamson 2007), and 64\% after 14 days (Bucher 2003; Merenstein 2005; Van Buchem 1997a; Varonen 2003; Williamson 2007).

\subsection{Clinically diagnosed rhinosinusitis}

The ITT population included 2450 participants (10 trials). We analysed data from 1687 participants (69\%). We excluded Meltzer 2005 (499 participants) and Garbutt 2012 (166 participants) because the proportion of participants cured at a specific time point was not reported as cure was not their main outcome measure. Stalman 1997 reported only the total cure rate for both groups and stated there was no difference between groups. We used the same percentages in both groups for pooling.

Despite choices made by some trial authors, we considered participants who started other antibiotics as treatment failures, not dropouts. The total dropout rate was 5.3\%.

Almost half (47\%) of participants were cured after one week (Bucher 2003; Kaiser 2001; Norrelund 1978; Williamson 2007), 51\% after 10 days (De Sutter 2002; Stalman 1997; Williamson 2007), and $71 \%$ after 14 days (Bucher 2003; Merenstein 2005; Varonen 2003; Williamson 2007), irrespective of treatment group.

The estimated odds ratio (OR) for the overall treatment effect of antibiotics relative to placebo was 1.25 (95\% confidence interval (Cl) 1.02 to 1.54 ; number needed to treat for an additional beneficial outcome (NNTB) $19,95 \% \mathrm{Cl} 10$ to $205 ; I^{2}=0 \%$; high-quality evidence; Analysis 1.1.1; Figure 4). 
Figure 4. Forest plot of comparison: 1 Antibiotics versus placebo in acute rhinosinusitis, outcome: 1.1 Cure.

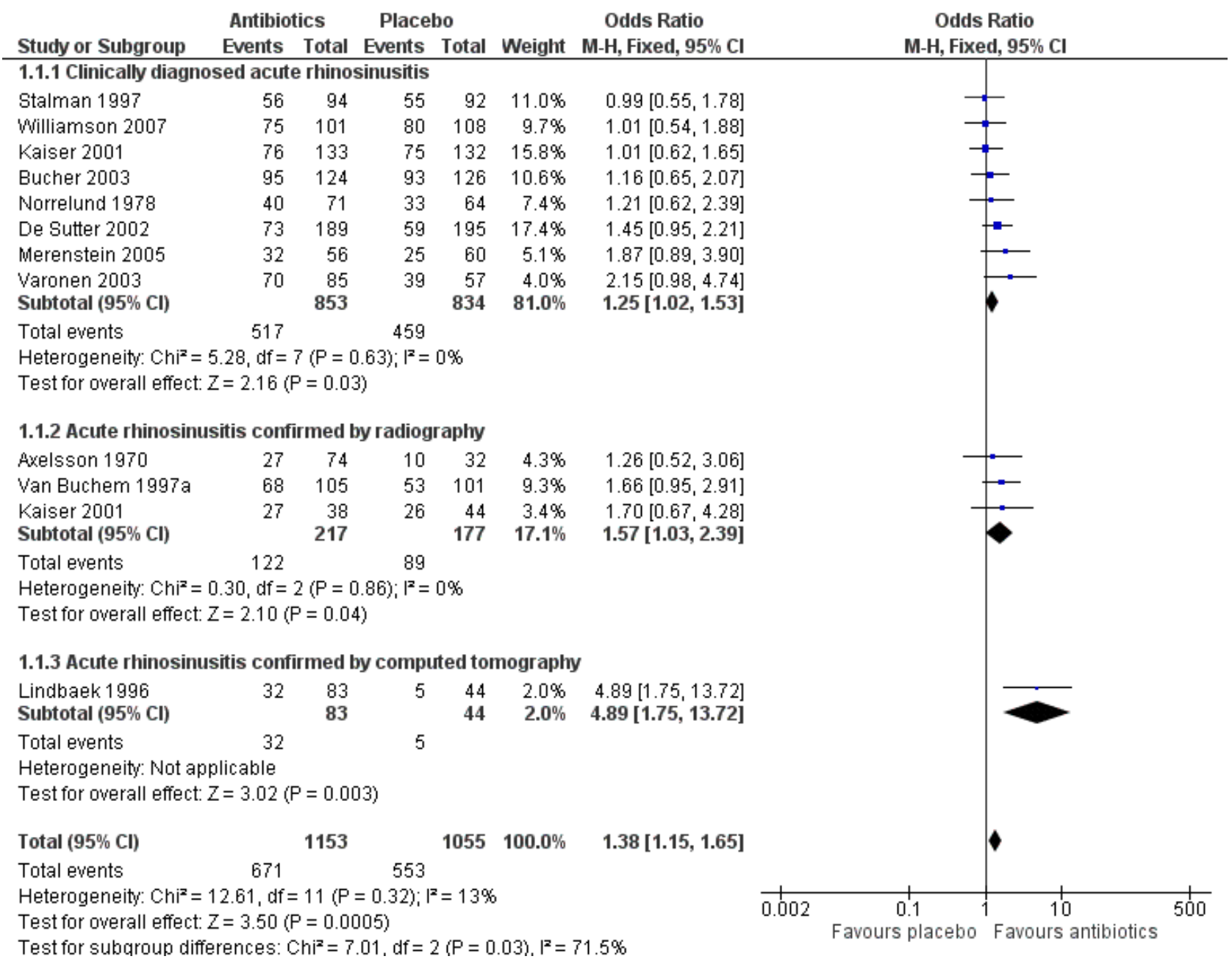

We categorised studies into three groups: cure assessed at one week (Bucher 2003; Kaiser 2001; Norrelund 1978; Williamson 2007); cure assessed at around day 10 (De Sutter 2002; Stalman 1997; Williamson 2007); and cure assessed at day 14 (Bucher 2003; Merenstein 2005; Varonen 2003; Williamson 2007). Heterogeneity among studies was very low (0\% at 1 week and 10 days; $6 \%$ at 14 days).

There were no significant differences between treatment groups: after one week, the OR for cure was $1.07(95 \% \mathrm{Cl} 0.81$ to 1.41 ; Analysis 3.1.1); after 10 days OR for cure was 1.19 (95\% Cl 0.92 to 1.53; Analysis 3.1.2); and after 14 days OR for cure was $1.37(95 \% \mathrm{Cl}$ 0.98 to 1.91; Analysis 3.1.3). Meltzer 2005 did not find any difference in symptom score between the antibiotic and placebo groups at day 15 , so we assumed that adding data from this study would not change our overall result. Garbutt 2012 found a significant difference in symptom score at day 7 , favouring amoxicillin (mean difference (MD) $0.19,95 \% \mathrm{Cl} 0.02$ to 0.35 ). This study also provided data about "significantly improved" participants. Including these data (Analysis 3.1.4 and Analysis 3.1.5) did not substantially change the overall result.

We used three methods to impute data to assess the influence of missing data on the overall results: assuming the outcomes of participants for whom no outcome was recorded as cured; not cured; or according to the cure rate observed in the control group. Twelve analyses revealed no clear differences for the baseline analyses (Analysis 3.1.6 to Analysis 3.1.17).

Excluding studies that included ITT analyses removed antibiotic benefit (OR 1.06, 95\% Cl 0.76 to 1.47) (Bucher 2003; De Sutter 2002; Merenstein 2005; Stalman 1997; Varonen 2003). Pooling studies with ITT analyses confirmed benefit of antibiotics (OR 1.39, 95\% Cl 1.07 to 1.79 ).

Pooling studies in which participants declared themselves as cured endorsed the benefit of antibiotics (OR $1.40,95 \% \mathrm{Cl} 1.08$ to 1.82 ) (Bucher 2003; De Sutter 2002; Merenstein 2005; Varonen 2003; Williamson 2007). Pooling studies in which the investigator decided if the participant was cured showed no benefit of antibiotics (OR $1.05,95 \%$ Cl 0.76 to 1.46) (Kaiser 2001; Norrelund 1978; Stalman 1997).

Studies that included only participants with pus on rhinoscopy revealed no benefits with antibiotics (OR $1.07,95 \% \mathrm{Cl} 0.74$ to 1.56 ) (Bucher 2003; Kaiser 2001).

\subsection{Rhinosinusitis confirmed by imaging}

The ITT population included 713 participants, and we analysed data from 652 participants (91.4\%). We excluded 61 participants 
from the Rantanen 1973 study because the primary outcome was sinus recovery progress instead of cure.

Four trials included participants on the basis of clinical signs and symptoms (Bucher 2003; De Sutter 2002; Kaiser 2001; Varonen 2003); radiographs were taken, but only one study used images to assess cure rates (Kaiser 2001). All participants underwent sinus ultrasound in Varonen 2003. The impact of ultrasound result cure rates was not reported.

We considered participants who started other antibiotics as treatment failures, not dropouts. The total dropout rate was $4.3 \%$. Rantanen 1973 did not report post-randomisation dropout rates.

Cure was evaluated at day 8 (Kaiser 2001), day 10 (Axelsson 1970; Lindbaek 1996; Lindbaek 1998), or day 14 (Van Buchem 1997a). The estimated OR for the overall treatment effect of antibiotics relative to placebo was 1.71 (95\% Cl 1.20 to 2.45 ; NNTB 8, $95 \% \mathrm{Cl} 5$ to 23; $1^{2}=41 \%$; Analysis 3.2.1). Heterogeneity was high, so we looked for outliers and split analyses for participants with rhinosinusitis confirmed by radiography or CT.

However, treatment effects among those who underwent CT differed significantly from effects in participants selected by radiography. Pooling these data was therefore not possible, and analyses were performed separately.

Three studies used radiography to confirm maxillary sinusitis (Axelsson 1970; Kaiser 2001; Van Buchem 1997a). The estimated OR was $1.57\left(95 \% \mathrm{Cl} 1.03\right.$ to 2.39 ; NNTB $10,95 \% \mathrm{Cl} 5$ to $136 ; \mathrm{I}^{2}=$ $0 \%$; moderate-quality evidence; Analysis 1.1.2; Figure 4). Omitting Axelsson 1970, which was assessed as at high risk of bias due to lack of blinding, did not have a significant impact on this result (OR 1.67, $95 \% \mathrm{Cl} 1.04$ to 2.70 , NNBT 9, $95 \% \mathrm{Cl} 5$ to 104 ).

Lindbaek 1996 and Lindbaek 1998 reported on two distinct participant groups who underwent $\mathrm{CT}$ examination: those with fluid level or total opacification in any sinus on $\mathrm{CT}$, and those with mucosal thickening on CT. The effect of antibiotics relative to placebo was only significant in the group with fluid level or total opacification in any sinus on CT (Lindbaek 1996: estimated OR 4.89, $95 \% \mathrm{Cl} 1.75$ to 13.72 ; NNTB 4, 95\% Cl 2 to 15 ; moderate-quality evidence; Analysis 1.1.3; Figure 4; ) (Lindbaek 1998: estimated OR $0.74,95 \% \mathrm{Cl} 0.25$ to 2.16 ).

Four studies reported on cure or improvement (Axelsson 1970; Lindbaek 1996; Lindbaek 1998; Van Buchem 1997a). The estimated OR for overall treatment effect of antibiotics relative to placebo was 2.08 (95\% Cl 1.35 to 3.21 ; NNTB 8, 95\% Cl 6 to $18 ; I^{2}=33 \%$; Analysis 3.2.2). Heterogeneity was high. Studies that used radiography to confirm maxillary sinusitis indicated no difference in improvement rates between participants who received antibiotics versus those who received placebo (estimated OR $1.59,95 \% \mathrm{Cl} 0.90$ to $2.80 ; \mathrm{I}^{2}=$ 0\%, NNTB 9, 95\% Cl 5 to 40) (Axelsson 1970; Van Buchem 1997a). The effect of antibiotics relative to placebo on 'improvement' was significant only in participants with fluid level or total opacification in any sinus on CT (Lindbaek 1996: estimated OR 4.5, 95\% Cl 1.91 to 10.57 ; NNTB 4, 95\% Cl 3 to 7) (Lindbaek 1998: estimated OR 1.60, $95 \% \mathrm{Cl} 0.51$ to 5.06$)$.

\section{Secondary outcomes}

\section{Ratings of measures of overall well-being}

Three studies investigated whether participants' general feeling of illness improved faster with antibiotics (De Sutter 2002; Merenstein 2005; Van Buchem 1997a). It was not possible to pool data for meta-analysis because De Sutter 2002 used data from a diary, Merenstein 2005 compared Likert scores at different time points, and Van Buchem 1997a looked at differences in symptom scores for "sickness" after one and two weeks. Only Van Buchem 1997a found a marginal but significant difference in symptom score for sickness after two weeks evaluated by the investigator (mean change 1.2 for placebo versus 0.8 for antibiotics, " $P<0.05$ " reported by Van Buchem 1997a). This finding did not persist when the degree of sickness was evaluated by the participant.

Williamson 2007 found no significant interaction between baseline severity (feeling unwell and level of daily activity restriction) and treatment group (antibiotic versus placebo).

\section{Severity or duration of different clinical symptoms}

\subsection{Resolution of purulent secretion}

Five studies reported outcome data for purulent secretion (De Sutter 2002; Meltzer 2005; Norrelund 1978; Stalman 1997; Van Buchem 1997a). We extracted data from one study on day 8 (Norrelund 1978), and two studies on day 10 (De Sutter 2002; Stalman 1997). De Sutter 2002 provided data upon request. Meltzer 2005 published only least-square means data. Outcomes were reported by participants in two studies (De Sutter 2002; Meltzer 2005), the investigator in two studies (Norrelund 1978; Stalman 1997), and by both participants and investigators in one study (Van Buchem 1997a).

The estimated OR for resolution of purulent secretion was 1.58 , irrespective of endpoint timing ( $95 \% \mathrm{Cl} 1.13$ to 2.22; NNTB 10, $95 \%$ $\mathrm{Cl} 6$ to $35 ; \mathrm{I}^{2}=0 \%$; high-quality evidence; Analysis 2.1).

We could not pool some data on purulent secretion. Norrelund 1978 found that $75 \%$ of participants in the antibiotic group and $56 \%$ in the placebo group had at least $50 \%$ reduction in secretion on day 8 (OR 2.29, $95 \% \mathrm{Cl} 1.11$ to 4.74 ; NNTB $6,95 \% \mathrm{Cl} 4$ to 40 ; $P=0.002$ ). Furthermore, De Sutter 2002 found a significant mean change in mean score on the symptom "thick nasal discharge" between baseline and 10-day follow-up $(P \leq 0.001)$. These results were confirmed by Meltzer 2005, who found a significant difference in least-square means for rhinorrhoea between days 2 and $15(P \leq$ 0.01). Van Buchem 1997a found a significant difference in symptom score for secretion at the right side after one week (reported by the participant) (mean change 1.0 for placebo versus 1.2 for antibiotics, "P < 0.05" reported by Van Buchem 1997a), but this difference disappeared after two weeks. Evaluation of secretion at clinical examination did not confirm this finding.

\subsection{Resolution of pain}

Five studies provided outcome data for pain (De Sutter 2002; Meltzer 2005; Stalman 1997; Van Buchem 1997a; Williamson 2007). Unfortunately, as the outcome measures were too different and raw data were not available, pooling of data was not possible.

Considering pain in general, no study found a difference in pain duration between the antibiotic and placebo groups (De Sutter 2002; Stalman 1997; Williamson 2007). Full resolution of pain 
occurred between day 4 and day 7 in most participants. Also, when considering specific types of pain such as unilateral facial pain (De Sutter 2002), pain on bending forward (De Sutter 2002; Stalman 1997), pain in upper teeth or when chewing (De Sutter 2002; Stalman 1997), facial pain, pressure, or tenderness (De Sutter 2002; Meltzer 2005), and sinus headache (De Sutter 2002; Meltzer 2005), none of the trials detected a significant difference in pain duration when comparing antibiotic and placebo groups. Evaluating differences in symptom scores, Van Buchem 1997a found no differences after one and two weeks for frontal pain, maxillary pain, headache on bending, or tapping pain.

\subsection{Illness duration}

Five studies calculated the mean illness duration (Kaiser 2001; Lindbaek 1996; Lindbaek 1998; Norrelund 1978; Varonen 2003). All studies compared illness duration between antibiotic and placebo groups. We could not pool the data because the standard deviations were not available. Kaiser 2001 reported the mean illness duration for participants with or without Streptococcus pneumoniae,Haemophilus influenzae, orMoraxella catarrhalis in their nasopharyngeal secretions (with bacteria: five days in the azithromycin group versus seven days in the placebo group; without bacteria: six days in the azithromycin group versus six days in the placebo group), but not for the total group. Norrelund 1978 found a subjective improvement after an average of 3.5 days in the antibiotic group compared with 3.7 days in the placebo group. They did not mention if this was a significant difference, but we can assume that it was not. Varonen 2003 also did not find a significant difference: the mean illness duration in participants taking antibiotics was 6.0 days, compared with 6.4 days in the placebo group $(P=0.66)$. Lindbaek 1996 found that participants with a fluid level or total opacification in any sinus on CT were cured seven days faster with antibiotic treatment than without (median time of the sinusitis episode: nine days in the amoxicillin group, 11 days in the penicillin group, and 17 days in the placebo group). Participants with only mucosal thickening on CT showed no significant difference in illness duration across the intervention groups (median time of the sinusitis episode: 10 days in the placebo and amoxicillin groups and 13.5 days in the placebo group) (Lindbaek 1998).

\subsection{Restriction of daily activities}

Four studies collected data on the restriction of daily activities due to rhinosinusitis (Bucher 2003; De Sutter 2002; Garbutt 2012; Stalman 1997). Pooling of data was not possible because the outcome measures were too different. None of the studies found a significant difference in activity restriction between the antibiotic and placebo groups.

Williamson 2007 found no significant interaction between baseline severity (feeling unwell and level of restriction on daily activity) and treatment group (antibiotic versus placebo).

\section{Use of concomitant medications}

\subsection{Analgesics}

Ten studies allowed the use of analgesics, that is paracetamol, in Bucher 2003, De Sutter 2002, Garbutt 2012, Lindbaek 1996,
Lindbaek 1998, Norrelund 1978, Stalman 1997, Van Buchem 1997a, and Varonen 2003, and/or ibuprofen, in De Sutter 2002, Kaiser 2001, Norrelund 1978, and Varonen 2003. Five of these studies also recorded the use of analgesics (De Sutter 2002; Garbutt 2012; Norrelund 1978; Stalman 1997; Varonen 2003). It was not possible to pool the data because the raw data were not available or the outcome measures were too different. There was no effect of antibiotics on the use of analgesics in four studies (De Sutter 2002; Garbutt 2012; Norrelund 1978; Stalman 1997). Varonen 2003 revealed that participants receiving placebo used analgesics more often than those receiving antibiotics $(43 \%$ in the placebo group and $26 \%$ in the antibiotic group, $P=0.03$ ).

\subsection{Nasal decongestants}

Eleven studies allowed the use of xylometazoline nose drops (Axelsson 1970; Bucher 2003; De Sutter 2002; Kaiser 2001; Lindbaek 1996; Lindbaek 1998; Norrelund 1978; Rantanen 1973; Stalman 1997; Van Buchem 1997a; Varonen 2003). Six studies prescribed nasal decongestants for every participant (Axelsson 1970; Bucher 2003; Garbutt 2012; Norrelund 1978; Rantanen 1973; Van Buchem 1997a). Garbutt 2012 permitted the use of pseudoephedrinesustained action. Merenstein 2005 did not mention if nose drops were permitted. Corticosteroid nose drops were part of the intervention in two studies (Meltzer 2005; Williamson 2007). Meltzer 2005 explicitly stated that use of concomitant medication that could interfere with the study medication was not permitted.

Only two studies registered intake of nose drops (vasoconstrictors), Stalman 1997 and Varonen 2003, and antihistamines, Varonen 2003. Pooling of data was not possible because the outcome measures were too dissimilar. Neither study found a significant difference between groups in use of these medications. Garbutt 2012 found no difference between groups in use of pseudoephedrine-sustained action.

\section{Side effects}

The side effects described in the trials were nausea, vomiting, abdominal pain, stomach pain, diarrhoea, skin rash, dizziness, fatigue, hot flushes, jittery feeling, dry mouth, headache, epistaxis, and vaginal discharge or pruritus. The most common side effects were gastrointestinal.

We pooled data from 10 trials on side effects in general (Axelsson 1970; De Sutter 2002; Garbutt 2012; Kaiser 2001; Lindbaek 1996; Merenstein 2005; Norrelund 1978; Stalman 1997; Van Buchem 1997a; Varonen 2003). De Sutter 2002 reported only data about diarrhoea. We did not add data from Lindbaek 1998 because the only side effects reported in this study were those that caused participants to stop their study medication. Of the participants who experienced side effects, $68.3 \%$ received antibiotics. This difference was statistically significant (OR $2.21,95 \% \mathrm{Cl} 1.74$ to 2.82 ; number needed to treat for an additional harmful outcome (NNTH) 8, 95\% $\mathrm{Cl} 6$ to $12 ; \mathrm{I}^{2}=16 \%$; high-quality evidence; Analysis 2.2; Figure 5). 
Figure 5. Forest plot of comparison: 2 Antibiotics versus placebo in acute rhinosinusitis whether or not confirmed by imaging, outcome: 2.2 Side effects: general.

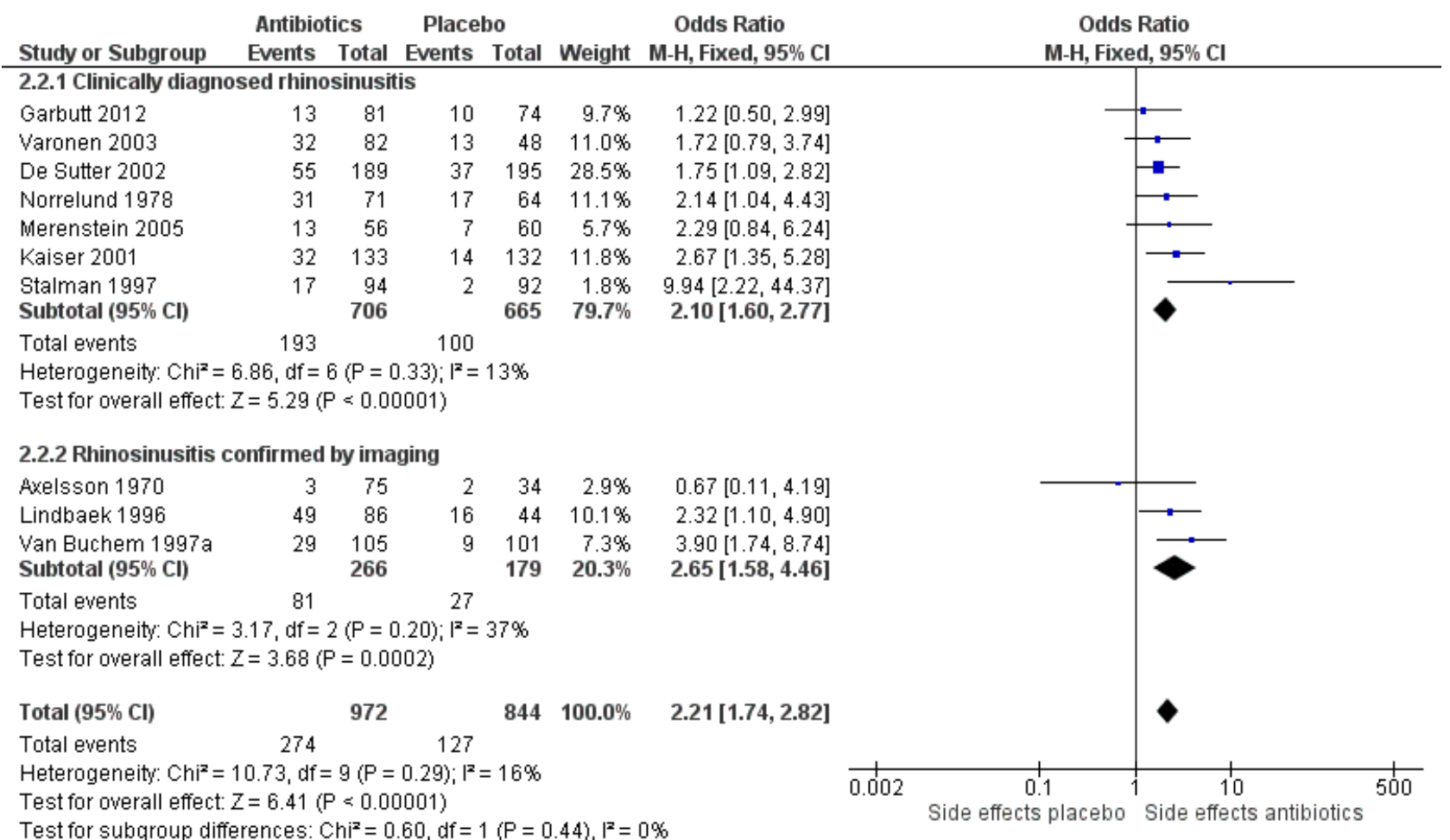

More specifically, we could pool data on diarrhoea from seven trials (Axelsson 1970; De Sutter 2002; Garbutt 2012; Lindbaek 1996; Merenstein 2005; Stalman 1997; Varonen 2003). Garbutt 2012 reported only the percentage of diarrhoea for both groups and stated there was no difference between groups. We used the same percentages in both groups for pooling.

Of participants who received antibiotics, $16.7 \%$ reported diarrhoea, versus $9.6 \%$ of participants who received placebo. This result was statistically significant (Peto OR $2.00,95 \% \mathrm{Cl} 1.41$ to 2.85 ); NNTH 13 , $95 \% \mathrm{Cl} 8$ to $29 ; \mathrm{I}^{2}=20 \%$; high-quality evidence; Analysis 2.3). We could not pool the results of Bucher 2003 because the raw data were not available, but their results were consistent with ours (OR 3.89, $95 \% \mathrm{Cl} 2.09$ to 7.25 at day $7 ;$ OR $1.71,95 \% \mathrm{Cl} 0.91$ to 3.23 at 14 days).

Meltzer 2005 only mentioned that there were no differences in treatment-emergent side effects among the treatment groups. In that trial, five participants in the amoxicillin group and six in the placebo group discontinued treatment because of side effects. Williamson 2007 and Rantanen 1973 did not provide any information for this outcome.

\section{Clinical failure}

We pooled data on clinical failure from 12 trials (Axelsson 1970; Bucher 2003; De Sutter 2002; Garbutt 2012; Kaiser 2001;
Lindbaek 1996; Lindbaek 1998; Meltzer 2005; Stalman 1997; Van Buchem 1997a; Varonen 2003; Williamson 2007). In eight trials, clinical failure was assessed as an abnormal course of rhinosinusitis (exacerbation, ongoing symptoms, respiratory complications, treatment failure) leading to commence or extend antibiotic therapy. The number of treatment failures in the control and active treatment groups were compared (Bucher 2003; De Sutter 2002; Garbutt 2012; Kaiser 2001; Lindbaek 1996; Lindbaek 1998; Van Buchem 1997a; Varonen 2003). Axelsson 1970 reported numbers of participants who deteriorated at day 5 and 10. Meltzer 2005 and Stalman 1997 reported numbers of participants who met the criteria for treatment failure, but did not report whether these were prescribed open antibiotic therapy. Williamson 2007 reported the number of participants that withdrew because of treatment failure.

The pooled result showed that clinical failure occurred less frequently in participants receiving antibiotics compared to placebo $(6.1 \%$ versus $11.2 \%$, Peto OR $0.48,95 \% \mathrm{Cl} 0.36$ to 0.63 ; NNTH $19,95 \% \mathrm{Cl} 15$ to $27 ; I^{2}=21 \%$; high-quality evidence; Analysis 2.4; Figure 6). 
Figure 6. Forest plot of comparison: 2 Antibiotics versus placebo in acute rhinosinusitis: secondary outcomes, outcome: 2.4 Clinical failure.

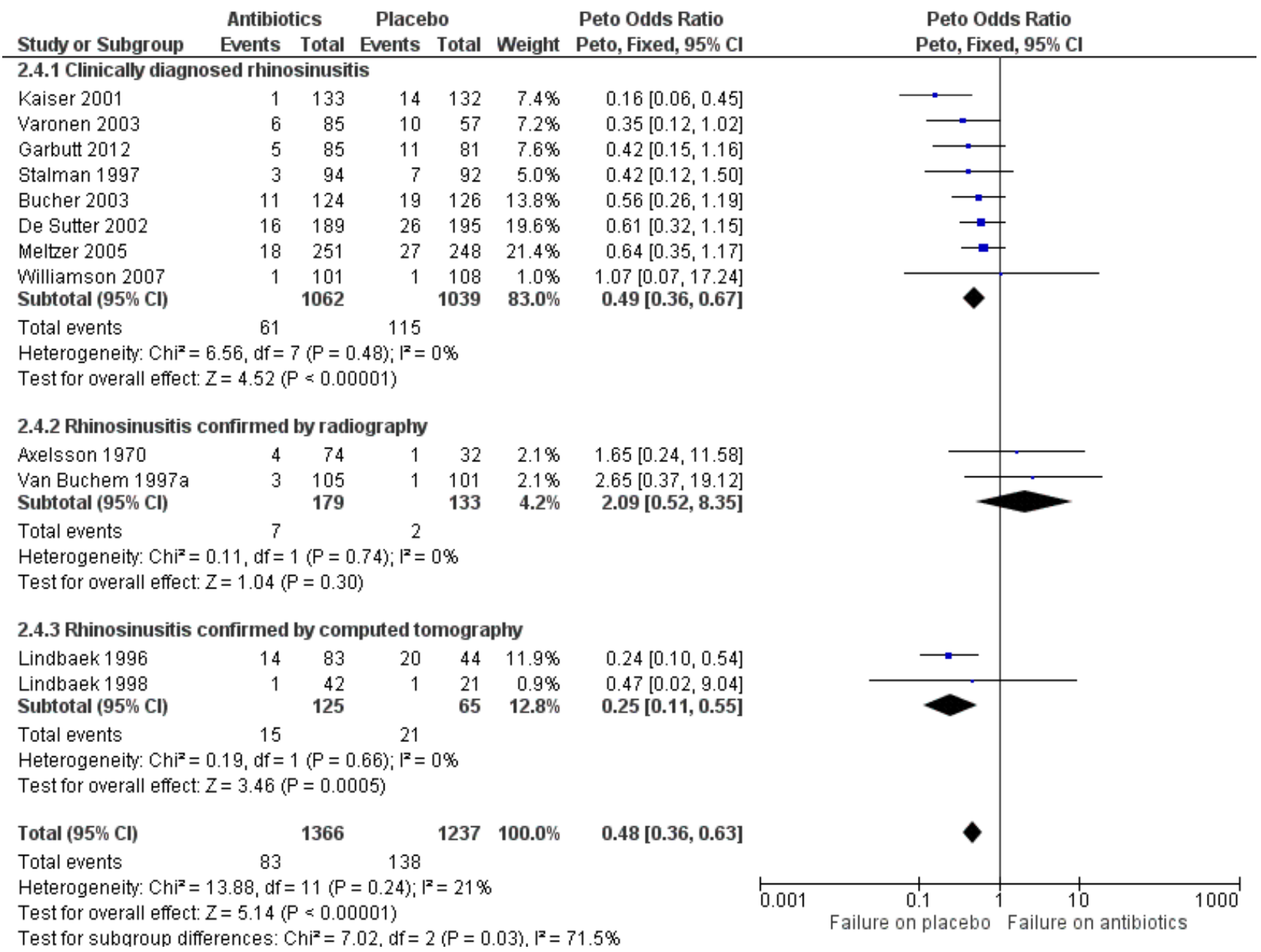

\section{Serious adverse events}

Only one serious disease-related adverse event occurred in the placebo group (Bucher 2003): after two weeks of symptomatic treatment, a participant who was treated for one week with amoxicillin-clavulanate ( $1 \mathrm{~g}$ twice daily, open antibiotic therapy) experienced a brain abscess caused by an amoxicillin-clavulanatesensitive strain of Streptococcus milleri. The participant was operated on and recovered but was reported to have a residual frontal syndrome.

There were two additional serious adverse events in the placebo group: one myocardial infarction and one severe depressive episode (Bucher 2003). Both were thought to be neither disease nor drug related. Other trials did not report any serious adverse events, which means that serious complications in participants with clinically diagnosed acute rhinosinusitis are rare.

\section{DISCUSSION}

\section{Summary of main results}

The intention-to-treat (ITT) population included 3057 participants 14 days. Antibiotics may slightly shorten the time to cure, but only 5 (diagnosis based on symptoms, range 1 to 10 ) to 11 (diagnosis confirmed by $\mathrm{x}$-ray, range 1 to 21) more participants per 100 would achieve cure faster by taking antibiotics instead of placebo. When a fluid level or total opacification was present on computed tomography (CT), 28 more participants per 100 (range 7 to 53) achieved cure faster with antibiotics. Antibiotics do not reduce the time to pain relief or the general feeling of illness. People who take antibiotics do not resume daily activities earlier and do not take less analgesics or nasal decongestants than people treated with placebo. In people with purulent rhinorrhoea, 10 more people per 100 (range 3 to 17) would experience a faster resolution of nasal discharge by taking antibiotics. However, we found that 13 more people per 100 (range 9 to 18) would experience side effects of the treatment. This potential harm needs to be compared to the possible benefit of people with purulent rhinorrhoea taking antibiotics. Five fewer people per 100 (range 3 to 7) would experience clinical failure if they took antibiotics instead of placebo (Summary of findings for the main comparison). This review did not investigate the effect of antibiotics in people with proven positive bacterial sinus cultures.

(15 trials). Without treatment, almost half of participants with acute rhinosinusitis, whether or not confirmed by radiography, recovered within one week, and two of three participants within 


\section{Overall completeness and applicability of evidence}

We investigated if antibiotic therapy could speed up the recovery process in people with acute rhinosinusitis, whether clinically diagnosed or confirmed by imaging. The main symptoms used for participant inclusion among the included studies were the presence of nasal discharge, facial pain, and a common cold or upper respiratory tract infection. This is in line with the clinical presentation of rhinosinusitis in patients in ambulatory care settings. We included studies where participant inclusion depended on clinical symptoms and abnormalities on radiography or CT. The reason for this was that in some countries, imaging is used to confirm diagnosis of rhinosinusitis. Based on included study populations, we are reasonably confident that this review covers the general population of people with rhinosinusitis-like symptoms. We could draw no conclusions about the efficacy of antibiotics in children, people with suppressed immune systems, or those with serious diseases (e.g. very high fever, prolonged symptoms, septic symptoms such as tachycardia, sweating, and low blood pressure) and people referred to an ear, nose, and throat specialist because of the serious course of the disease or fear of complications, since trials did not include these groups of patients, and it is unlikely that they will be included in future placebocontrolled trials.

\section{Quality of the evidence}

We used GRADEpro GDT 2015 to assess evidence quality for each outcome (Summary of findings for the main comparison).

We assessed high-quality evidence for the following outcomes: cure in adults with clinically diagnosed acute rhinosinusitis; severity or duration of different clinical symptoms - resolution of purulent secretion; general side effects; side effects relating to diarrhoea; and clinical failure. We assessed moderate-quality evidence for cure in adults with acute rhinosinusitis confirmed by radiography, downgrading the quality of the evidence due to few trials reporting this outcome $(n=3)$ and wide confidence intervals. It is unlikely that participants in Axelsson 1970 were blinded: the study report not provide any information about blinding and give the study design, it is highly likely that "treatment" was compared to "no treatment". Therefore we assessed this study as at high risk of bias for this domain. Nevertheless, omitting the results of Axelsson 1970 did not substantially changed the odds ratios (OR $1.67,95 \% \mathrm{Cl} 1.04$ to 2.70 , NNTB $9,95 \% \mathrm{Cl} 5$ to 104). For this reason, we did not further downgrade evidence quality for this outcome.

Only one study with few participants $(\mathrm{N}=127)$ reported cure in adults with acute rhinosinusitis confirmed by CT (Lindbaek 1996). Although this was a robust trial, we downgraded the quality of the evidence to moderate because of the limited number of participants.

All but three included studies reported on the main review outcome of rhinosinusitis cure (Garbutt 2012; Meltzer 2005; Rantanen 1973). The analyses show a consistent result.

\section{Potential biases in the review process}

We carried out thorough searches in several different databases on 18 January 2018. We used a predefined selection procedure for including and excluding studies and followed this strategy consistently. We documented reasons for exclusion. We predefined the research questions and answered them in the same sequence.
We assessed the included studies and summarised information in the Characteristics of included studies table. We assessed risk of bias rigorously. It is possible we evaluated three studies as poor undeservedly, but this does not mean that the studies were performed incorrectly (Rantanen 1973; Meltzer 2005; Norrelund 1978); rather, we evaluated them as unclear risk of bias due to insufficient information reported in the articles.

Some studies did not report raw data. In such cases, we estimated numbers of events by multiplying the percentage with the total number of participants in the group to make pooling of results possible. Stalman 1997 reported only the total cure rate for both groups and stated there was no difference between groups. We used the same percentages in both groups for pooling. This assumption could be imprecise; however, omitting these data did not substantially change odds ratios. Young 2008 performed a meta-analysis on clinically diagnosed acute rhinosinusitis using individual patient data meta-analysis (IPDMA). Young 2008 had raw data from Stalman 1997 at his disposal, and reported that the exact cure rate was $63 \%$ in the placebo group and $66 \%$ in the antibiotic group when the primary outcome was assessed. Using these cure rates in our analysis did not substantially change odds ratios (OR $1.27,95 \% \mathrm{Cl} 1.04$ to 1.56 ; number needed to treat for an additional beneficial outcome (NNTB) 18, 95\% Cl 10 to 104; Analysis 3.1.18). Garbutt 2012 reported only the percentage of diarrhoea for both groups and stated there was no difference between groups. We used the same percentages in both groups for pooling. Omitting these data from the analyses did not substantially change the odds ratios (OR 2.19, $95 \% \mathrm{Cl} 1.51$ to 3.18; NNTB $11,95 \% \mathrm{Cl} 7$ to 24 ).

Definitions of cure varied among trials, and this raised questions about the comparability of studies; however, the underlying interpretation of cure was similar. As well as calculating the overall treatment effect, we divided the studies into three groups (cure at one week, 10 days, and 14 days) to assess the effect at various time points.

For the primary outcome of cure, we checked if inputting missing data in three different ways changed the overall result (Analysis 3.1.6 to Analysis 3.1.17).

For the secondary outcome, resolution of purulent secretion, data were collected once by the participant, and once by the clinician (inspection). Due to the low number of studies, we did not take this into account.

There was important variation in choices of antibiotics and dosage schedules. This may be due to differences in antibiotic resistance at different time points and in different countries. We assumed that the trial authors' choice of antibiotics was suitable for their countries and local resistance patterns at that point in time, and that this did not influence the effect of the antibiotic treatment on cure rates. However, since the trials did not perform bacterial cultures, we cannot prove this.

As we considered only studies that included adults without bacteriological cultures, the proportion of adults with bacterial rhinosinusitis is unknown. However, as described, we wanted to focus on adults who visited general practitioners with acute rhinosinusitis symptoms and who are treated empirically, with or without imaging. This review answers the important clinical question of whether these people should be treated with antibiotics or not. 


\section{Agreements and disagreements with other studies or reviews}

We compared our meta-analysis results with those from Rosenfeld 2007, Young 2008, Falagas 2008, Fokkens 2012, and Burgstaller 2016.

Rosenfeld 2007 included trials based on a clinical diagnosis, as well as trials that used technical investigations to establish the diagnosis (Gananca 1973 (bacteriology); Hansen 2000a (elevated CRP or ESR); Haye 1998 (radiography); Lindbaek 1996 (CT); Lindbaek 1998 (CT); Van Buchem 1997a (radiography). Rosenfeld 2007 excluded Norrelund 1978 because of a language barrier. Williamson 2007 and Garbutt 2012 were not yet published. This study group found a modest antibiotic benefit for people with uncomplicated acute rhinosinusitis 7 to 12 days after entering a clinical trial (absolute risk difference $0.15,95 \% \mathrm{Cl} 0.04$ to 0.25 ; risk ratio 1.28, P = 0.007; NNTB 7), based on data from Bucher 2003, De Sutter 2002, Gananca 1973, Hansen 2000a, Haye 1998, Kaiser 2001, Lindbaek 1996, Lindbaek 1998, and Stalman 1997. However, there was a high level of heterogeneity $\left(I^{2}=80 \%\right)$. The forest plot shows that the benefit of antibiotics is higher in studies with an inclusion based on specific technical investigations (bacteriology, diagnostic algorithm, including CRP, CT; (NNTB 3)). The risk difference of studies that enrolled participants with a negative imaging or based strictly on clinical criteria was $0.03(95 \% \mathrm{Cl}-0.02$ to 0.08 ; NNTB 12.5 to 50). This is in accordance with our results. At 14 to 15 days, there was no longer any statistical benefit (results based on data from Bucher 2003; Meltzer 2005; Merenstein 2005; Van Buchem 1997a). Benefits were offset by a relative increase of $83 \%$ in adverse events (number needed to treat for an additional harmful outcome (NNTH) 9), which is similar to our calculations.

Young 2008 performed a IPDMA on clinically diagnosed acute rhinosinusitis. An IPDMA is the best way of performing subgroup analyses given that individual patient data from a number of RCTs can be obtained. As well as investigating the effect of antibiotics in the total group, the authors were able to investigate the effect of antibiotics in subgroups, such as people with at least seven days of rhinosinusitis-like symptoms, as guidelines advocate prescribing antibiotics for this patient group (Hickner 2001). Young 2008 completed this IPDMA by further analysis of the effect of antibiotics in people with specific signs and symptoms, with the aim of identifying people who benefit most from antibiotic therapy. Young 2008 included the same trials, except for Norrelund 1978, because they could not get the raw data for the IPDMA, and Garbutt 2012 because this trial was not yet published.Young 2008 included the raw data of Meltzer 2005 and of an identical unpublished trial run by Schering-Plough. The estimated OR for the overall treatment effect of antibiotics relative to placebo was 1.37 ( $95 \% \mathrm{Cl} 1.13$ to 1.66 ; NNTB $15,95 \% \mathrm{Cl} 7$ to 190 , data IPDMA). The ORs of analyses of aggregated data of Young 2008 were similar (OR 1.35, 95\% Cl 1.15 to 1.59). This OR for overall treatment effect in clinically diagnosed rhinosinusitis is slightly higher than in this review, probably due to the favourable results of Meltzer 2005. Young 2008 found that older people and people reporting severe symptoms or longer duration of symptoms (six days or more) took longer to cure but were no more likely to benefit from treatment than other people. For other patientreported symptoms (previous common cold or two stages of illness, pain on bending, unilateral facial pain, pain in the teeth, and purulent nasal discharge), estimates were not sufficiently precise to draw any conclusion about their prognostic value. Participants with purulent discharge in the pharynx, ascertained by a physician, seemed to cure more slowly and to have some non-significant benefits from antibiotics (OR $1.60,95 \% \mathrm{Cl} 0.95$ to 2.76; NNTB 8, $95 \% \mathrm{Cl} 4$ to 47). The same was found for people with a higher temperature (OR $1.28,95 \% \mathrm{Cl} 0.87$ to 1.88 ). As we did not have the raw data, we could not perform this subgroup analyses. Young 2008 did not investigate adverse events.

Falagas 2008 included trials in adults or children based on clinical diagnosis and/or specific technical investigations (extra trials: Gananca 1973 (bacteriology); Garbutt 2001 (children); Hansen 2000a (elevated CRP or ESR); Haye 1998 (radiography); Kristo 2005 (children); Lindbaek 1996 (CT); Lindbaek 1998 (CT); Wald 1986 (children)). Falagas 2008 excluded Norrelund 1978 due to a language barrier. For Kaiser 2001, Falagas 2008 only took into account the subgroup of people with rhinosinusitis confirmed by radiography. Falagas 2008 did not include Garbutt 2012 because this study was not yet published. Falagas 2008 made a distinction between "cured or improved" and "cured". Considering the different definitions, "cure" or "improvement" seem to be a subjective interpretation of how a patient feels at one time point, expressed in resolution of symptoms, restriction in daily activities, or feeling cured; therefore, we did not choose to make this distinction in this review. Taking cure as an outcome measure, Falagas 2008 found a higher cure rate in people taking antibiotics compared to placebo (OR $1.82,95 \% \mathrm{Cl} 1.34$ to 2.46 ; NNTB $7,95 \%$ $\mathrm{Cl} 5$ to 14). In this analysis, the diagnosis was made on clinical criteria only in only 4 of the 12 trials. Falagas 2008 omitted the trials by Kaiser 2001, Meltzer 2005, Stalman 1997, and Varonen 2003 because these trials did not report rates for cure (as defined by Falagas 2008) separately. As in Rosenfeld 2007, the forest plot revealed heterogeneity $\left(I^{2}=50 \%\right)$ : the trials with inclusion based on specific technical investigations (CT or laboratory tests) showed more benefit for antibiotics than the trials with inclusion on a clinical basis. Furthermore, taking cure or improvement as an outcome measure, Falagas 2008 found that people with rhinosinusitis benefit from antibiotics (OR $1.64,95 \% \mathrm{Cl} 1.35$ to 2.00; NNTB 11, 95\% Cl 8 to 17). However, for the Meltzer 2005 study, Falagas 2008 used the number of treatment failures as the number of people who were not cured, which makes the cure rate artificially high. Heterogeneity was low, but the same trend (more technical investigations, more benefit of antibiotics) can be seen. Falagas 2008 put their positive result into perspective by comparing the NNTB of 7 (95\% Cl 5 to 14) to a NNTH (adverse events) of 9 (95\% $\mathrm{Cl} 5$ to 30), a number that is, irrespective of the different kinds of studies included in the analysis, comparable to our results. Falagas 2008 found no significant difference in cure or improvement for adults versus children, imaging versus clinical criteria for inclusion, assessment at 7 to 11 versus 14 to 15 days, or year of publication.

Burgstaller 2016 included original studies that compared treatment of any antibiotic with placebo in people with symptoms and signs of acute rhinosinusitis lasting for seven or more days. The reason given by Burgstaller 2016 for this inclusion criterion was the recommendation of the 'European position paper on rhinosinusitis and nasal polyps' (Fokkens 2012). Fokkens 2012 recommend antibiotic treatment only in people with duration of symptoms of more than 10 days; however, as no original study included this kind of participant, Burgstaller 2016 used seven days or more as their criterion. Only Garbutt 2012 (clinical criteria), Merenstein 2005 (clinical criteria), Hadley 2010 (radiography and bacteriology), Lindbaek 1996 (CT), and Lindbaek 1998 (CT) were 
selected. Burgstaller 2016 looked separately at improvement and cure, finding a significantly higher proportion of people with improvement of symptoms after 3 and 7 days in people treated with antibiotics compared to placebo (OR $2.78,95 \% \mathrm{Cl} 1.39$ to 5.58 at day 3, based on data from Garbutt 2012, Hadley 2010, Lindbaek 1996, and Lindbaek 1998; and OR 2.29, 95\% Cl 1.19 to 4.41 at day 7 , based on data from Garbutt 2012). There was no relevant difference in the rate of cure at day 10 (OR $1.92,95 \% \mathrm{Cl} 0.63$ to 5.8, based on data from Lindbaek 1996 and Lindbaek 1998) or at day 14 (OR $1.57,95 \% \mathrm{Cl} 0.79$ to 3.13 , based on data from Merenstein 2005). It was difficult to compare results because there was minimal overlap in pooled studies. Furtermore, we questioned if symptoms lasting for seven days or more is a good criterion for selecting participants who could benefit from antibiotics. Lindbaek 2002 reviewed the clinical diagnosis of acute purulent sinusitis in general practice. The strongest predictor for the diagnosis of purulent sinusitis is the presence of purulent secretion in the nasal cavity. Pain in the teeth and an elevated ESR were associated in two of the four studies. Two phases in the illness history, ineffectiveness of decongestants and transillumination of the sinuses, might be of some value. We found no evidence that people with symptoms lasting seven days or more before consulting their physician are more likely to have bacterial sinusitis. Of the 440 people in Lindbaek 1996 and Lindbaek 1998 combined, 202/254 (80\%) of people with CT-confirmed sinusitis were symptomatic for more than seven days, while $131 / 186(70 \%)$ of people without CT-confirmed sinusitis were symptomatic for more than seven days. The difference is statistically significant $(P=0.03)$, but has not been analysed in a multivariate logistic regression. This means that about $60 \%$ of people presenting to general practices with sinusitis symptoms for more than seven days would have CT-confirmed sinusitis, and $40 \%$ would have a prolonged viral infection. But of people presenting with symptoms of seven days or less duration, about $50 \%$ will have a CT-confirmed sinusitis, and about 50\% viral upper respiratory tract infections (Lindbaek 2015 [pers comm]). Consequently, despite only $20 \%$ of people with CT-confirmed sinusitis having symptoms for seven or fewer days (Hickner 2001), duration of symptoms is a poor predictor of acute bacterial sinusitis.

In conclusion, people with clinically diagnosed rhinosinusitis and rhinosinusitis confirmed by imaging (radiography, CT) or laboratory findings (CRP, bacteriology) constitute different groups, and we are convinced that they cannot be pooled in one analysis, as performed by Burgstaller 2016, Falagas 2008, and Rosenfeld 2007. The separate results are very relevant: when a clinician makes a clinical diagnosis, the one analysis is applicable; when a decision is made to confirm the diagnosis by imaging, the other analysis is applicable. This would be clear for any clinician and avoids confusion.

\section{AUTHORS' CONCLUSIONS}

\section{Implications for practice}

Our review showed that there could be a beneficial therapeutic effect of antibiotics in adults with clinically diagnosed acute rhinosinusitis. But this effect is small, and only around 5 more people per 100 will be cured faster if they receive antibiotics instead of placebo. The lack of effect of antibiotics could be related to the non-specificity of the clinical presentation of acute bacterial sinusitis. Performing radiography increases this number from 5 to 11 per 100 . In adults with a fluid level or total opacification present on computed tomography, 28 more people per 100 cured faster with antibiotics. In clinically diagnosed rhinosinusitis, the subgroup of people with purulent discharge could benefit slightly more than those without. However, the benefits need to be seen in the context of the risk of experiencing adverse effects, especially of a gastrointestinal nature, and health risks of radiation exposure. Five fewer people per 100 will experience clinical failure if they receive antibiotics instead of placebo. This review addresses mainly people assessed in a ambulatory care setting and excluded people who were investigated further with laboratory tests. Considering the worldwide high antibiotic prescription rate for rhinosinusitis, growing antibiotic resistance, and the very low incidence of complications, we can conclude that there is no place for the use of antibiotics in adults with uncomplicated acute rhinosinusitis. For subgroups that are potentially more vulnerable, such as children, adults with a suppressed immune system, and adults with severe sinusitis (e.g. very high fever, prolonged symptoms, findings suggestive of severe sepsis such as hypotension) and people referred to an ear, nose, and throat specialist because of confirmed or perceived complications, no evidence is available from randomised, placebo-controlled trials. Complications are so rare (1/3057 participants in our review) that only case reports can give information about their course, hence evidence that serious complications can be prevented by giving antibiotics early is lacking.

\section{Implications for research}

Despite the availability of several studies and meta-analyses, there is still insufficient clinical data to enable subgroup analysis of people who probably could benefit more from antibiotics, for example people with high fever, severe facial pain, or rhinorrhoea. It may be unlikely that such data will become available, as they pose ethical (exposing vulnerable people to placebo treatment) and feasibility (a relatively small group that would take a long time to collect data) issues. Better recording of routinely collected data and morbidity, as well as adverse drug reaction registers, might be helpful in answering this question. The possibility of C-reactive protein (CRP) measurement or bacteriological investigations to select people that benefit from antibiotics should be further explored.

\section{ACK N O WLEDGEMENTS}

We would like to thank Sarah Thorning, David Honeyman, and Justin Clark for help in searching the literature, and Managing Editors Elizabeth Dooley and Ann Jones for all their patience and help.

We wish to acknowledge the following people for commenting on draft versions of this review: Roy Buffery, Mireya Aznar, Nelcy Rodriguez, Raghda Rashad, Noorin Bhimani, Jack Anon, Helena Liira, Pakpoom Supiyaphun, Conor Teljeur, Bruce Arroll, Sree Nair, Dilip Raghavan, Meenu Sing, Abimbola Farinde, José Luis Ferrero Albert, Terry Neeman, Devada Singh-Franco, Shunjie Chua, Cheow Peng Ooi, Theo Verheij, and Allen Cheng.

We would like to thank Dr Morten Lindbaek for providing additional information about his trial.

We would also like to thank everyone who contributed to De Sutter 2012 and Ahovuo-Saloranta 2014 
And last but not least, we wish to thank Anneli Ahovuo-Saloranta and James Young for their great contributions to previous published versions of this review. 


\section{RE F E R E N C E S}

\section{References to studies included in this review}

Axelsson 1970 \{published data only\}

Axelsson A, Chidekel N, Grebelius N, Jensen C. Treatment of acute maxillary sinusitis. A comparison of four different methods. Acta Otolaryngologica 1970;70(1):71-6.

\section{Bucher 2003 \{published data only\}}

Bucher HC, Tschudi P, Young J, Periat P, Welge-Luussen A, Zust $\mathrm{H}$, et al. Effect of amoxicillin-clavulanate in clinically diagnosed acute rhinosinusitis: a placebo-controlled, doubleblind, randomized trial in general practice. Archives of Internal Medicine 2003;163(15):1793-8. [PUBMED: 12912714]

\section{De Sutter 2002 \{published data only\}}

De Sutter AI, De Meyere MJ, Christiaens TC, Van Driel ML, Peersman W, De Maeseneer JM. Does amoxicillin improve outcomes in patients with purulent rhinorrhea? A pragmatic randomized double-blind controlled trial in family practice. Journal of Family Practice 2002;51(4):317-23. [PUBMED: 11978253]

\section{Garbutt 2012 \{published data only\}}

Garbutt JM, Banister C, Spitznagel E, Piccirillo JF. Amoxicillin for acute rhinosinusitis: a randomized controlled trial. JAMA 2012;307(7):685-92.

\section{Kaiser 2001 \{published data only\}}

Kaiser L, Morabia A, Stalder H, Ricchetti A, Auckenthaler R, Terrier $\mathrm{F}$, et al. Role of nasopharyngeal culture in antibiotic prescription for patients with common cold or acute sinusitis. European Journal of Clinical Microbiology and Infectious Diseases 2001;20(7):445-51.

\section{Lindbaek 1996 \{published data only\}}

Lindbaek M, Hjortdahl P, Johnsen ULC. Randomised, double blind, placebo controlled trial of penicillin $\mathrm{V}$ and amoxycillin in treatment of acute sinus infections in adults. BMJ 1996;313(7053):325-9.

\section{Lindbaek 1998 \{published data only\}}

Lindbaek M, Kaastad E, Dolvik S, Johnsen U, Laerum E, Hjortdahl P. Antibiotic treatment of patients with mucosal thickening in the paranasal sinuses, and validation of cut-off points in sinus CT. Rhinology 1998;36(1):7-11.

\section{Meltzer 2005 \{published data only\}}

* Meltzer EO, Bachert C, Staudinger H. Treating acute rhinosinusitis: comparing efficacy and safety of mometasone furoate nasal spray, amoxicillin, and placebo. Journal of Allergy and Clinical Immunology 2005;116(6):1289-95. [PUBMED: 16337461]

Svensson J, Lundberg J, Olsson P, Stjärne P, Tennvall GR. Cost-effectiveness of mometasone furoate nasal spray in the treatment of acute rhinosinusitis. Primary Care Respiratory Journal 2012;21(4):412-8.
Merenstein 2005 \{published data only\}

Merenstein D, Whittaker C, Chadwell T, Wegner B, D'Amico F. Are antibiotics beneficial for patients with sinusitis complaints? A randomized double-blind clinical trial. Journal of Family Practice 2005;54(2):144-51. [PUBMED: 15689289]

\section{Norrelund 1978 \{published data only\}}

Norrelund N. Treatment of sinusitis in general practice. A controlled investigation of pivampicillin (Pondocillin) [Behandling af sinuitis i almenpraksis. En kontrolleret undersogelse over pivampicillin (Pondocillin)]. Ugeskrift for Laeger 1978;140(45):2792-5. [PUBMED: 362655]

\section{Rantanen 1973 \{published data only\}}

Rantanen T, Arvilommi H. Double-blind trial of doxicycline in acute maxillary sinusitis. A clinical and bacteriological study. Acta Otolaryngologica 1973;76(1):58-62.

\section{Stalman 1997 \{published data only\}}

Stalman W, van Essen GA, van der Graaf Y, de Melker RAC. The end of antibiotic treatment in adults with acute sinusitis-like complaints in general practice? A placebo-controlled doubleblind randomized doxycycline trial. British Journal of General Practice 1997;47(425):794-9. [PUBMED: 9463979]

\section{Van Buchem 1997a \{published data only\}}

* Van Buchem FL, Knottnerus JA, Schrijnemaekers VJ, Peeters MF. Primary-care-based randomised placebo-controlled trial of antibiotic treatment in acute maxillary sinusitis. Lancet 1997;349(9053):683-7.

\section{Varonen 2003 \{published data only\}}

Varonen H, Kunnamo I, Savolainen S, Makela M, Revonta M, Ruotsalainen J, et al. Treatment of acute rhinosinusitis diagnosed by clinical criteria or ultrasound in primary care. A placebo-controlled randomised trial. Scandinavian Journal of Primary Health Care 2003;21(2):121-6. [PUBMED: 12877377]

\section{Williamson 2007 \{published data only\}}

Williamson IG, Rumsby K, Benge S, Moore M, Smith PW, Cross M, et al. Antibiotics and topical nasal steroid for treatment of acute maxillary sinusitis: a randomized controlled trial. JAMA 2007;298(21):2487-96. [PUBMED: 18056902]

\section{References to studies excluded from this review}

Gananca 1973 \{published data only\}

Gananca M, Trabulsi LR. The therapeutic effects of cyclacillin in acute sinusitis: in vitro and in vivo correlations in a placebocontrolled study. Current Medical Research and Opinion 1973;1(6):362-8.

\section{Gananca 1977 \{published data only\}}

Gananca MM, Gasel JJ. A double-blind study with the association tetracycline, acetylsalicylic acid, phenacetin, caffeine and phenyltoloxamine in the treatment of acute sinusitis. Folha Medica 1977;75(5):583-5. 
Hadley 2010 \{published data only\}

Hadley JA, Mosges R, Desrosiers M, Haverstock D, van Veenhuyzen D, Herman-Gnjidic Z. Moxifloxacin five-day therapy versus placebo in acute bacterial rhinosinusitis. Laryngoscope 2010;120(5):1057-62.

Hansen 2000a \{published data only\}

* Hansen JG, Schmidt H, Grinsted P. Randomised, double blind, placebo controlled trial of penicillin $\mathrm{V}$ in the treatment of acute maxillary sinusitis in adults in general practice. Scandinavian Journal of Primary Health Care 2000;18(1):44-7.

Haye 1998 \{published data only\}

Haye R, Lingaas E, Hoivik HO, Odegard T. Azithromycin versus placebo in acute infectious rhinitis with clinical symptoms but without radiological signs of maxillary sinusitis. European Journal of Clinical Microbiology and Infectious Diseases 1998;17(5):309-12.

\section{Additional references}

\section{Ah-See 2007}

Ah-See KW, Evans AS. Sinusitis and its management. BMJ 2007;334:358-61.

\section{Atkins 2004}

Atkins D, Best D, Briss PA, Eccles M, Falck-Ytter Y, Flottorp S, et al. GRADE Working Group. Grading quality of evidence and strength of recommendations. BMJ 2004;328(7454):1490.

\section{Autio 2015}

Autio TJ, Koskenkorva T, Närkiö M, Leino TK, Koivunen P, Alho OP. Diagnostic accuracy of history and physical examination in bacterial acute rhinosinusitis. Laryngoscope 2015;125(7):1541-6. [DOI: 10.1002/lary.25247]

\section{Axelsson 1972}

Axelsson A, Chidekel N. Symptomatology and bacteriology correlated to radiological findings in acute maxillary sinusitis. Acta Oto-laryngologica 1972;74(1):118-22.

\section{Bachert 2003}

Bachert C, Hörmann K, Mösges R, Rasp G, Riechelmann H, Müller R, et al. An update on the diagnosis and treatment of sinusitis and nasal polyposis. Allergy 2003;58(3):176-91.

\section{Berg 1986}

Berg O, Carenfelt C, Rystedt G, Anggärd A. Occurence of asymptomatic sinusitis in common cold and other acute ENTinfections. Rhinology 1986;24(3):223-5.

\section{Blackwell 2014}

Blackwell DL, Lucas JW, Clarke TC. Summary health statistics for U.S. adults: national health interview survey, 2012. Vital and Health Statistics. Series 10, Data from the National Health Survey 2014;10(260):1-161. [PUBMED: 24819891]

\section{Brazzelli 2003}

Brazzelli MG, Astin MP. Making the Best Use of Department of Clinical Radiology. Guidelines for Doctors. 5th Edition. London: Royal College of Radiologists, 2003.

\section{Burgstaller 2016}

Burgstaller JM, Steurer J, Holzmann D, Geiges G, Soyka MB. Antibiotic efficacy in patients with a moderate probability of acute rhinosinusitis: a systematic review. European Archives of Oto-rhino-laryngology 2016;273(5):1067-77. [DOI: 10.1007/ s00405-015-3506-z; PUBMED: 25597034]

\section{Costelloe 2010}

Costelloe C, Metcalfe C, Lovering A, Mant D, Hay AD. Effect of antibiotic prescribing in primary care on antimicrobial resistance in individual patients: systematic review and metaanalysis. BMJ 2010;340:c2096. [DOI: 10.1136/bmj.c2096]

\section{Ebell 2017}

Ebell MH, Hansen JG. Proposed clinical decision rules to diagnose acute rhinosinusitis among adults in primary care. Annals of Family Medicine 2017;15(4):347-54. [DOI: 10.1370/ afm.2060]

\section{Falagas 2008}

Falagas ME, Giannopoulou KP, Vardakas KZ, Dimopoulos G, Karageorgopoulos DE. Comparison of antibiotics with placebo for treatment of acute sinusitis: a meta-analysis of randomised controlled trials. Lancet Infectious Diseases 2008;8(9):543-52.

\section{Fleming-Dutra 2016}

Fleming-Dutra KE, Hersh AL, Shapiro DJ, Bartoces M, Enns EA, File TM Jr, et al. Prevalence of inappropriate antibiotic prescriptions among US ambulatory care visits, 2010-2011. JAMA 2016;315(17):1864-73. [DOI: 10.1001/jama.2016.4151]

\section{Fokkens 2012}

Fokkens WJ, Lund VJ, Mullol J, Bachert C, Alobid I, Baroody F, et al. EPOS 2012: European position paper on rhinosinusitis and nasal polyps 2012. A summary for otorhinolaryngologists. Rhinology 2012;50(1):1-298.

\section{Garbutt 2001}

Garbutt JM, Goldstein M, Gellman E, Shannon W, Littenberg B. A randomized, placebo-controlled trial of antimicrobial treatment for children with clinically diagnosed acute sinusitis. Pediatrics 2001;107(4):619-25. [PUBMED: 11335733]

\section{GRADEpro GDT 2015 [Computer program]}

McMaster University (developed by Evidence Prime, Inc.). GRADEpro GDT. Version (accessed prior to 10 May 2018). Hamilton (ON): McMaster University (developed by Evidence Prime, Inc.), 2015.

\section{Gulliford 2014}

Gulliford MC, Dregan A, Moore MV, Ashworth M, Staa Tv, McCann G, et al. Continued high rates of antibiotic prescribing to adults with respiratory tract infection: survey of $568 \mathrm{UK}$ general practices. BMJ Open 2014;4(10):e006245. [DOI: 10.1136/ bmjopen-2014-006245] 


\section{Gwaltney 1994}

Gwaltney JM Jr, Phillips CD, Miller RD, Riker D. Computed tomographic study of the common cold. New England Journal of Medicine 1994;330(1):25-30.

\section{Gwaltney 1996}

Gwaltney JM Jr. Acute community-acquired sinusitis. Clinical Infectious Diseases 1996;23(6):1209-23.

\section{Gwaltney 2005}

Gwaltney JM Jr. Sinusitis. In: Mandell GL, Bennett JE, Dolin R editor(s). Mandell, Douglas, and Bennett's Principles and Practice of Infectious Diseases. Philadelphia: Elsevier, 2005:772-83.

\section{Hanssen 2000b}

Hansen JG, Schmidt H, Grinsted P. [Penicillin treatment of acute maxillary sinusitis in adults. A randomized, double-blind, placebo-controlled trial from general practice].. Ugeskr Laeger 2000;162(40):5351-3.

\section{Hickner 2001}

Hickner JM, Bartlett JG, Besser RE, Gonzales R, Hoffman JR, Sande MA. Principles of appropriate antibiotic use for acute rhinosinusitis in adults: background. Annals of Internal Medicine 2001;134(6):498-505.

\section{Higgins 2011a}

Higgins JP, Altman DG, Sterne JAC. Chapter 8: Assessing risk of bias in included studies. In: Higgins JP, Green S, editor(s). Cochrane Handbook for Systematic Reviews of Interventions Version 5.1.0 (updated March 2011). The Cochrane Collaboration, 2011. Available from handbook.cochrane.org.

\section{Higgins 2011b}

Higgins JP, Green S, editor(s). Cochrane Handbook for Systematic Reviews of Interventions Version 5.1.0 (updated March 2011). The Cochrane Collaboration, 2011. Available from handbook.cochrane.org.

\section{Kenealy 2013}

Kenealy T, Arroll B. Antibiotics for the common cold and acute purulent rhinitis. Cochrane Database of Systematic Reviews 2013, Issue 6. [DOI: 10.1002/14651858.CD000247.pub3]

\section{Kristo 2005}

Kristo A, Uhari M, Luotonen J, Ilkko E, Koivunen P, Alho OP. Cefuroxime axetil versus placebo for children with acute respiratory infection and imaging evidence of sinusitis: a randomized, controlled trial. Acta Paediatrica 2005;94(9):1208-13. [PUBMED: 16278986]

\section{Lanza 1997}

Lanza DC, Kennedy DW. Adult rhinosinusitis defined. Otolaryngology Head and Neck Surgery 1997;117(3 Suppl 2):1-7.

\section{Lethbridge-Cejku 2006}

Lethbridge-Cejku M, Rose D, Vickerie J. Summary health statistics for US adults: national health interview survey, 2004. Vital and Health Statistics. Series 10, Data from the National Health Survey 2006;10(228):19-22.

\section{Lindbaek 2002}

Lindbaek M, Hjortdahl P. The clinical diagnosis of acute purulent sinusitis in general practice - a review. British Journal of General Practice 2002;52(479):491-5.

\section{Lindbaek 2015 [pers comm]}

Lindbaek M. Illness duration of 7 days and purulent sinusitis: a question [personal communication]. Lemiengre MB, De Sutter Al 12 February 2015.

\section{Low 1997}

Low DE, Desroires M, McSherry J, Garber G, Williams JW, Remy $\mathrm{H}$, et al. A practical guide for the diagnosis and treatment of acute sinusitis. Canadian Medical Association Journal 1997;156(Suppl 6):1-14.

\section{McCaig 1995}

McCaig LF, Hughes JM. Trends in antimicrobial drug prescribing among office-based physicians in the United States. JAMA 1995;273(3):214-9.

\section{Moher 2009}

Moher D, Liberati A, Tetzlaff J, Altman DG, The PRISMA Group. Preferred reporting items for systematic reviews and metaanalyses: The PRISMA Statement. BMJ 2009;339:2535.

\section{Morris 2002}

Morris P, Leach A. Antibiotics for persistent nasal discharge (rhinosinusitis) in children. Cochrane Database of Systematic Reviews 2002, Issue 4. [DOI: 10.1002/14651858.CD001094.pub2]

\section{Okkes 2005}

Okkes I, Oskam S, Van Boven K. EFP. Episodes of care in Dutch family practice. Epidemiological data based on the routine use of the International Classification of Primary Care (ICPC) in the Transition Project of the Academic Medical Center, University of Amsterdam (1985 to 2003). www.transhis.nl. Login required. Amsterdam: Academic Medical Center/University of Amsterdam, Department of Family Medicine, (accessed prior to 10 August 2018).

\section{Review Manager 2014 [Computer program]}

Nordic Cochrane Centre, The Cochrane Collaboration. Review Manager 5 (RevMan 5). Version 5.3. Copenhagen: Nordic Cochrane Centre, The Cochrane Collaboration, 2014.

\section{Rosenfeld 2007}

Rosenfeld RM, Singer M, Jones S. Systematic review of antimicrobial therapy in patients with acute rhinosinusitis. Otolaryngology-Head and Neck Surgery 2007;137(3 Suppl):S32-45.

\section{Rún 2015}

Rún Sigurðardóttir N, Nielsen AB, Munck A, Bjerrum L. Appropriateness of antibiotic prescribing for upper respiratory tract infections in general practice: comparison between Denmark and Iceland. Scandinavian Journal of Primary Health Care 2015;33(4):269-74. [DOI: 10.3109/02813432.2015.1114349] 


\section{Schappert 1998}

Schappert SM. Ambulatory care visits to physician offices, hospital outpatient departments, and emergency departments: United States, 1996. Vital and Health Statistics. Series 13, Data from the National Health Survey 1998;13(134):1-37.

\section{Van Buchem 1997b}

Van Buchem FL, Knottnerus JA, Schrijnemaekers VJJ, Peeters MF. No benefit of antibiotic treatment in acute maxillary sinusitis: a randomized double-blind placebo-controlled study. Nederlands Tijdschrift voor Geneeskunde 1997;141(49):2405-11.

\section{Varonen 2000}

Varonen H, Mäkelä M, Savolainen S, Läärä E, Hilden J. Comparison of ultrasound, radiography, and clinical examination in the diagnosis of acute maxillary sinusitis: a systematic review. Journal of Clinical Epidemiology 2000;53(9):940-8. [PUBMED: 11004420 ]

\section{Wald 1986}

Wald ER, Chiponis D, Ledesma-Medina J. Comparative effectiveness of amoxicillin and amoxicillin-clavulanate potassium in acute paranasal sinus infections in children: a double-blind, placebo-controlled trial. Pediatrics 1986;77(6):795-800. [PUBMED: 3520469]

\section{Willet 1994}

Willet LR, Carson JL, Williams JW Jr. Current diagnosis and management of sinusitis. Journal of General Internal Medicine 1994;9(1):38-45.

\section{Williams 1993}

Williams JWJ, Simel DL. Does this patient have sinusitis? Diagnosing acute sinusitis by history and physical examination. JAMA 1993;270(10):1242-6.

\section{Young 2008}

Young J, De Sutter A, Merenstein D, van Essen GA, Kaiser L, Varonen $\mathrm{H}$, et al. Antibiotics for adults with clinically diagnosed acute rhinosinusitis: a meta-analysis of individual patient data. Lancet 2008;371(9616):908-14.

\section{References to other published versions of this review}

\section{Ahovuo-Saloranta 2011}

Ahovuo-Saloranta A, Rautakorpi U-M, Borisenko OV, Liira H, Williams JW Jr, Mäkelä M. Antibiotics for acute maxillary

\section{CHARACTERISTICS OF STUDIES}

Characteristics of included studies [ordered by study ID] sinusitis. Cochrane Database of Systematic Reviews 2011, Issue 3. [DOI: 10.1002/14651858.CD000243.pub2]

\section{Ahovuo-Saloranta 2014}

Ahovuo-Saloranta A, Rautakorpi UM, Borisenko OV, Liira H, Williams JW Jr, Mäkelä M. Antibiotics for acute maxillary sinusitis in adults. Cochrane Database of Systematic Reviews 2014, Issue 2. [DOI: 10.1002/14651858.CD000243.pub3]

\section{De Sutter 2006}

De Sutter AIM, Lemiengre M, Merenstein D, Young J, van Driel ML. Antibiotics for clinically diagnosed acute rhinosinusitis in adults. Cochrane Database of Systematic Reviews 2006, Issue 3. [DOI: 10.1002/14651858.CD006089]

\section{De Sutter 2012}

De Sutter AIM, Lemiengre MB, Merenstein D, Young J, van Driel ML. Antibiotics for clinically diagnosed acute rhinosinusitis in adults. Cochrane Database of Systematic Reviews 2012, Issue 9. [DOI: 10.1002/14651858.CD006089.pub3]

\section{Lemiengre 2012}

Lemiengre MB, van Driel ML, Merenstein D, Young J, De Sutter AIM. Antibiotics for clinically diagnosed acute rhinosinusitis in adults. Cochrane Database of Systematic Reviews 2012, Issue 10. [DOI: 10.1002/14651858.CD006089.pub4]

\section{Williams 1997}

Williams J Jr, Aguilar C, Makela M, Cornell J, Hollman D, Chiquette $\mathrm{E}$, et al. Antibiotic therapy for acute sinusitis: a systematic literature review. Cochrane Database of Systematic Reviews 1997, Issue 1. [DOI: 10.1002/14651858.CD000243]

\section{Williams 1999}

Williams JW Jr, Aguilar C, Makela M, Cornell J, Hollman DR, Chiquette $\mathrm{E}$, et al. Antimicrobial therapy for acute maxillary sinusitis. Cochrane Database of Systematic Reviews 1999, Issue 3. [DOI: 10.1002/14651858.CD000243.pub2]

\section{Williams 2003}

Williams JW Jr, Aguilar C, Cornell J, Chiquette E, Dolor RJ, Makela M, et al. Antibiotics for acute maxillary sinusitis. Cochrane Database of Systematic Reviews 2003, Issue 2. [DOI: 10.1002/14651858.CD000243]

* Indicates the major publication for the study

Axelsson 1970

\begin{tabular}{ll} 
Methods & Study design: RCT \\
& Study duration: not reported \\
\hline Participants & Setting: not reported \\
Country: Sweden
\end{tabular}


Health status: clinically suspected sinusitis with secretion confirmed on radiography (different projections were used to prove fluid in the sinus, and thereby called an "affected sinus"). Completely opaque maxillary sinuses were only accepted if the secretion was confirmed by a single diagnostic irrigation.

Number: treatment (78 (38 penicillin $V$ and 40 lincomycin)); control (34)

Age: mean 33 (range 13 to 80 years)

Sex: $60 \%$ women

Exclusion criteria: history of nasal allergy and people recently treated with nasal decongestants or antibiotics

\begin{tabular}{l} 
Treatment group: \\
Interventions \\
\hline Group 1 \\
$\circ$ intervention: irrigation \\
$\circ$ dose, duration, frequency, administration: every second day until the lavage was clear, after radi- \\
ological examination \\
$\circ$ This intervention was excluded from the analyses, since it comprises neither placebo nor an an- \\
tibiotic treatment \\
Group 2 \\
$\circ$ intervention: penicillin $\mathrm{V}$ \\
$\circ$ dose, duration, frequency, administration: $400 \mathrm{mg}, 10$ days, 3 times daily, orally \\
Group 3 \\
$\circ$ intervention: lincomycin 500 mg \\
$\circ$ dose, duration, frequency, administration: $500 \mathrm{mg}, 8$ days, 3 times daily, orally \\
Control group: \\
- intervention: no treatment \\
dose, duration, frequency, administration: / \\
Co-interventions: concomitant use of oxymetazoline (three drops in each nostril three times daily) was \\
prescribed for all treatment arms.
\end{tabular}

Outcomes

Primary outcomes:

1. Radiological evaluation (mean number of severity points per sinus) at days 5 and 10

2. Subjective evaluation of the treatment (recovered, improved, unimproved, deteriorated) at days 5 and 10

Secondary outcome:

1. Adverse effects

Correlation between subjective and radiological improvement

Contact with study authors for additional information: none

Other notes: 
Axelsson 1970 (Continued)

\section{- Results:}

- Recovered (patients' evaluation):

- treatment group: $6 / 75$ (day 5), $27 / 74$ (day 10)

- control group (no treatment): 2/34 (day 5), 10/32 (day 10)

- Improved (patient's evaluation)

- treatment group: 60/75 (day 5), 62/74 (day 10)

- control group (no treatment): 24/34 (day 5), 23/32 (day 10)

- Side effects:

- No serious side effects

- Nausea: treatment group (2/75); control group (2/34)

- Diarrhoea: treatment group (1/75); control group (0/34)

- Clinical failure (defined as "deterioration")

- treatment group: $3 / 75$ (day 5), 4/74 (day 10)

- control group (no treatment): 2/34 (day 5), 1/32 (day 10)

\section{Risk of bias}

\begin{tabular}{lll}
\hline Bias & Authors' judgement & Support for judgement \\
\hline $\begin{array}{ll}\text { Random sequence genera- } \\
\text { tion (selection bias) }\end{array}$ & Unclear risk & $\begin{array}{l}\text { Comment: it is unclear if participants were a convenience sample or a con- } \\
\text { secutive series of eligible patients. Participants were randomly divided into } 4 \\
\text { treatment groups. No details about randomisation (simple, unrestricted, re- } \\
\text { stricted) were provided. }\end{array}$ \\
\hline
\end{tabular}

\begin{tabular}{|c|c|c|}
\hline $\begin{array}{l}\text { Allocation concealment } \\
\text { (selection bias) }\end{array}$ & Unclear risk & $\begin{array}{l}\text { Comment: no information provided about randomisation list or numbering or } \\
\text { appearance of drug containers }\end{array}$ \\
\hline
\end{tabular}

Blinding (performance High risk
Comment: blinding not reported, but probably not done since

bias and detection bias)

All outcomes

1. The placebo group did not take tablets, only nose drops.

2. It was not possible to blind "sinus irrigation" as an intervention (group 1)

3. Only group 1 underwent radiological evaluation every second day

4. Group 2 received a longer course of tablets than group 3

\begin{tabular}{|c|c|c|}
\hline $\begin{array}{l}\text { Incomplete outcome data } \\
\text { (attrition bias) } \\
\text { All outcomes }\end{array}$ & Low risk & $\begin{array}{l}\text { Post-randomisation dropout rate: } 6 / 98(6.1 \%) \\
\text { - treatment group: } 4 \text { ( } 3 \text { penicillin V group, } 1 \text { lyncomycin group) } \\
\text { - control group: } 2\end{array}$ \\
\hline
\end{tabular}

The reasons for missing data: not reported.

The ratio of participants with missing data to participants with events: 0.16

Compliance with treatment: not reported

\begin{tabular}{lll}
\hline $\begin{array}{l}\text { Selective reporting (re- } \\
\text { porting bias) }\end{array}$ & Unclear risk & $\begin{array}{l}\text { Comment: the study protocol was described in the methods. The primary end- } \\
\text { points (cure, improvement) were not adequately defined. Nevertheless, study } \\
\text { authors reported which outcomes were recorded. }\end{array}$ \\
\hline Other bias & Unclear risk & $\begin{array}{l}\text { Comment: it appears that groups were balanced, although information on de- } \\
\text { mographic characteristics was limited (similar according to mean age, radio- } \\
\text { logical state). }\end{array}$ \\
\hline
\end{tabular}


Bucher 2003

$\begin{array}{ll}\text { Methods } & \text { Study design: RCT } \\ & \text { Study duration: from November } 1 \text { to April } 30 \text { of } 1997 \text { to } 2001 \text { (4 winter seasons) }\end{array}$

Participants

Setting: general practice and the internal medicine and otolaryngology outpatient clinics of the University Hospital Basel (only walk-in patients and not referred patients) ( 24 general practices and 2 outpatient clinics)

Country: Switzerland

Health status: people presenting with a history of repeated purulent nasal discharge and maxillary or frontal unilateral or bilateral pain for at least 48 hours, but less than 1 month, and presence of pus under rhinoscopy (this last criterion was withdrawn after the first winter season).

Number:

- total: treatment (125); control (127)

- analysed at day 7: treatment (122); control (125)

- analysed at day 14: treatment (124); control (126)

Age: mean 37

\section{Sex: $54 \%$ women}

Exclusion criteria: age younger than 18, an upper respiratory tract infection or use of antibiotics for any reason within the previous 4 weeks, an upper respiratory tract infection or intermittent fever that persisted for more than 4 weeks, pathologic features or malformation of nasal cavities or the pharynx, immunosuppressive treatment, HIV infection, allergy to amoxicillin-clavulanate, pregnancy or breastfeeding, and no fluency in one of the national languages. After 2000, an extra exclusion criterion was introduced because of a brain abscess in the placebo group: (1) people with a CRP level greater than 100 $\mathrm{mg} / \mathrm{L}$ (2) people with a CRP level between 50 and $99 \mathrm{mg} / \mathrm{L}$ if 3 days after inclusion clinical worsening or an increase in CRP level higher than $100 \mathrm{mg} / \mathrm{L}$ occurred.

- intervention: amoxicillin with clavulanic acid

- dose, duration, frequency, administration: 875 mg/125 mg, 6 days, 2 times daily, orally

Control group:

- intervention: placebo

- dose, duration, frequency, administration: 6 days, 2 times daily, orally

Co-interventions: decongestant therapy (xylometazoline hydrochloride spray) and paracetamol tablets (500 $\mathrm{mg}$ with a maximum dose of 6 tablets a day) were provided. Steam inhalation was allowed.

\section{Outcomes}

\section{Primary outcomes:}

1. Time to cure ( 7 days, 14 days, 28 days)

a. Cure, defined as 0 days (since the previous interview) during which rhinosinusitis restricted activities at home or work

b. Cure, defined as a rating of 1 on a 10-point, equal-distance scale for the severity of restricted activity at home or work

\section{Secondary outcomes:}

1. Number of days during which rhinosinusitis restricted activities at home or work

2. Frequency of adverse effects

3. Recurrence rate of rhinosinusitis at 28 days 
Bucher 2003 (Continued)

Contact with study authors for additional information: none

Other notes:

- Registration: medical history for rhinosinusitis-like symptoms, number of days during which rhinosinusitis restricted activities at home or work, previous upper respiratory tract infections, clinical examination, questionnaire (rating of severity), radiograph maxillary and frontal sinus (occipitomental view), blood sampling (white blood cell count and CRP level) at inclusion

- Follow up:

- day 7: clinical examination, number of tablets taken, and 2nd questionnaire

- day 14 and 28: telephone interview by study nurse (questions about rhinosinusitis-related symptoms, adverse effects, use of other drugs or other visits to physicians)

- Results:

- Cure at day 7 :

- treatment group: $36 / 122$

- control group: $38 / 125$

- Cure at day 14:

- treatment group: 95/124

- control group: 93/126

- Side effects:

- diarrhoea: OR $3.89(95 \% \mathrm{Cl} 2.09$ to 7.25$)$ at 7 days and OR 1.71 (95\% $\mathrm{Cl} 0.91$ to 3.23$)$ at 14 days (exact numbers not available)

- vaginal discharge or pruritus and abdominal pain: no significant differences

- 4 possibly drug-related adverse events of moderate or severe intensity: treatment (2, diarrhoea); control (2, diarrhoea and vomiting)

- Clinical failure (requiring open antibiotic therapy)

- treatment group: $11 / 124$

- control group: 19/126 (1 serious adverse event)

\section{Risk of bias}

\begin{tabular}{lll}
\hline Bias & Authors' judgement & Support for judgement \\
\hline $\begin{array}{l}\text { Random sequence genera- } \\
\text { tion (selection bias) }\end{array}$ & Low risk & $\begin{array}{l}\text { Comment: a computer random number generator was used. Stratified ran- } \\
\text { domisation: general practice or outpatient clinic as stratification unit, partici- } \\
\text { pants randomised in blocks of } 6\end{array}$ \\
\hline $\begin{array}{l}\text { Allocation concealment } \\
\text { (selection bias) }\end{array}$ & Low risk & $\begin{array}{l}\text { Comment: tablets were provided in identical, numbered containers. The allo- } \\
\text { cation sequence was performed by a statistician who was not involved in the } \\
\text { final analysis. }\end{array}$ \\
\hline
\end{tabular}

Blinding (performance Low risk

bias and detection bias)

All outcomes
Comment: tablets of equal size, colour, and taste. All study physicians and the study nurse were blinded to the treatment given to each participant. Data were entered by the study nurse. Randomisation code was kept at the 24-hour emergency call centre in Basel.

Postrandomisation dropout rate: $2 / 252(0.8 \%)$

- treatment group: 1

- control group: 1

Reasons for missing data: loss of follow-up (1 participant) or adherence problems (1 participant). 1 participant with a serious adverse event was considered as a dropout by the authors but included in this review as a failure.

Ratio of participants with missing data to participants with events: 0.01

Comment: 
Bucher 2003 (Continued)

- intention-to-treat principle was followed (all participants except 1 participant who never started treatment were included in the analysis). The authors did not mention how they imputed information from the participants who were lost to follow-up at certain time points

- people taking fewer tablets than instructed: 24 participants in the treatment group and 15 in the control group

Selective reporting (re- Low risk
porting bias)

Comment: the study protocol is described in the methods section. The primary and secondary endpoints were predefined.

\section{De Sutter 2002}

Methods Study design: RCT

Study duration: from October 1998 to December 1999

Setting: general practice (69 practices)
Country: Belgium
Health status: adults presenting with a respiratory tract infection and purulent rhinorrhoea
Number:
- total: treatment (207); control (209)
- analysed: treatment (189); control (195) (incorporating all available information from the question-
naire, diary, physical examination and dropouts)

Age: mean 37 in amoxicillin group and 39 in placebo group

Sex: $54 \%$ women

Exclusion criteria: allergy to penicillin or ampicillin, having received antibiotic therapy within the previous week, symptoms lasting more than 30 days, abnormality on clinical chest examination, complications of sinusitis (facial oedema or cellulitis; orbital, visual, meningeal, or cerebral signs), pregnancy or lactation, comorbidity that might impair immune competence, and inability to follow the protocol because of language or mental health problems

$\begin{array}{ll}\text { Interventions } & \text { Treatment group: } \\ \text { - intervention: amoxicillin } \\ \text { - dose, duration, frequency, administration: } 500 \mathrm{mg}, 10 \text { days, } 3 \text { times daily, orally }\end{array}$


De Sutter 2002 (Continued)

\section{Control group:}

- intervention: placebo

- dose, duration, frequency, administration: 10 days, 3 times daily, orally

Co-interventions: decongestant therapy (xylometazoline 1\% nose drops) and paracetamol or ibuprofen

\section{Outcomes}

\section{Primary outcomes:}

1. cure after 10 days of treatment (all the symptoms that the participant had included in the list of "most important item affecting my health" scored 0 (absent) or 1 (very mild present))

2. duration of general illness (as noted in the diary)

3. duration of pain (as noted in the diary)

4. duration of purulent rhinorrhoea (as noted in the diary)

Secondary outcomes:

1. mean change in severity score (between day 1 and day 10 of the various symptoms)

2. incidence of unfavourable evolution

3. incidence of side effects

4. intake of analgesics stopped

5. duration of sick leave

Contact with study authors for additional information: none

Other notes:

- Registration: history, generally ill to very ill, unilateral facial pain, pain on bending forward, pain in upper teeth or when chewing, physical examination, sinus tenderness, pain on bending forward, postnasal discharge on throat inspection, purulent rhinorrhoea on rhinoscopy, and body temperature $>$ $37^{\circ} \mathrm{C}$ at inclusion. Completion of a symptom questionnaire (SNOT-20, 0-to-5 Likert scale) and 3 questions about pain, indication of the most troublesome symptoms ( $\max 5$ ) at inclusion. Invitation for an optional radiologic examination of the maxillary sinuses (single Waters view) for the estimation of the proportion of sinusitis cases among included participants

- Follow-up:

- diary for 10 days (daily drug intake (trial medication and symptomatic medication), general feeling of illness, presence of nasal discharge, pain and cough, body temperature, occurrence of presumed adverse drug effects, and absence from school or work)

- Clinical evaluation at day 10 (physical examination, symptom questionnaire (SNOT-20, 0-to-5 Likert scale) and 3 questions about pain, indication of the most troublesome symptoms ( $\max 5)$ ). If participants were insufficiently recovered, general practitioner could prescribe an antibiotic without revealing the previous treatment phase. These participants completed their diary until day 15 and got a new evaluation at day 15 .

- Results:

- Cure after 10 days of treatment:

- treatment group: $73 / 189$

- control group: 59/195

- Side effects:

- treatment group: 55/189 (diarrhoea)

- control group: 37/195 (diarrhoea)

- no differences concerning skin rash, abdominal pain, vomiting (no numbers reported)

- Clinical failure (requiring open antibiotic treatment)

- treatment group: 16/189 (1 before day 10, 7 after day 10)

- control group: 26/195 (7 before day 10, 19 after day 10)

\section{Risk of bias}


De Sutter 2002 (Continued)

\begin{tabular}{lll} 
Bias & Authors' judgement & Support for judgement \\
\hline $\begin{array}{l}\text { Random sequence genera- } \\
\text { tion (selection bias) }\end{array}$ & Low risk & $\begin{array}{l}\text { Comment: assignment via a computer-generated random number list to re- } \\
\text { ceive antibiotics or placebo }\end{array}$ \\
\hline $\begin{array}{l}\text { Allocation concealment } \\
\text { (selection bias) }\end{array}$ & Low risk & $\begin{array}{l}\text { Comment: the randomisation list was kept at the pharmacy of the Universi- } \\
\text { ty Hospital. The randomisation list was accessible to the participating fami- } \\
\text { ly physician only in case of a serious adverse event. The trial medication was } \\
\text { supplied in numbered, uniform cardboard boxes. }\end{array}$
\end{tabular}

Blinding (performance Low risk bias and detection bias)

All outcomes
Comment: capsules had the same size, colour, and shape for active and placebo treatment. To assess effectiveness of masking, participants and family physician guessed their treatment group at day 10. Data were encoded and entered without knowledge of allocation.

\section{Incomplete outcome data Low risk} (attrition bias)

All outcomes
Postrandomisation dropout rate: $32 / 416$ (7,6\%)

- treatment group: 18 participants (5 violation inclusion criteria (symptoms > 30 days), 2 concurrent pathology, 1 allergic reaction, 1 gastrointestinal side effect, 9 lost to follow-up)

- control group: 14 participants ( 3 violation inclusion criteria ( 2 symptoms $>30$ days, 1 allergy to penicillin), 4 suspected allergic reaction, 7 lost to follow-up)

Reasons for missing data: loss to follow-up or withdrawal without knowing if they were cured or not.

Ratio of participants with missing data to participants with events: 0.18

Withdrawal with "known" illness course:

- treatment group: 2 participants (1 clinical exacerbation, 1 complete recovery)

- control group: 8 participants (7 clinical exacerbation, 1 complete recovery)

Open antibiotic therapy (after 10 days follow-up)

- treatment group: 15 participants

- control group: 19 participants

Sensitivity analysis performed.

Selective reporting (re- Low risk
porting bias)

Comment: the study protocol is described in the methods section. The primary and secondary endpoints were predefined.

Other bias Low risk Comment:

- with the available information, we could not detect reasons for bias (no design-specific risks of bias, the study was not stopped early, no imbalance of participant characteristics at baseline, blinding was not broken due to side effects, no bias due to increased or different diagnostic activity)

- number of patients included per practice: 5.6

\section{Garbutt 2012}

$\begin{array}{ll}\text { Methods } & \text { Study design: RCT } \\ & \text { Study duration: between November 1, } 2006 \text { and May 1, } 2009\end{array}$


Garbutt 2012 (Continued)

Participants
Setting: ambulatory care (10 offices)

Country: USA

Health status: people presenting with a history of maxillary pain or tenderness in the face or teeth, purulent nasal secretions, and rhinosinusitis symptoms for 7 days or more and 28 days or less that were not improving or worsening, or rhinosinusitis symptoms lasting for less than 7 days that had significantly worsened after initial improvement. Symptoms had to be moderate, severe, or very severe.

Numbers:

- total: treatment (85), control (81)

- analysed: treatment (81), control (74)

Age: median 32 in the amoxicillin group, 31 in the placebo group

Sex: $64 \%$ women

Exclusion criteria: allergy to penicillin or amoxicillin, prior antibiotic treatment within 4 weeks, complications of sinusitis, a comorbidity that could impair their immune response, cystic fibrosis, requiring an antibiotic for a concurrent condition, pregnancy, and people who rated their symptoms as very mild or mild

\begin{tabular}{l} 
Treatment group: \\
Interventions \\
- intervention: amoxicillin \\
Control group: \\
- intervention: placebo \\
- dose, duration, frequency, administration: 10 days, 3 times daily, orally \\
Co-interventions: to be used as needed during 5 to 7 days (except if contra-indications) \\
- paracetamol for pain or fever at a dose of $500 \mathrm{mg}$ every 6 hours \\
- guaifenesin to thin secretions at a dose of $600 \mathrm{mg}$ every $12 \mathrm{hours,}$ \\
- $10 \mathrm{mg} / 5 \mathrm{~mL}$ of dextromethorphan hydrobromide and $100 \mathrm{mg} / 5 \mathrm{~mL}$ of guaifenesin for cough at a dose \\
\\
of $10 \mathrm{~mL}$ every 4 to 6 hours, \\
- pseudoephedrine-sustained action for nasal congestion at a dose of $120 \mathrm{mg}$ every 12 hours \\
\hline
\end{tabular}

1. effect of treatment on disease-specific quality of life at day 3 (measured using the SNOT-16)

Secondary outcomes:

1. significant improvement ("symptom change" based on symptom scores (6-point scale), reporting their symptoms a lot better or absent)

2. change in functional status

3. recurrent sinus infection

4. satisfaction with treatment

5. adverse effects of treatment

6. treatment compliance

7. adequacy of blinding

Notes

Funding source: grant U01-AI064655-01A1 from the National Institute of Allergy and Infectious Diseases. This institute did not have a role in the design and conduct of the study; in the collection, management, analysis, or interpretation of the data; or in the preparation, review, or approval of the manuscript. 
Garbutt 2012 (Continued)

Contact with study authors for additional information: none

Other notes:

- registration at inclusion: brief interview with research assistant, SNOT-16 questionnaire, registration of demographic and disease-related information, signs and symptoms. Telephone interview later that day to standardise the mode of data collection.

- follow-up with telephone interview 3, 7, 10, and 28 days after treatment initiation (structured questionnaire, trained research assistants)

- results:

- Significant improvement at day 3

- treatment group: $30 / 81$

- control group: $25 / 74$

- Significant improvement at day 7

- treatment group:60/81

- control group: $41 / 74$

- Significant improvement at day 10

- treatment group: $63 / 81$

- control group: 59/74

- Side effects:

- Discontinuating intervention because of adverse effects from the study medication: treatment group (16/81); control group (14/77)

- Headache: treatment group (18/81), control group (17/74)

- Extensive tiredness: treatment group (8/81), control group (16/74)

- Other side effects (no numbers reported): no differences between the treatment groups (nausea $(7 \%)$, diarrhoea (9\%), abdominal pain (5\%), vaginitis ( $6 \%$ of women)

- No serious side effects

- Clinical failure (needing treatment with other antibiotics)

- treatment group: $5 / 85$

- control group: $11 / 81$

\section{Risk of bias}

\begin{tabular}{lll}
\hline Bias & Authors' judgement & Support for judgement \\
\hline $\begin{array}{l}\text { Random sequence genera- } \\
\text { tion (selection bias) }\end{array}$ & Low risk & $\begin{array}{l}\text { Comment: blocked randomisation scheme. Computer-generated random } \\
\text { numbers were used to determine how the } 2 \text { study drugs were allocated to the } \\
\text { consecutively numbered study treatment packages. Randomisation occurred } \\
\text { when the research assistant assigned the treatment package. }\end{array}$ \\
\hline
\end{tabular}

Allocation concealment Low risk
(selection bias)
(selection bias)

Blinding (performance bias and detection bias) All outcomes

Low risk

Comment: randomisation was performed in advance by the investigational pharmacist who did not participate in participants' enrolment or outcome assessment.

Comment: the tablets were similar in appearance and taste and dispensed in the same fashion. Research assistants were blinded to group assignment. The percentage of participants who guessed their treatment assignment correctly did not differ by study group (36\% in amoxicillin group and $37 \%$ in placebo group, $\mathrm{P}=0.2$ ).

Incomplete outcome data Low risk

(attrition bias)

All outcomes
Post-randomisation dropout rate: $11 / 166$ (6.6\%) due to missing data

- treatment group: 4 participants

- control group: 7 participants

Discontinuation of treatment rate: $23 / 166$ (13.9\%) 
Garbutt 2012 (Continued)
- treatment group: 11 out of 85 participants (2 failure to improve, 3 worsening symptoms, 4 improved symptoms, 1 adverse events, 1 unknown reasons)

- control group: 12 out of 81 participants (6 failure to improve, 4 worsening symptoms, 2 unknown reasons)

Treatment with other antibiotics: 16/166 (9.6\%)

- treatment group: 5 participants

- control group: 11 participants

Ratio of participants with missing data to participants with events (outcome: significant improvement after 10 days): 0.09 .

Intention-to-treat analysis

Selective reporting (re- Low risk porting bias)

Comment: the study protocol is described in the methods section. The primary and secondary endpoints were predefined. Sensitivity analysis for participants who completed 10 days of treatment with the study drug and those with symptoms for 7 days or more and 28 days or less. Findings were consistent with the primary analysis.

\begin{tabular}{ll}
\hline Other bias & Comments: \\
& \\
& - approval by the institutional review board at Washington University. \\
& - written consent obtained from each participant. \\
& - average number of participants per practice: 15.5
\end{tabular}

Kaiser 2001

\begin{tabular}{ll}
\hline Methods & Study design: RCT \\
Study duration: unknown
\end{tabular}

Participants

Setting: outpatient clinic of the University of Geneva Hospital

Country: Switzerland

Health status: people presenting with common cold or acute sinusitis and had a history of rhinorrhoea of less than 4 weeks and a confirmed upper respiratory tract infection at physical examination, including rhinoscopy.

Number:

- total: 269

- analysed: treatment (133); control (132)

Age: median 35

Sex: $52 \%$ women (gender of 4 dropouts not reported)

Exclusion criteria: high fever $\left(>38.5^{\circ} \mathrm{C}\right)$ and an overall clinical impression that antibiotic treatment was absolutely required ( $\sim 4 \%$ of the screened population), chronic ear, nose, and throat disease, a positive pharyngeal culture for Streptococcus pyogenes, known allergy to macrolides, antibiotic treatment in the previous 10 days, immunosuppression, and underlying pulmonary disease

- intervention: azithromycin

- dose, duration, frequency, administration: 500 mg, 3 days, once daily, orally 
Kaiser 2001 (Continued)

\section{Control group:}

- intervention: placebo

- dose, duration, frequency, administration: 3 days, once daily, orally

Co-interventions: ibuprofen and nasal drops containing oxymetazoline was offered to all participants.

\begin{tabular}{|c|c|}
\hline Outcomes & $\begin{array}{l}\text { Primary outcome: } \\
\text { 1. Cure at day } 8 \\
\text { Secondary outcomes: } \\
\text { 1. Occurrence of a respiratory complication that required the introduction of open antibiotic treatment } \\
\text { 2. Occurrence of severe sinusitis (defined as worsening of initial symptoms accompanied by facial pain, } \\
\text { discharge at middle meatus, or fever) } \\
\text { Definitions of cure: } \\
\text { 1. Reduction of more than } 80 \% \text { of the mean baseline symptom score (evaluated at day } 7 \text { ) (definition } 1 \text { ) } \\
\text { 2. Clinical evaluation (definition } 2 \text { ) } \\
\text { Subgroup analysis: predefined subset of participants with and without Streptococcus pneumoniae, } \\
\text { Haemophilus influenzae, or Moraxella catarrhalis }\end{array}$ \\
\hline Notes & $\begin{array}{l}\text { Funding source: not stated } \\
\text { Contact with study authors for additional information: none } \\
\text { Other notes: } \\
\text { - registration: medical history, examination, including anterior rhinoscopy by ear, nose, and throat spe- } \\
\text { cialist. Participants were submitted to a rhinoscopy (with aspiration of nasopharyngeal secretions) } \\
\text { and sinus radiography (occipitomental view). } \\
\text { - follow-up: } \\
\text { - diary for } 7 \text { days (nasal obstruction, rhinorrhoea, fatigue, headache, facial pain, feverishness, cough, } \\
\text { sputum, sore throat, postnasal drip, and loss of voice) } \\
\text { - clinical evaluation at day } 8 \text { (cured, improved, same, or worsened; rhinoscopy) } \\
\text { - Questionnaire after } 1 \text { month } \\
\text { results: } \\
\text { cure at day } 8 \\
\text { - treatment group: } 93 / 133 \text { (definition } 1 \text { ), } 76 / 133 \text { (definition } 2 \text { ) } \\
\text { - control group: } 77 / 132 \text { (definition } 1 \text { ), } 75 / 132 \text { (definition } 2 \text { ) } \\
\text { cure at day } 8 \text { in the subgroup with radiologically confirmed sinusitis } \\
\text { - treatment group: } 27 / 38 \\
\text { - control group: } 26 / 44 \\
\text { side effects: } \\
\text { - treatment group: } 32 / 133 \text { (gastrointestinal disturbances) } \\
\text { - control group: } 14 / 132 \text { (gastrointestinal disturbances) } \\
\text { - no side effect required withdrawal of treatment } \\
\text { clinical failure (requiring open antibiotic treatment) } \\
\text { - treatment group: } 1 / 133 \\
\text { - control group: } 14 / 132\end{array}$ \\
\hline
\end{tabular}

\section{Risk of bias}

Bias Authors' judgement Support for judgement


Kaiser 2001 (Continued)

Random sequence genera- Unclear risk Comment: random assignment. No further information available. tion (selection bias)

\begin{tabular}{|c|c|c|}
\hline $\begin{array}{l}\text { Allocation concealment } \\
\text { (selection bias) }\end{array}$ & Unclear risk & $\begin{array}{l}\text { Comment: drugs and placebo were in identical containers. No further informa- } \\
\text { tion available. No information about the centralisation of randomisation or } \\
\text { the numbering of the containers }\end{array}$ \\
\hline
\end{tabular}

Blinding (performance Low risk

bias and detection bias)

Comment: drugs and placebo had the same shape and taste. Participants and

All outcomes investigators were blinded to the treatment administered. This investigator remained blinded to bacteriological and radiological results, even if an open antibacterial treatment was deemed necessary. The sinus radiograph (occipitomental view) was interpreted independently by 2 radiologists blinded to the clinical results.

$\begin{array}{ll}\begin{array}{l}\text { Incomplete outcome data } \\ \text { (attrition bias) }\end{array} & \text { Low risk } \\ \text { All outcomes } & \text { Post-randomisation dropout rate: } 4 / 269(1.5 \%) \\ & \text { Dropout balance: not known (reasons for losses to follow-up were not report- }\end{array}$

Ratio of participants with missing data to participants with events: 0.03

Open antibiotic treatment (treatment failure): 15/265 (5.7\%).

- treatment group: 1 (severe sinusitis)

- control group: 14 out of the placebo group (severe sinusitis, purulent bronchitis, exudative pharyngitis, otitis media).

Comment: it appeared that all these participants receiving open antibiotic therapy were included in the analysis.

\begin{tabular}{ll}
$\begin{array}{l}\text { Selective reporting (re- } \\
\text { porting bias) }\end{array}$ & Low risk \\
\hline Other bias & $\begin{array}{l}\text { Comment: the study protocol is described in the methods section. The primary } \\
\text { and secondary endpoints were predefined. }\end{array}$ \\
& $\begin{array}{l}\text { Comment: } \\
\text { - }\end{array}$ \\
& $\begin{array}{l}\text { with the available information, we could not detect reasons for bias (no de- } \\
\text { participant characteristics at baseline, blinding was not broken due to side } \\
\text { effects, no bias due to increased or different diagnostic activity). } \\
\text { participants were recruited from } 1 \text { outpatient clinic at the University of Gene- } \\
\text { va Hospital. }\end{array}$
\end{tabular}

\section{Lindbaek 1996}

\begin{tabular}{ll}
\hline Methods & Study design: randomised, double-blind trial \\
& Study duration: January to May 1994 and November 1994 to May 1995 \\
\hline Participants & Setting: general practice \\
& Country: Norway \\
& Health status: clinical diagnosis of acute sinusitis, confirmed by computed tomography (presence of \\
& fluid level or total opacification in any sinus, independently scored by 2 experienced radiologists). Ear, \\
& nose, and throat comorbidity was not assessed. \\
& Number: \\
- total: treatment (86 (penicillin V (41); amoxicillin 45); control 44
\end{tabular}


Age: mean 38.6 (range 16 to 74 )

Sex: $65 \%$ women

Exclusion criteria: age 15 or under, pregnancy, ongoing antibiotic treatment, immunosuppressive treatment, previous operations in the nose or sinus region, misuse of alcohol or narcotics, rheumatic disease, and allergy to penicillin. Participants with symptoms for more than 30 days were excluded because of possible chronic sinusitis. Participants with high fever and strong pain were not included because of ethical considerations.

Interventions

Treatment group:

- group 1

$\circ$ intervention: penicillin $\mathrm{V}$

- dose, duration, frequency, administration: $1320 \mathrm{mg}, 10$ days 3 times daily, orally

- group 2

$\circ$ intervention: amoxicillin

- dose, duration, frequency, administration: $500 \mathrm{mg}, 10$ days, 3 times daily, orally

Control group:

- intervention: placebo

- dose, duration, frequency, administration: 10 days, 3 times daily

Co-interventions: concomitant use of nasal decongestants and paracetamol was allowed.

Comment: For this review, group 1 and 2 were combined in the analyses.

\section{Outcomes}

Primary outcomes:

1. subjective status: evaluation of the clinical condition by the participant (recovered, much better, somewhat better, unimproved, worse) at days 3 and 10

2. difference in clinical severity score (day 10 vs day 0 ) evaluated by the general practitioner

3. difference in score from computed tomography scans (day 10 vs day 0 )

4. duration of the illness episode (cure) (answering "no" at the question "Do you think you still have sinusitis today?")

Secondary outcomes:

1. bacteriology

2. side effects

3. clinical failure

Other notes:

- Clinical evaluation (clinical severity score) and bacteriological sample from the nasopharynx at inclusion

- Follow-up:

- diary (scoring degree of nasal obstruction, rhinorrhoea, sinus-related pain, and malaise on VAS scale and answering the question "Do you think you still have sinusitis today?" (yes, uncertain, or no)). If they did not answer "no" at day 10, they went on with the daily registering until they could answer "no", with a maximum of 30 days.

- Clinical evaluation at day 10 combined with computed tomography 
Lindbaek 1996 (Continued)

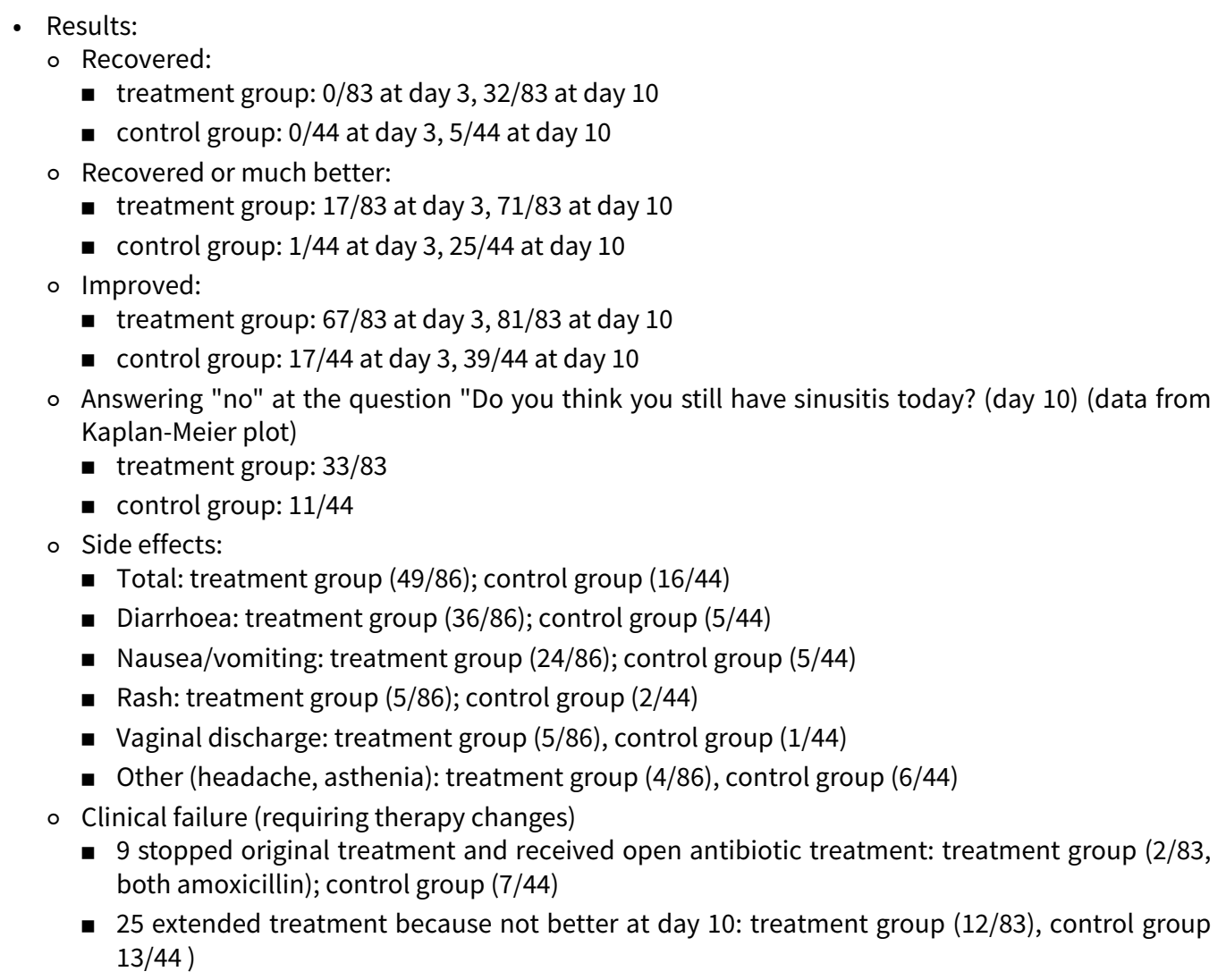

\section{Risk of bias}

\section{Bias \\ Authors' judgement Support for judgement}

Random sequence genera- Low risk tion (selection bias)

Comment: restricted randomisation (blocks of 3 within each of 6 subgroups). A dice was used to generate the random allocation.

Stratified randomisation: according to clinical severity score (breakpoint 9.0) and localisation of the sinusitis (unilateral maxillary, bilateral maxillary or in at least 1 of the remaining sinus regions). If maxillary sinusitis in combination with sinusitis in 1 of the other sinus regions: stratification to 1 of the maxillary sinusitis groups

Allocation concealment Low risk (selection bias)

Comment: the statistician sent the randomisation list to the company that produced the medication boxes with numbers according to the list. The author received the numbered boxes for each of the subgroups from the company (information from the main investigator). Tablets appeared similar.

Blinding (performance Low risk

bias and detection bias)

All outcomes
Comment: the trial was double-blind (at participant, general practitioner, and radiologist level). The randomisation codes were broken after the whole study was finished. If another antibiotic was prescribed because of clinical failure (evaluation day 10), the randomisation code was not broken.

\footnotetext{
Incomplete outcome data Low risk (attrition bias)

All outcomes

Post-randomisation dropout rate at day 10: 3/130 (2.3\%)

- treatment group: 3 (2 out of the penicillin (severe gastrointestinal side effects) and 1 out of the amoxicillin group (severe gastrointestinal side effects)

- control group: 0
}

The ratio of participants with missing data to participants with events: 0.07 . 
- treatment group: 5 (2 out of the penicillin group (severe gastrointestinal side effects), 3 out of the amoxicillin group (1 severe gastrointestinal side effects, 1 sinus puncture executed and changed to doxycycline, 1 changed to doxycycline without reported reason from day 5),

- control group: 7 (6 changed to amoxicillin, 1 referred to ENT specialist, sinus puncture and penicillin V).

Treatment compliance was not reported.

\begin{tabular}{ll}
\hline $\begin{array}{l}\text { Selective reporting (re- } \\
\text { porting bias) }\end{array}$ & Low risk \\
\end{tabular}

Other bias Low risk Comment:

- detailed description of demographic characteristics and sinusitis severity rating at baseline, but actual numbers are not given.

- 93/130 had maxillary sinusitis on CT

\section{Lindbaek 1998}

Methods Study design: RCT

Study duration: January to May 1994 and November 1994 to May 1995

Setting: general practice
Country: Norway
Health status: clinical diagnosis of acute sinusitis ( 7 and $<30$ days), confirmed by computed tomogra-
phy (presence of mucosal thickening of $5 \mathrm{~mm}$ without fluid levels or total opacification, independently
scored by 2 experienced radiologists). Ear, nose, and throat comorbidity was not assessed.
Number:
- total: 68
- analysed: treatment (42, penicillin V (20); amoxicillin (22)); control (21)
Age: mean 39.7 (range 16 to 83$)$
Sex: $61 \%$ women
Exclusion criteria: age 15 or under, pregnancy, ongoing antibiotic treatment, immunosuppressive treat-
ment, previous operations in the nose or sinus region, misuse of alcohol or narcotics, rheumatic dis-
ease, and allergy to penicillin. Participants with symptoms for more than 30 days were excluded be-
cause of possible chronic sinusitis. Participants with high fever and strong pain were not included be-
cause of ethical considerations.

Interventions Treatment group:

- Group 1

○ intervention: penicillin $\mathrm{V}$

- dose, duration, frequency, administration: $1320 \mathrm{mg}, 10$ days 3 times daily, orally

- Group 2

○ intervention: amoxicillin

○ dose, duration, frequency, administration: $500 \mathrm{mg}, 10$ days, 3 times daily, orally

Control group: 
Lindbaek 1998 (Continued)

- intervention: placebo

- dose, duration, frequency, administration: 10 days, 3 times daily

Co-interventions: concomitant use of nasal decongestants and paracetamol was allowed.

Comment: For this review, group 1 and 2 were combined in the analyses.

\section{Outcomes}

Primary outcomes:

1. subjective status: evaluation of the clinical condition by the participant (recovered, much better, somewhat better, unimproved, worse) at days 3 and 10

2. difference in clinical severity score (day 10 vs day 0 ) evaluated by the general practitioner

3. difference in score from computed tomography scans (day 10 vs day 0 )

4. duration of the illness episode (cure) (answering "no" to the question "Do you think you still have sinusitis today?")

Secondary outcomes:

1. Bacteriology

2. Side effects

3. Clinical failure

Contact with study authors for additional information: none

Other notes:

- Clinical evaluation (clinical severity score) and bacteriological sample from the nasopharynx at inclusion

- Follow-up:

- diary (scoring degree of nasal obstruction, rhinorrhoea, sinus-related pain, and malaise on VAS scale and answering the question "Do you think you still have sinusitis today?" (yes, uncertain, or no)). If they did not answer "no" at day 10 , they went on with the daily registering until they could answer "no", with a maximum of 30 days.

- Clinical evaluation at day 10 combined with computed tomography

- Results:

- Recovered:

- treatment group: $15 / 42$ at day 10

- control group: $9 / 21$ at day 10

- Recovered or much better:

- treatment group: $32 / 42$ at day 10

- control group: $14 / 21$ at day 10

- Side effects (serious, reason to stop treatment; GI origin):

- treatment group: $3 / 42$

- control group: $0 / 21$

- Clinical failure, requiring extended treatment with amoxicillin:

- treatment group: $1 / 42$

- control group: $1 / 21$

- Clinical failure, no recovery after 30 days:

- treatment group: $4 / 42$

- control group: $2 / 21$

\section{Risk of bias}


Lindbaek 1998 (Continued)

Random sequence genera- Low risk tion (selection bias)
Comment: restricted randomisation (blocks of 3 within each of 6 subgroups). A dice was used to generate the random allocation.

Stratified randomisation: according to clinical severity score (breakpoint 9.0) and localisation of the sinusitis (unilateral maxillary, bilateral maxillary or in at least 1 of the remaining sinus regions). If maxillary sinusitis in combination with sinusitis in 1 of the other sinus regions: stratification to 1 of the maxillary sinusitis groups.

Comment: the statistician sent the randomisation list to the company that produced the medication boxes with numbers according to the list. The author received the numbered boxes for each of the subgroups from the company (information from the main investigator). Tablets appeared similar.

Blinding (performance Low risk bias and detection bias)

Comment: the trial was double-blind (at participant, general practitioner, and radiologist level). The randomisation codes were broken after the whole study was finished. If another antibiotic was prescribed because of clinical failure (evaluation day 10), the randomisation code was not broken.

\section{Incomplete outcome data Low risk} (attrition bias)

All outcomes

2/70 participants were taken out of the study because of bad-quality CT scans.

Post-randomisation dropout rate at day 10: 5/68 (7.4\%)

- Dropout balance: unknown

Ratio of participants with missing data to participants with events: 0.11

Discontinuation of trial medication rate: $5 / 63$

- Treatment group: 4 (1 out of the penicillin group (marked gastrointestinal side effects), 3 out of the amoxicillin group ( 2 marked gastrointestinal side effects, 1 unknown reason but recovered without further treatment)

- Control group: 1 (unknown reason but recovered without further treatment)

Treatment compliance: not reported

Selective reporting (re- Low risk porting bias)

Comment: the study protocol is described in the methods section. The primary and secondary endpoints were predefined.

Comment: detailed description of demographic characteristics and sinusitis severity rating with which to assess the comparability of the groups at baseline

\section{Meltzer 2005}

\begin{tabular}{ll}
\hline Methods & Study design: RCT \\
& Study duration: January to September 2003 \\
\hline Participants & Setting: not specified (71 medical centres) \\
& Country: 14 countries \\
& Health status: people presenting with signs and symptoms of acute rhinosinusitis for $\geq 7$ days but $\leq$ \\
& 28 days and major symptom score $\geq 5$ but $\leq 12$ at screening and baseline visits with no more than 3 of \\
& the 5 following symptoms rated severe at the baseline visit: rhinorrhoea, postnasal drip, nasal conges- \\
& tion/stuffiness, sinus headache and facial pain/pressure/tenderness on palpation over the paranasal si- \\
& nuses \\
& Numbers:
\end{tabular}


- analysed for the purpose of this review: treatment group 3 (242); control group (231)

Age: age 35.9 in treatment group 3, 34.4 in control group

Sex: $66 \%$ women

Exclusion criteria: signs or symptoms suggestive for fulminant bacterial sinusitis (fever $\geq 101^{\circ} \mathrm{F} / 38.3^{\circ} \mathrm{C}$, persistent severe unilateral facial or tooth pain, facial swelling, dental involvement, or a worsening of symptoms after initial improvement), chronic rhinosinusitis (or sinus or nasal surgery for this condition within 6 months before screening), otitis or atrophic rhinitis, nasal polyps noted on anterior rhinoscopic examination, symptomatic seasonal allergic rhinitis (after pollen exposure during the study), an allergy to corticosteroids, any other condition that would interfere with study evaluations, unstable asthma or with a history of exacerbations within 30 days before screening or forced expiratory volume in 1 second (FEV1) $<65 \%$ of predicted within 3 months before screening

Interventions
Treatment group:

- Group 1

○ intervention: mometasone furoate nasal

- dose, duration, frequency, administration: $200 \mu \mathrm{g}, 10$ days 1 time daily (AM), nose spray

- intervention: placebo

- dose, duration, frequency, administration: 10 days 1 time daily (PM), nose spray

o intervention: placebo

- dose, duration, frequency, administration: 10 days, 3 times daily, orally

- This group was excluded from the analyses, since it comprises neither only placebo nor an antibiotic treatment.

- Group 2

- intervention: mometasone furoate nasal spray

- dose, duration, frequency, administration: $200 \mu \mathrm{g}, 10$ days 2 times daily (AM), nose spray

o intervention: mometasone furoate nasal spray

- dose, duration, frequency, administration: $200 \mu \mathrm{g}, 10$ days 2 times daily (PM), nose spray

o intervention: placebo

- dose, duration, frequency, administration: 10 days, 3 times daily, orally

- This group was excluded from the analyses, since it comprises neither only placebo nor an antibiotic treatment.

- Group 3

- intervention: placebo

- dose, duration, frequency, administration: 10 days 1 time daily (AM), nose spray

- intervention: placebo

- dose, duration, frequency, administration: 10 days 1 time daily (PM), nose spray

o intervention: amoxicillin

- dose, duration, frequency, administration: $500 \mathrm{mg}, 10$ days, 3 times daily, orally

Control group:

- intervention: placebo

- dose, duration, frequency, administration: 10 days 1 time daily (AM), nose spray

- intervention: placebo

- dose, duration, frequency, administration: 10 days 1 time daily (PM), nose spray

- intervention: placebo

- dose, duration, frequency, administration: 10 days, 3 times daily

Co-interventions: forbidden (nasal saline, nasal cromolyn sodium ipratropium bromide, corticosteroids (excluding oral inhaled corticosteroids for mild to moderate persistent asthma), antihistamines, decongestants, leukotriene pathway modifiers, analgesics, non-steroidal anti-inflammatory drugs). 
Meltzer 2005 (Continued)

Outcomes
Primary outcome:

1. Mean AM/PM major symptom score over days 2 to 15 of the treatment phase

Secondary outcomes:

1. Mean major symptom score

2. Total symptom score

3. Individual scores for each symptom (average weekly and for days 2 to 15 and 16 to 29)

4. Global response to treatment (at visit 4 or last treatment visit, scale 0 (complete relief) to 4 (no relief)) evaluated by the investigator and the participant

5. Time to onset of action (the first day of active treatment on which major symptom score was statistically significantly different from placebo and sustained thereafter)

6. Evaluation of the proportion of participants presenting with symptoms suggestive of fulminant bacterial rhinosinusitis or worsening or no improvement of symptoms by day 3 or 4 (Kaplan-Meier)

7. Adverse effects related to treatment (mild, moderate, severe, life-threatening)

8. The proportion of participants, as assessed by the physician, who met disease criteria for recurrence/relapse during the follow-up phase

Other notes:

- Registration: major symptom score (rhinorrhoea, postnasal drip, nasal congestion/stuffiness, sinus headache, facial pain/pressure/tenderness on palpation over the nasal sinuses), total symptom score, vital signs, nasal examination, clinical laboratory test, and physical examination

- Follow-up:

- telephone call on days 3 and 4 and by diary (symptom recording, 2 times daily)

- treatment visits on days 8,15 , and 29: evaluation of major symptom score, total symptom score, examination and treatment compliance

- Results:

- No significant difference in mean AM/PM major symptom score over days 2 to 15 of the treatment phase (no numbers or $\mathrm{P}$ values reported)

- Side effects:

- No exact numbers reported

- Loss to follow up due to adverse events: treatment group 3 (5); control group (6)

- Treatment-emergent adverse events: treatment group 3 (33.5\%); control group (38\%)

- Detailed information concerning treatment-emergent adverse events): treatment group (9/251 nausea, 7/251 diarrhoea, 3/251 abdominal pain); control group (7/252 nausea, 10/252 diarrhoea, $3 / 252$ abdominal pain)

- Clinical failure (evaluation of participants with symptoms suggestive of fulminant bacterial rhinosinusitis or worsening or no improvement of symptoms by day 3 to 4 or thereafter to determine whether they had failed to respond to treatment)

- treatment group: $18 / 251$

- control group: $27 / 248$

\section{Risk of bias}

\begin{tabular}{lll}
\hline Bias & Authors' judgement & Support for judgement \\
\hline $\begin{array}{l}\text { Random sequence genera- } \\
\text { tion (selection bias) }\end{array}$ & Low risk & Quote: "Subjects ... were randomized in a 1:1:1:1 ratio to 4 treatment arms" \\
& $\begin{array}{l}\text { Quote: "Randomisation was performed according to a computer-generated } \\
\text { code, stratified on the basis of duration of rhinosinusitis symptoms before } \\
\text { baseline (7 to } 14 \text { days and } 15 \text { to } 28 \text { days)" }\end{array}$ \\
\end{tabular}


Meltzer 2005 (Continued)

Allocation concealment (selection bias)
Low risk Helsinki and guidelines on Good Clinical Practice."

Comment: the randomisation schedule for blinding of treatments was maintained by the sponsor and was disclosed only after the study completion and database closure. A set of sealed envelopes corresponding to the individual participant supplies, which contained the identification of the test drug, was provided to each site to enable the investigator to identify the treatment assignment of an individual participant, in the event of an emergency that requires this knowledge, without compromising the blinding of other study participants. These envelopes were returned to the sponsor, and open envelopes were accompanied by a written explanation.
Blinding (performance

All outcomes bias and detection bias)

Low risk

Comment: a double-dummy blinding technique was used during the treatment phase. Participants units were numbered from 0001 to 3000 . All study drugs dispensed were labelled with the study number, packaging requisition number, treatment unit number, and the investigational use statement with the instructions for proper storage conditions. Placebo or amoxicillin were identical in appearance. Mometasone furoate nasal spray and placebo spray were identical in appearance.

Post-randomisation dropout rate: $13 / 499(2.6 \%)$ at day $15,26 / 499(5.2 \%)$ at day 29

(attrition bias)

Unclear risk

All outcomes

(4/503 participants were excluded after randomisation since they did not meet the protocol criteria for entry. These were not considered as drop outs)

- Dropout balance:

- treatment group: 9 (6 after treatment phase, 3 during follow-up phase)

- control group: 17 (7 after treatment phase, 10 during follow-up phase)

Reasons for missing data: loss to follow-up (13 lost to follow-up after treatment phase, 13 during follow-up phase)

Ratio of participants with missing data to participants with events: not calculable, because the primary outcome was not 'cure' but a difference in symptom scores

Discontinuation of treatment: $49 / 499(9,8 \%)$

- treatment group: 20

- control group: 29

- (We used the numbers of the table, because there was a discrepancy between the text and the table.)

Reasons for discontinuation of treatment: adverse events, treatment failure, lost to follow-up, wish to discontinue, non-compliance with the protocol

The authors stated that the analyses were based on an ITT population.

Selective reporting (re- Unclear risk
porting bias)

Comment: the study protocol is described in the methods section. The primary and secondary endpoints were predefined. The outcomes of interest in the review are reported incompletely so that they cannot be entered in a metaanalysis.

Other bias Low risk Comment:

- with the available information, we could not detect reasons for bias (no design-specific risks of bias, the study was not stopped early, no imbalance of participant characteristics at baseline, blinding was not broken due to side effects, no bias due to increased or different diagnostic activity). 
- E Meltzer received grant support from Schering-Plough for this study and is a consultant on the speakers' bureau and has received grants from numerous pharmaceutical companies. $\mathrm{H}$ Staudinger and C Bachert have disclosed no conflict of interest.

- number of participants per centre: 6.8 participants (instead of 16 as foreseen).

\section{Merenstein 2005}

Methods Study design: RCT

Study duration: 1 October 2001 to 31 March 2003

\begin{tabular}{|c|c|}
\hline Participants & $\begin{array}{l}\text { Setting: ambulatory care ( } 1 \text { suburban ambulatory care office) } \\
\text { Country: USA } \\
\text { Health status: people presenting with at least } 1 \text { cardinal feature described by the clinical prediction } \\
\text { rule and having symptoms for at least } 7 \text { days } \\
\text { - cardinal features: purulent nasal discharge predominating on } 1 \text { side, local facial pain predominating } \\
\text { on } 1 \text { side, purulent nasal discharge on both sides and pus in the nasal cavity } \\
\text { Numbers: } \\
\text { - total: treatment (67); control (68) } \\
\text { - analysed: treatment (56); control (60) } \\
\text { Age: mean } 35.1 \text { in the amoxicillin group and } 32.6 \text { in the placebo group } \\
\text { Sex: } 69 \% \text { women } \\
\text { Exclusion criteria: antibiotic treatment within the past month in the history, allergy to penicillin, sinus } \\
\text { surgery in history, compromised immunity, pneumonia in history, and streptococcal pharyngitis in his- } \\
\text { tory }\end{array}$ \\
\hline Interventions & $\begin{array}{l}\text { Treatment group: } \\
\text { - intervention: amoxicillin } \\
\text { - dose, duration, frequency, administration: } 500 \mathrm{mg}, 10 \text { days, twice daily, orally } \\
\text { Control group: } \\
\text { - intervention: placebo } \\
\text { - dose, duration, frequency, administration: } 10 \text { days, twice daily, orally }\end{array}$ \\
\hline Outcomes & $\begin{array}{l}\text { Primary outcome } \\
\text { 1. Entirely improved (yes or no) at day } 14 \\
\text { Secondary outcomes } \\
\text { 1. Day of improvement } \\
\text { 2. Side effects (diarrhoea, nausea, emesis, abdominal pain, rash, hot flashes, jittery, dizziness, dry } \\
\text { mouth, vaginal infection) }\end{array}$ \\
\hline
\end{tabular}

\section{Notes}

Funding source: supported by a grant from the American Academy of Family Physicians and the American Academy of Family Physicians Foundation Joint AAFP/F-AAFP Grant Awards Program. Support was also provided by the Capitol Area Primary Care Research Network. 
Contact with study authors for additional information: about random sequence generation, allocation concealment, blinding

Other notes:

- Follow-up: telephone interviews on days 3, 7, and 14 following patients' visits for sinusitis to the physician to assess clinical improvement (12 follow-up questions (clinical improvement)

- Results:

- Entirely improved at day 14

- treatment group: $32 / 56$

- control group: $25 / 60$

- Side effects:

- treatment group:13/56 (diarrhoea 4, nausea 4, emesis 1, abdominal pain 2, rash 2, hot flashes 0 , jittery 0 , dizziness 3 , dry mouth 1 , vaginal infection 2 )

- control group: 7/60 (diarrhoea 1 , nausea 5 , emesis 0 , abdominal pain 1 , rash 0 , hot flashes 1 , jittery 1 , dizziness 0 , dry mouth 0 , vaginal infection 0 )

- No dropouts due to side effects

- Clinical failure: no data reported

\section{Risk of bias}

Bias Authors' judgement Support for judgement

Random sequence genera- Low risk tion (selection bias)
Comment: they used stratified randomisation with each physician representing the strata, and participants were randomised in block sizes of 6 . A computer random number generator was used to create the permuted blocks. A biostatistician who was not employed by Georgetown University performed the allocation sequence.

\begin{tabular}{|c|c|c|}
\hline $\begin{array}{l}\text { Allocation concealment } \\
\text { (selection bias) }\end{array}$ & Low risk & $\begin{array}{l}\text { Comment: prior to the start of the trial, envelopes containing amoxicillin or } \\
\text { placebo were prepared by the pharmacy, and each envelope was labelled } \\
\text { with a study ID. The envelopes given to each participant contained } 40 \text { cap- } \\
\text { sules, either placebo or amoxicillin, with instructions to take twice daily for } \\
10 \text { days. The randomisation codes were sent to the Pharmacy Department at } \\
\text { Georgetown and were kept in a locked cabinet. Participants were consecutive- } \\
\text { ly enrolled over the 18-month enrolment period. }\end{array}$ \\
\hline
\end{tabular}

Blinding (performance Low risk bias and detection bias)

All outcomes

\begin{abstract}
Comment: the envelopes were opaque, and the pills within were identical in appearance, size, shape, colour, and taste. All study physicians, participants, and research co-ordinators were blinded to the treatment given to each participant. Through this process allocation concealment was achieved over the entire course of the enrolment period; neither physician nor participant could determine which treatment the next participant would receive.
\end{abstract}

Post-randomisation dropout rate: 19/135 (14\%)

- treatment group: 11

- control group 8

Reasons for missing data: loss to follow-up (only baseline data collected)

Ratio of participants with missing data to participants with events: 0.33

The authors state that the primary analyses were performed using the ITT principle. The dropouts were counted as "not improved" in the ITT analysis.

$\begin{array}{ll}\begin{array}{l}\text { Selective reporting (re- } \quad \text { Low risk } \\ \text { porting bias) }\end{array} & \begin{array}{l}\text { Comment: the study protocol is described in the methods section. The primary } \\ \text { and secondary endpoints were predefined. The analysis of the subgroups was } \\ \text { not specified in the methods section. }\end{array}\end{array}$


Merenstein 2005 (Continued)

Other bias Low risk
- With the available information, we could not detect reasons for bias (no design-specific risks of bias, the study was not stopped early, no imbalance of participant characteristics at baseline, blinding was not broken due to side effects, no bias due to increased or different diagnostic activity)

- None of the authors report any conflicts of interest

- Participants were recruited from 1 general practice

Norrelund 1978

Methods Study design: RCT

Study duration: between January 10, 1977 and June, 30, 1977

Participants

Setting: general practice (19 general practitioners)

Country: Denmark

Health status: participants showing at least 3 symptoms, including at least 1 of the main symptoms

- main symptoms: yellow or yellowish-green or possibly blood-stained nasal discharge on blowing the nose; good nasal passage together with a nasal voice

- other symptoms: feeling of malaise; headache, particularly behind the eyes, behind the bridge of the nose, or corresponding to the maxilla; irritative cough

Number:

- total: treatment (73); control (67)

- analysed: treatment (71); control (64)

Age: older than 14 years, mean unknown

Sex: $61 \%$ women

Exclusion criteria: penicillin allergy, pregnancy

Interventions

Treatment group:

- intervention: pivampicillin

- dose, duration, frequency, administration: $700 \mathrm{mg}, 6$ days, 2 times daily, orally

Control group:

- intervention: placebo

- dose, duration, frequency, administration: 6 days, 2 times daily, orally

Co-interventions: concomitant use of nasal decongestants allowed (xylometazoline $0.1 \%$ nasal spray, 4 times daily).

Outcomes

Primary outcome:

1. Cure at day 8 (sum of endpoints for the individual participant was reduced by at least $2 / 3$ at follow-up investigation on day 8 )

Secondary outcomes:

1. Resolution of purulent secretion

2. Resolution of irritative cough

3. Subjective improvement 
Norrelund 1978 (Continued)

\section{Side effects}

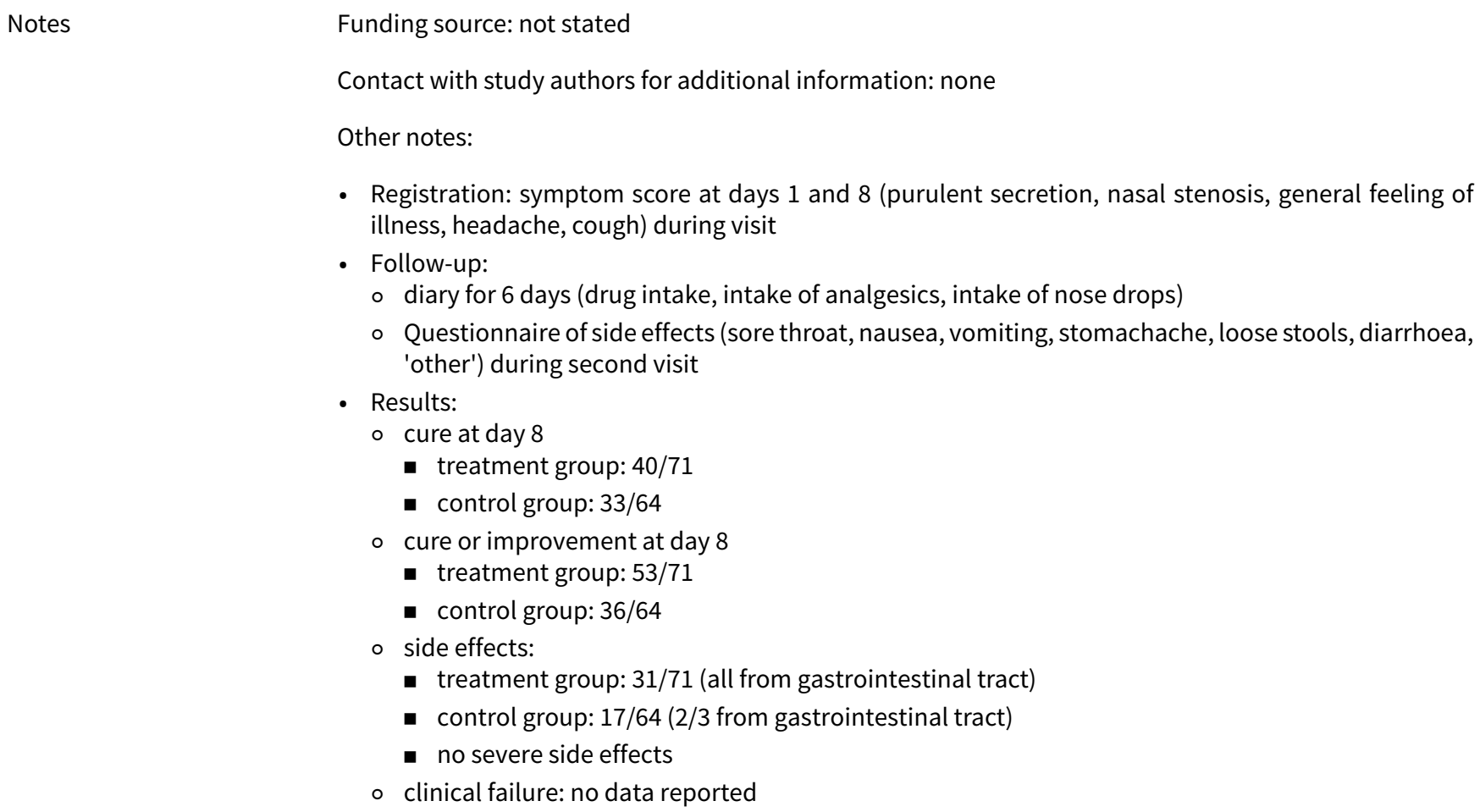

- Registration: symptom score at days 1 and 8 (purulent secretion, nasal stenosis, general feeling of illness, headache, cough) during visit

- Follow-up:

- diary for 6 days (drug intake, intake of analgesics, intake of nose drops)

- Questionnaire of side effects (sore throat, nausea, vomiting, stomachache, loose stools, diarrhoea, 'other') during second visit

- Results:

- cure at day 8

- treatment group: $40 / 71$

- control group: $33 / 64$

- cure or improvement at day 8

- treatment group: $53 / 71$

- control group: $36 / 64$

- side effects:

- treatment group: $31 / 71$ (all from gastrointestinal tract)

- control group: $17 / 64$ (2/3 from gastrointestinal tract)

- no severe side effects

- clinical failure: no data reported

\section{Risk of bias}

\begin{tabular}{lll}
\hline Bias & Authors' judgement & Support for judgement \\
\hline $\begin{array}{ll}\text { Random sequence genera- } \\
\text { tion (selection bias) }\end{array}$ & Unclear risk & $\begin{array}{l}\text { Comment: blocked randomisation (each doctor had been sent a box contain- } \\
\text { ing 10 glasses, of which half in random sequence contained an active ingredi- } \\
\text { ent). No information about the process of selecting the blocks }\end{array}$ \\
& & $\begin{array}{l} \\
\end{array}$
\end{tabular}

\begin{tabular}{|c|c|c|}
\hline $\begin{array}{l}\text { Allocation concealment } \\
\text { (selection bias) }\end{array}$ & Unclear risk & $\begin{array}{l}\text { Comment: no information about the centralisation of randomisation or the } \\
\text { numbering of the glasses }\end{array}$ \\
\hline
\end{tabular}

\begin{tabular}{|c|c|c|}
\hline $\begin{array}{l}\text { Blinding (performance } \\
\text { bias and detection bias) } \\
\text { All outcomes }\end{array}$ & Unclear risk & $\begin{array}{l}\text { Comment: the glasses contained pivampicillin or identical-looking placebo } \\
\text { tablets. No information about the blinding of healthcare providers and out- } \\
\text { come assessors }\end{array}$ \\
\hline
\end{tabular}

Incomplete outcome data Low risk
(attrition bias)

All outcomes

Post-randomisation dropout rate: 5/140 (3.6\%)

- treatment group: 2 (adherence problems)

- control group: 3 ( 2 because of adverse events, 1 because of adherence problems)

The ratio of participants with missing data to participants with events: 0.07 .

No ITT analysis: participants who needed referral to an ENT specialist or discontinued medication because of side effects were allowed to be removed from the trial.

$\begin{array}{ll}\begin{array}{l}\text { Selective reporting (re- } \\ \text { porting bias) }\end{array} & \begin{array}{l}\text { Comment: the study protocol is described in the methods section. The prima- } \\ \text { ry and secondary endpoints were not predefined. Nevertheless, they prede- } \\ \text { fined which symptoms, side effects, and medication intakes they would regis- } \\ \text { ter. The definition of 'cure' is described for the first time in the results section. }\end{array}\end{array}$


Norrelund 1978 (Continued)

Other bias Low risk Comment:

- no information was provided about the balance of participant characteristics at baseline, except for gender.

- with the available information, we could not detect other reasons for bias (no design-specific risks of bias, the study was not stopped early, blinding was not broken due to side effects, no bias due to increased or different diagnostic activity).

- average number of participants per practice: 7.1

\section{Rantanen 1973}

\begin{tabular}{|c|c|}
\hline Methods & $\begin{array}{l}\text { Study design: RCT } \\
\text { Study duration: not reported }\end{array}$ \\
\hline Participants & $\begin{array}{l}\text { Setting: "outpatients" } \\
\text { Country: not specified } \\
\text { Health status: participants were diagnosed with acute maxillary sinusitis. The diagnosis was based on } \\
\text { anamnestic data, clinical examination, and irrigation findings (rated macroscopically with respect to } \\
\text { the amount and quality of the secretion: purulent secretion, mucous secretion, no secretion). X-ray ex- } \\
\text { amination (4 projections) revealed homogenous shadows in the sinuses or fluid level. Secretion for } \\
\text { bacteriological examination was withdrawn through a puncture needle under sterile conditions. } \\
\text { Number: treatment (27); control (34) } \\
\text { Age: mean } 34 \text { years } \\
\text { Sex: } 64 \% \text { women } \\
\text { Exclusion criteria: cases of sinusitis who were treated previously }\end{array}$ \\
\hline Interventions & $\begin{array}{l}\text { Treatment group: } \\
\text { - intervention: doxycycline } \\
\text { - dose, duration, frequency, administration: } 200 \mathrm{mg} \text { first day, followed by } 100 \mathrm{mg}, 5 \text { days, once daily, } \\
\text { orally } \\
\text { Control group: } \\
\text { - intervention: placebo } \\
\text { - dose, duration, frequency, administration: } 6 \text { days, once daily, orally } \\
\text { Co-interventions (for all participants): } \\
\text { - weekly irrigation of the maxillary sinuses with } 100 \mathrm{~mL}(0.9 \% \text { saline) } \\
\text { - xylometazoline chloride } 0.1 \% 3 \text { times daily }\end{array}$ \\
\hline
\end{tabular}

Outcomes

Primary outcome:

1. cure, with respect to clinical picture, irrigation findings, and ostium function

Secondary outcomes:

1. a negative irrigation

2. regained ostial patency 
Other notes:

- Results:

- Recovery progress of sinuses (not participants) with respect to clinical picture, irrigation findings, and ostium function:

- Treatment group: $14 / 32$ sinuses at day $7,24 / 32$ sinuses at day $14,30 / 32$ sinuses at day $21,32 / 32$ sinuses at day 28

- Control group: $19 / 44$ sinuses at day 7, 36/44 sinuses at day $14,42 / 44$ sinuses at day $21,44 / 44$ sinuses at day 28

- Macroscopic changes of secretion after 1 week "good":

- Treatment group: $16 / 32$ sinuses

- Control group: $21 / 44$ sinuses

- No retention in secretion

- Treatment group: 10/32 sinuses after 1 week, 22/32 sinuses after 2 weeks

- Control group: 10/44 sinuses after 1 week, 34/44 sinuses after 2 weeks

- Improvement of the patency of the ostium:

- Treatment group: $22 / 32$ sinuses obstructed at the start, $10 / 32$ sinuses after 1 week, 5/32 after 2 weeks

- Control group 30/44 sinuses obstructed at the start, 17/44 after 1 week, 5/44 after 2 weeks

- Side effects: not reported

\section{Risk of bias}

\begin{tabular}{lll}
\hline Bias & Authors' judgement & Support for judgement \\
\hline $\begin{array}{l}\text { Random sequence genera- } \\
\text { tion (selection bias) }\end{array}$ & Unclear risk & Comment: no information provided about assignment. \\
\hline $\begin{array}{l}\text { Allocation concealment } \\
\text { (selection bias) }\end{array}$ & Unclear risk & $\begin{array}{l}\text { Comment: no information provided about randomisation list. Information } \\
\text { about numbering or appearance of drug containers is lacking. }\end{array}$ \\
\hline $\begin{array}{l}\text { Blinding (performance } \\
\text { bias and detection bias) } \\
\text { All outcomes }\end{array}$ & Unclear risk & $\begin{array}{l}\text { Quote: "The examiners did not know to which of the therapeutic schemes each } \\
\text { participant belonged." }\end{array}$ \\
\hline $\begin{array}{l}\text { Incomplete outcome data } \\
\text { (attrition bias) }\end{array}$ & Unclear risk & $\begin{array}{l}\text { Comment: double-blind } \\
\text { All outcomes }\end{array}$ \\
$\begin{array}{l}\text { Quote: "All participants recovered completely within 4 weeks." } \\
\text { Comment: }\end{array}$ \\
$\begin{array}{l}\text { Selective reporting (re- } \\
\text { porting bias) }\end{array}$ & Low risk & $\begin{array}{l}\text { exclusion after randomisation: not reported } \\
\text { post-randomisation dropout rate and missing data: not reported }\end{array}$ \\
\hline $\begin{array}{l}\text { Other bias } \\
\text { and secondary endpoints were predefined. "Cure" was measured for each "si- } \\
\text { nus" instead of each participant, which was confusing and made pooling with } \\
\text { other studies impossible. }\end{array}$
\end{tabular}


Stalman 1997

$\begin{array}{ll}\text { Methods } & \text { Study design: RCT } \\ & \text { Study duration: between September 1, } 1993 \text { and August 31, } 1995\end{array}$

\begin{tabular}{|c|c|}
\hline Participants & $\begin{array}{l}\text { Setting: general practice ( } 12 \text { family practices) } \\
\text { Country: the Netherlands } \\
\text { Health status: people with symptoms of an upper respiratory tract infection for at least } 5 \text { days, and } 3 \\
\text { main symptoms or } 2 \text { main symptoms and } 1 \text { other symptom } \\
\text { - main symptoms: symptoms after a common cold or influenza, purulent nasal discharge, pain in the } \\
\text { maxillary sinuses on bending forward } \\
\text { - other symptoms: predominantly unilateral maxillary pain, toothache, or pain when chewing } \\
\text { Number: } \\
\text { - total: treatment (98); control (94) } \\
\text { analysed: treatment (94); control ( } 92 \text { ) } \\
\text { Age: mean } 37 \\
\text { Sex: } 65 \% \text { women } \\
\text { Exclusion criteria: people with xylometazoline nose drop treatment lasting more than } 7 \text { days, comor- } \\
\text { bidity (diabetes mellitus, heart failure, immune deficiency), pregnancy or breastfeeding, symptoms } \\
\text { lasting longer than } 3 \text { months, antibiotic treatment in the previous } 4 \text { weeks, allergy to doxycycline, se- } \\
\text { vere illness resulting from a sinusitis in } 1 \text { of the other sinuses, antiacid or iron treatment, referral to an } \\
\text { ENT specialist, inability to speak Dutch }\end{array}$ \\
\hline Interventions & $\begin{array}{l}\text { Treatment group: } \\
\text { - intervention: doxycycline } \\
\text { - dose, duration, frequency, administration: } 100 \mathrm{mg} \text {, two tablets for the first day, followed by } 100 \mathrm{mg} \text {, } \\
9 \text { days, once daily, orally (coated tablets) } \\
\text { Control group: } \\
\text { - intervention: placebo } \\
\text { - dose, duration, frequency, administration: } 2 \text { tablets first day, followed } 1 \text { tablet, } 9 \text { days, once daily, } \\
\text { orally (coated tablets) } \\
\text { Co-interventions (for all participants): } \\
\text { - xylometazoline } 0.1 \% \text { nose drops and steam inhalation for } 15 \text { minutes } 3 \text { times daily as long as they had } \\
\text { symptoms } \\
\text { - paracetamol } 500 \mathrm{mg} \text { if needed }\end{array}$ \\
\hline
\end{tabular}

Outcomes

Primary outcomes:

1. resolution of facial pain (McGill-Melzack Pain Questionnaire, recorded daily by the participant, score: none or mild)

2. resumption of daily activities (recorded daily by the participant, score: normal level)

Secondary outcomes:

1. resumption of school or work

2. intake of analgesics stopped

3. intake of nose drops stopped

4. resolution of all initial symptoms except preceding common cold or influenza 10 and 42 days after inclusion 
Stalman 1997 (Continued)

5. cure at day 10 ('completely cured': meeting all primary and secondary outcome events)

6. side effects (nausea, vomiting, abdominal pain, diarrhoea, rash, dizziness)

Notes

Funding source: supported by grants from the Nederlandse organisatie voor Wetenschappelijk Onderzoek and Pharbita Ltd

Contact with study authors for additional information: none. Young 2008 had contact with the study authors and obtained the exact cure rates at day 10 .

Other notes:

- registration: medical history, sex, age, health insurance, season, multiple-choice questions about the duration of symptoms, reason for encounter, demand for help, medical history and ear, nose, and throat examination during the first visit

- follow-up:

- diary for 10 days (absenteeism from school or work, frequency of steaming, intake of nose drops and analgesics, intake of study medication, adverse effects)

- Evaluation by the general practitioner at 10 and 42 days (evaluation of symptoms, repeated ear, nose, and throat examination)

- Results:

- cure at day 10 ("completely cured")

- We estimated numbers of events by multiplying the percentage with the total number of participants in the group to make pooling of results possible.

- treatment group: 56/94

- control group: $55 / 92$

- cure at day 10 (meeting the primary outcome)

- Since exact numbers for each treatment group were not reported, we used the numbers obtained by Young 2008

- treatment group: $63 / 95$

- control group: 59/93

- improvement at day 10

- treatment group: $80 / 94$

- control group: $79 / 92$

- side effects:

- treatment group: 17/94 (nausea 9, vomiting 5, abdominal pain 5, diarrhoea 2, rash 2, dizziness 1)

- control group: $2 / 92$ (nausea 2)

- clinical failure (discontinuation of trial medication due to treatment failure, no information about whether or not open antibiotic treatment was started)

- treatment group: $3 / 94$

- control group: $7 / 92$

- relapse:

- treatment group: $5 / 94$

- control group: $1 / 92$

\section{Risk of bias}

\begin{tabular}{lll}
\hline Bias & Authors' judgement & Support for judgement \\
\hline $\begin{array}{l}\text { Random sequence genera- } \\
\text { tion (selection bias) }\end{array}$ & Low risk & $\begin{array}{l}\text { Comment: participants were assigned to doxycyline or placebo treatment in } \\
\text { blocks of } 4 \text { according to a computer-generated randomisation schedule. }\end{array}$ \\
\hline
\end{tabular}

$\begin{array}{lll}\begin{array}{l}\text { Allocation concealment } \\ \text { (selection bias) }\end{array} & \text { Unclear risk } & \begin{array}{l}\text { Comment: no information about centralisation of randomisation, numbering } \\ \text { of drug containers, or opaque, sealed envelopes }\end{array}\end{array}$

Blinding (performance Low risk

bias and detection bias)

All outcomes
Comment: doxycycline and placebo appeared and tasted the same. Blinding of participants and treatment team was maintained throughout the study. 
Stalman 1997 (Continued)

Incomplete outcome data Low risk
(attrition bias)

All outcomes
Post-randomisation dropout rate at day 10: 6/192 (3.1\%)

- treatment group: 4 ( 2 of them because of vomiting and abdominal pain)

- control group: 2

Ratio of participants with missing data to participants with events: 0.05

Discontinuation of trial medication rate: $20 / 186(10.7 \%)$

- treatment group: 12 (3 for treatment failure, 5 for recurrence, 4 for side effects)

- control group: 8 (7 for treatment failure, 1 for recurrence)

All these participants were included in the analysis following the ITT principle.
Selective reporting (re- Low risk porting bias)
The study protocol is described in the methods section. The primary and secondary endpoints were predefined. Only the definition of "improvement" was not stated clearly.

Other bias Low risk

\section{Comment:}

- concerning the characteristics at baseline, there were slight differences between treatment groups with regard to reason for encounter, demand for help, season, relapse of sinusitis, nasal speech, and cervical lymphatic glands.

- with the available information, we could not detect other reasons for bias (no design-specific risks of bias, the study was not stopped early, blinding was not broken due to side effects, there was no bias due to increased or different diagnostic activity).

- number of recruited participants per practice: 15.6

Van Buchem 1997a

\begin{tabular}{ll}
\hline Methods & Study design: RCT \\
& Study duration: between 1 March 1993 and 1 March 1994 \\
\hline
\end{tabular}

\section{Participants}

$$
\begin{aligned}
& \text { Setting: general practice } \\
& \text { Country: the Netherlands }
\end{aligned}
$$

Health status: adults with a clinical diagnosis of maxillary sinusitis (history, physical examination), for whom antibiotic therapy was considered, confirmed by radiograph (> $5 \mathrm{~mm}$ mucosal thickening, opacity or air-fluid level). Ear, nose, and throat comorbidity was assessed; approximately $12 \%$ had allergic disease.

Number:

- total: treatment (108); control (106)

- analysed: treatment (105); control (101)

Age: mean 34

\section{Sex: $63 \%$ women}

Exclusion criteria: other nasal disorders (e.g. nasal polyps), concurrent bronchitis, current episodes of longer than 3 months, antibiotic treatment during the previous month, known hypersensitivity to amoxicillin, hepatic, renal, or immunological disorder, and coagulation abnormalities 
Van Buchem 1997a (Continued)

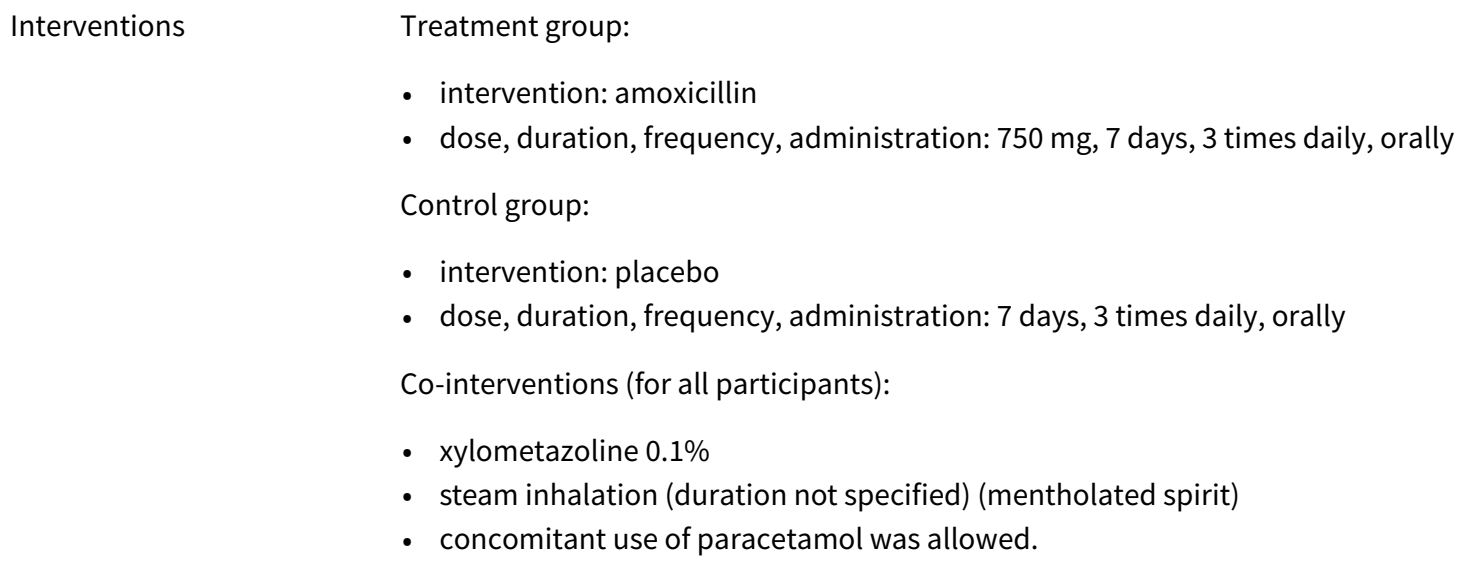

Outcomes

Primary outcomes:

1. cure rate after 14 days ("Cure" was defined as "no symptoms")

2. symptom scores after 7 and 14 days.

- "Cure" was defined as "no symptoms"

- "Greatly decreased symptoms" was defined as "at most two patient accounts of symptoms or sets of examination data had a score lower than 5" (which means that they are still present)

Secondary outcomes:

1. resolution of radiographic abnormalities after 14 days

2. occurrence of side effects

3. relapses (during 1-year follow-up)

4. chronic evolution

Bacteriological outcomes were not assessed.

Other notes:

- All participants were referred to the ENT specialist after inclusion for an extended anamnesis and profound physical examination with rhinoscopy and blood examination.

- Follow-up:

- at day 7 by ENT specialist (intercurrent history and physical examination, number of capsules, side effects)

- at day 14 by ENT specialist (intercurrent history, physical examination, number of capsules, side effects, blood examination, sinus radiograph) (or earlier when extra follow-up was needed).

- When extra therapy was needed after day 14 , a maxillary puncture was performed.

- Relapses and complications were registered by the general practitioner during 1 year 
Van Buchem 1997a (Continued)

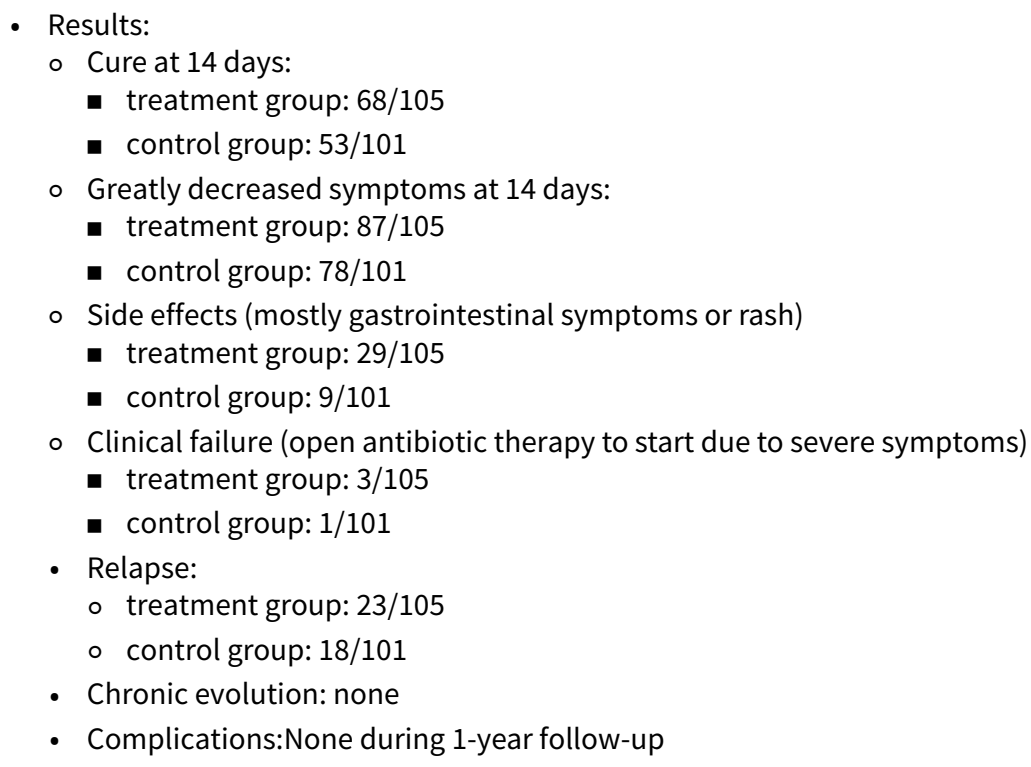

Risk of bias

\begin{tabular}{lll}
\hline Bias & Authors' judgement & Support for judgement \\
\hline $\begin{array}{l}\text { Random sequence genera- } \\
\text { tion (selection bias) }\end{array}$ & Low risk & $\begin{array}{l}\text { Comment: unrestricted randomisation (computer-generated list used for allo- } \\
\text { cation) }\end{array}$ \\
$\begin{array}{l}\text { Quote: "The randomisation of allocation of the amoxicillin or placebo (distrib- } \\
\text { uted in identical bottles) was computer generated" }\end{array}$
\end{tabular}

Allocation concealment Low risk
vided by the hospital pharmacy in the hospital to which participants were referred to the ENT specialist."

Quote: "During the trial, the code of allocation schedule was kept in the office of the head of the hospital pharmacy, and was broken prematurely only if severe clinical development or severe adverse effects occurred"

Comment: the capsules with amoxicillin or placebo looked and tasted identical and were prescribed in the same frequency and for the same duration. The capsules were distributed in identical bottles.

$\begin{array}{ll}\text { Blinding (performance } & \text { Low risk } \\ \text { bias and detection bias) } & \text { participant, and ENT specialist. }\end{array}$
All outcomes

$\begin{array}{ll}\begin{array}{ll}\text { Incomplete outcome data } \\ \text { (attrition bias) }\end{array} & \text { Low risk } \\ \text { All outcomes } & \text { Post-randomisation dropout rate: } 8 / 214(3.7 \%) \\ & \text { - treatment group: } 3 \\ & \text { Reason for missing data: not attending follow-up visit } \\ & \text { Ratio of participants with missing data to participants with events: } 0.07 \\ & \text { Discontinuation of trial medication rate: } 1 / 210(0.5 \%) \\ & - \text { treatment group: } 0 \\ & - \text { control group: } 1 \text { (adverse effects) }\end{array}$


Treatment compliance reported as $98 \%$ assessed by pills taking by participants.

Intention-to-treat analysis

\begin{tabular}{|c|c|c|}
\hline $\begin{array}{l}\text { Selective reporting (re- } \\
\text { porting bias) }\end{array}$ & Low risk & $\begin{array}{l}\text { Comment: the study protocol is described in the methods section. The primary } \\
\text { and secondary endpoints were predefined. }\end{array}$ \\
\hline Other bias & Unclear risk & $\begin{array}{l}\text { Comment: } \\
\text { - selection of participants with worse symptoms: only } 20 \% \text { of participants with } \\
\text { possible maxillary sinusitis entered the trial (declining participation, meeting } \\
\text { exclusion criteria, infringement of protocol, or participants with symptoms } \\
\text { that did not justify antibiotics). }\end{array}$ \\
\hline
\end{tabular}

Varonen 2003

$\begin{array}{ll}\text { Methods } & \text { Study design: RCT } \\ & \text { Study duration: from November } 1998 \text { to October } 1999\end{array}$

\section{Participants}

Setting: ambulatory care (9 practices)

Country: Finland

Health status: people with an upper respiratory tract infection and having at least 3 main symptoms and 1 clinical sign

- main symptoms: nasal obstruction, nasal discharge, headache, post-nasal drip, cough, sinus pain, unilateral facial pain, maxillary toothache, hyposmia, anosmia, malaise, or fever

- clinical signs: purulent secretion in the nasal cavity, discharge in the pharynx, and tenderness in sinus tapping

Numbers:

- total: treatment (88); control (60), missing treatment data (2)

- analysed: treatment (85); control (57)

Age: mean 40.6 in treatment group and 38.1 in control group

Sex: $70 \%$ women (2 unknown sex)

Exclusion criteria were acute maxillary sinusitis symptoms lasting over 30 days, antibiotics during the previous month, allergy to study medications, pregnancy, breastfeeding, exacerbation of a diagnosed chronic maxillary sinusitis, previous paranasal sinus surgery, clinical suspicion of dental or frontal sinusitis or pansinusitis, suspicion of a severe complication, and previous sinus surgery.

Interventions

Treatment group:

- Group 1

○ intervention: amoxicillin

- dose, duration, frequency, administration: $750 \mathrm{mg}, 7$ days, twice daily, orally

- Group 2

○ intervention: penicillin $\mathrm{V}$

- dose, duration, frequency, administration: 1500 IU, 7 days, twice daily, orally

- Group 3

○ intervention: doxycycline

- dose, duration, frequency, administration: $100 \mathrm{mg}, 7$ days, twice daily, orally 
Varonen 2003 (Continued)

\section{Control group:}

- intervention: placebo

- dose, duration, frequency, administration: 7 days, twice daily

Co-interventions: allowed if the physician considered them necessary.

- xylometazoline

- paracetamol

- anti-inflammatory agents

For this review, group 1, 2, and 3 were combined in the analyses.

\section{Outcomes}

\section{Primary outcome:}

1. recovery rate after 2 weeks (according to the telephone interview)

Secondary outcomes:

1. incidence of side effects

2. subjective symptom score (at days 3 and 10 )

3. duration of sinusitis

4. use of additional medication

5. frequency of chronic or recurrent sinusitis during 1-year follow-up

6. number of physician consultations during 1-year follow-up

Funding source: Stakes, the National Research and Development Centre for Welfare and Health covered the administrative and travel costs of this study. Leiras-Schering and SmithKline Beecham provided the study medication.

Contact with study authors for additional information: none

Other notes:

- Registration:

- Completion of a questionnaire (12 symptoms (3-step scale), duration of symptoms, double sickening)

- Recording of history and clinical findings

- Performance of ultrasound examination, nasal samples, and sinus radiography (occipitomental, Waters view)

- Follow-up:

- diary for 2 weeks (12 symptoms (3-step scale), possible self medication, side effects, overall estimate whether they thought they continued to have sinusitis)

- Telephone interview after 2 weeks (subjective symptoms, severity, possible side effects, participants' estimate of recovery or recurrence)

- Check of patient records after 1 year to register recurrent or chronic sinusitis

- Results:

- Cure at 2 weeks:

- treatment group: $70 / 85$

- control group: $39 / 57$

- Side effects:

- treatment group:32/82 (29/79 + 3 loss to follow-up due to side effects) (diarrhoea 7\% (6/82), stomach pain $22 \%$, headache $6 \%$, rash $2 \%$, vaginal discharge $4 \%$, fatigue $6 \%$ )

- control group: $13 / 48$ (12/47 + 1 loss to follow-up due to side effects) (diarrhoea 6\% (3/48), stomach pain $12 \%$, headache $4 \%$, rash $0 \%$, vaginal discharge $0 \%$, fatigue $6 \%$ )

- Clinical failure (requiring open antibiotic treatment)

- treatment group: 6/85

- control group: $10 / 57$ 
Varonen 2003 (Continued)

Risk of bias

\begin{tabular}{lll}
\hline Bias & Authors' judgement & Support for judgement \\
\hline $\begin{array}{l}\text { Random sequence genera- } \\
\text { tion (selection bias) }\end{array}$ & Unclear risk & $\begin{array}{l}\text { Quote: "The treatments were previously randomised in blocks of 20 consecu- } \\
\text { tive participants at the Military Pharmacy in Helsinki." }\end{array}$ \\
\hline $\begin{array}{l}\text { Allocation concealment } \\
\text { selection bias) }\end{array}$ & Low risk & $\begin{array}{l}\text { Quote: "The study medications were coded with 6-number individual codes." } \\
\text { Quote: "During the trial, the senior researcher kept the code and was the pri- } \\
\text { mary contact in the case of adverse effects or severe complications. All study } \\
\text { centres also had the code in a closed envelope to be opened only if the senior } \\
\text { researcher could not be reached." }\end{array}$ \\
\hline
\end{tabular}

Blinding (performance Low risk bias and detection bias)

All outcomes
Comment: the medication bottles were identically sealed.

Quote: "Physicians, participants, and the main researcher remained blinded to the treatments until the recruitment was ended."

Comment: the result of the ultrasound was not disclosed to the participant.

Comment: the main researcher did not know the participant's history, treatment, or the result of the ultrasound examination while interviewing the participant 14 to 16 days after inclusion.

Incomplete outcome data Low risk (attrition bias)

All outcomes

Post-randomisation dropout rate: $8 / 150$ (5,3\%)

- no treatment data: 2

- treatment group: 3 (side effects)

- control group: 3 (1 violation of the study protocol (pregnancy), 1 not reached by phone, 1 side effects)

Ratio of participants with missing data to participants with events: 0.07

Comment:

- the authors analysed the data for the main outcomes by intention-to-treat. Withdrawals (trial medication or other antibiotics) were analysed as treatment failures.

- duration of sinusitis was analysed only in participants who recovered fully during the 2-week follow-up

\begin{tabular}{lll}
\hline $\begin{array}{l}\text { Selective reporting (re- } \\
\text { porting bias) }\end{array}$ & Low risk & $\begin{array}{l}\text { Comment: the study protocol is described in the methods section. The primary } \\
\text { and secondary endpoints were predefined. }\end{array}$ \\
\hline Other bias & Low risk & Number of participants per health centre: 15.8 \\
\hline
\end{tabular}

\section{Williamson 2007}

\begin{tabular}{ll}
\hline Methods & Study design: RCT (factorial design) \\
& Study duration: from November 2001 to November 2005 \\
\hline Participants & Setting: ambulatory care (58 family practices, 74 family physicians) \\
& Country: UK
\end{tabular}


Williamson 2007 (Continued)

Health status: people presenting with uncomplicated acute illness (<28 days) and at least 2 symptoms and 1 clinical sign of sinusitis (according to the Berg and Carenfelt criteria: purulent nasal discharge predominating on 1 side, local facial pain predominating on 1 side, purulent nasal discharge on both sides, pus in the nasal cavity)

Numbers:

- total: treatment (113, including treatment group 1 and 2); control (127, including treatment group 3 and control group)

- analysed: treatment (101, including treatment group 1 and 2); control (108, including treatment group 3 and control group)

Age: mean 43 in amoxicillin group and 42 in placebo group

Sex: $72.5 \%$ women

Exclusion criteria: $<2$ of the Berg and Carenfelt criteria (low probability of sinusitis), history of recurrent sinusitis ( $\geq 2$ attacks of acute sinusitis in the previous 12 months), significant morbidities (poorly controlled diabetes or heart failure), pregnant or breastfeeding, allergies, a history of adverse reactions to either medications, and receiving antibiotics or steroids in the previous month

- Group 1

- intervention: amoxicillin

- dose, duration, frequency, administration: $750 \mathrm{mg}, 7$ days, twice daily, orally

- intervention: budesonide

- dose, duration, frequency, administration: 1 dosis, 10 days, once daily, nose spray (in each nostril)

- Group 2

o intervention: amoxicillin

- dose, duration, frequency, administration: $750 \mathrm{mg}, 7$ days, twice daily, orally

- intervention: placebo

- dose, duration, frequency, administration: 10 days, once daily, nose spray (in each nostril)

- Group 3

○ intervention: placebo

- dose, duration, frequency, administration: 7 days, twice daily, orally

○ intervention: budesonide

- dose, duration, frequency, administration: 1 dosis, 10 days, once daily, nose spray (in each nostril)

Control group:

- intervention: placebo

- dose, duration, frequency, administration: 7 days, twice daily, orally

- intervention: placebo

- dose, duration, frequency, administration: 1 dosis, 10 days, once daily, nose spray (in each nostril)

For this review, we reduced the 4 treatment arms to 2 (factorial design): treatment group 1 and 2 (treatment group) versus treatment group 3 and control group (control group)

1. symptom resolution (all symptoms score 0 in the diary)

Secondary outcome:

1. symptom severity score

Notes

Funding source: supported by the UK Department of Health. The UK Department of Health did not participate in the design and conduct of the study, in the collection, analysis, and interpretation of the data, or in the preparation, review, or approval of the manuscript. 
Williamson 2007 (Continued)

Contact with study authors for additional information: none

Other notes:

- Registration at inclusion: baseline questionnaire including clinical signs and confirmation of entry criteria completed by general practitioners, basic physical examination of temperature recording, sinus tenderness, and anterior nasal cavity inspection (anterior rhinoscopy), recording of symptom duration and pain severity, collection of baseline demographic details.

- Follow-up:

- diary for 14 days (11 symptom variables, 7-point Likert scale)

- questionnaire on other variables (clinical features and satisfaction), and a telephone call during the first week to encourage adherence and improve the quality of the diary returns

- Subgroup analysis of the pain and unwell group

- Results:

- Symptom resolution at day 10 :

- treatment group: $71 / 101$

- control group: $71 / 108$

- Side effects: no information available

- Clinical failure (withdrawal because of ongoing symptoms)

- treatment group: $1 / 101$

- control group: $1 / 108$

- no serious adverse events

\section{Risk of bias}

Bias Authors' judgement Support for judgement

Random sequence genera- Low risk tion (selection bias)
Quote: "Recruitment plan was for 4 recruited cases per family physician (1 block randomised pack of 4 per physician and 2 physicians per practice)." Quote: "The packs were made up using random number tables."

Quote: "Randomisation was performed at the level of the patient."

Quote: "Each randomized pack therefore consisted of an auditable sequence of the 4 possible combinations of the 2 interventions and physicians were instructed to use the packs in sequence."

Allocation concealment Low risk
(selection bias)

Quote: "An independent person to the trial team was employed for distribution using the random sequence and trial code."

Quote: "The code break was kept in a sealed envelope in a locked filing cabinet at the university throughout the study period."

Quote: "All drug containers and all trial materials were identifiable only by the randomisation code number."

Comment: blind-sequenced trial packs.

Quote: "The sealed, opaque, numbered packages contained physician instructions and either active or placebo drugs that were distributed in batches in randomised blocks of $4 . "$

Blinding (performance Low risk
bias and detection bias)

Quote: "Neither the antibiotic nor the nasal steroid spray was recognisable as active or placebo medication, identical in taste and appearance."

All outcomes
Comment: no significant difference in participant's belief in the effectiveness of the treatment allocated ( 0 -to- 5 scales) for the antibiotic tablet versus placebo tablet $(P=0.07)$, or for steroid spray versus placebo spray $(P=0.25)$.

Comment: the single code break envelope was not opened until all data collection had been completed and all variables had been entered into the data- 
Williamson 2007 (Continued)

base. All outcome assessments were recorded on a central database and checked and verified when necessary by a research fellow blinded to treatment grouping.

Incomplete outcome data Low risk (attrition bias)

All outcomes
Post-randomisation dropout rate: $31 / 240$ (12.9\%) due to loss to follow-up

- treatment group: 12

- control group: 19

Reasons for missing data: loss to follow-up

2 additional participants withdrew ( 1 in the amoxicillin group and 1 in the placebo group) because of ongoing symptoms; we considered these as failures in our review.

Ratio of participants with missing data to participants with events: 0.23

Comment:

1. the authors remarked that participants who had pus on examination and were male were more likely to be lost to follow-up

2. the authors performed a sensitivity analysis in 2 ways: with imputation of data (assuming those lost to follow-up were still symptomatic at day 14) and with and without the additional telephone information obtained. They found no significant difference in results.

\section{Selective reporting (re- Low risk} porting bias)

Comment: the study protocol is described in the methods section. The primary and secondary endpoints were predefined.

Other bias Low risk Comment:

1. there was no significant imbalance of participant characteristics at baseline, except for temperature (slightly higher temperature in the placebo group, but the difference was too small to have any clinical importance).

2. with the available information, we could not detect other reasons for bias (no design-specific risks of bias, the study was not stopped early, no imbalance of participant characteristics at baseline, blinding was not broken due to side effects, no bias due to increased or different diagnostic activity).

3. Dr Little reported receiving consultancy fees for 2 half days from Abbott Pharmaceuticals regarding complications of respiratory tract infections. No other authors reported financial disclosures. Family physicians received USD 50 per participant recruited from government funding, but participants received no reimbursement.

4. average number of participants per practice: 3.6

CRP: C-reactive protein

$\mathrm{CT}$ : computed tomography

ENT: ear, nose, and throat

ITT: intention-to-treat

$\mathrm{RCT}$ : randomised controlled trial

SNOT: Sino-Nasal Outcome Test

VAS: visual analogue scale

Characteristics of excluded studies [ordered by study ID] 


\begin{tabular}{ll}
\hline Study & Reason for exclusion \\
\hline Gananca 1973 & $\begin{array}{l}\text { Randomised, double-blind, placebo-controlled trial. Acute sinusitis diagnostic criteria did not fulfil } \\
\text { inclusion criteria for this review (clinical symptoms and signs and bacteriologic criteria). }\end{array}$ \\
\hline Gananca 1977 & $\begin{array}{l}\text { Randomised, double-blind, placebo-controlled trial. Acute sinusitis diagnostic criteria did not fulfil } \\
\text { inclusion criteria for this review (clinical symptoms and signs and bacteriologic criteria). }\end{array}$ \\
\hline Hadley 2010 & $\begin{array}{l}\text { Prospective, multicentre, placebo-controlled, randomised, double-blind phase IIIb clinical trial. } \\
\text { acute sinusitis diagnostic criteria did not fulfil inclusion criteria for this review (clinical symptoms } \\
\text { and signs, confirmed by radiography; analysis only performed for participants with positive sinus }\end{array}$ \\
\hline Hansen 2000a & $\begin{array}{l}\text { Randomised, double-blind, placebo-controlled trial. Acute sinusitis diagnostic criteria did not fulfil } \\
\text { inclusion criteria for this review (clinical symptoms (maxillary pain) and raised values of either C-re- } \\
\text { active protein or erythrocyte sedimentation rate. }\end{array}$ \\
\hline Haye 1998 & $\begin{array}{l}\text { Randomised, double-blind, placebo-controlled trial. Acute sinusitis diagnostic criteria did not ful- } \\
\text { fil inclusion criteria for this review (exclusion of participants with empyema (defined as complete } \\
\text { opacity or an air-fluid level, or a mucosal thickness of } 6 \text { mm or more as measured at the upper lat- } \\
\text { eral border of the maxillary sinus)). }\end{array}$
\end{tabular}

\section{DATA AND ANALYSES}

\section{Comparison 1. Antibiotics versus placebo for acute rhinosinusitis: cure}

\begin{tabular}{lllll}
\hline Outcome or subgroup title & No. of studies & $\begin{array}{l}\text { No. of partici- } \\
\text { pants }\end{array}$ & Statistical method & Effect size \\
\hline 1 Cure & 11 & 2208 & $\begin{array}{l}\text { Odds Ratio (M-H, Fixed, 95\% } \\
\text { Cl) }\end{array}$ & $1.38[1.15,1.65]$ \\
\hline $\begin{array}{l}1.1 \text { Clinically diagnosed acute rhinos- } \\
\text { inusitis }\end{array}$ & 8 & 1687 & $\begin{array}{l}\text { Odds Ratio (M-H, Fixed, 95\% } \\
\text { Cl) }\end{array}$ & $1.25[1.02,1.53]$ \\
\hline $\begin{array}{l}1.2 \text { Acute rhinosinusitis confirmed by } \\
\text { radiography }\end{array}$ & 3 & 394 & $\begin{array}{l}\text { Odds Ratio (M-H, Fixed, 95\% } \\
\text { Cl) }\end{array}$ & $1.57[1.03,2.39]$ \\
\hline $\begin{array}{l}1.3 \text { Acute rhinosinusitis confirmed by } \\
\text { computed tomography }\end{array}$ & 1 & 127 & $\begin{array}{l}\text { Odds Ratio (M-H, Fixed, 95\% } \\
\text { Cl) }\end{array}$ & $4.89[1.75,13.72]$ \\
\hline
\end{tabular}

Analysis 1.1. Comparison 1 Antibiotics versus placebo for acute rhinosinusitis: cure, Outcome 1 Cure.

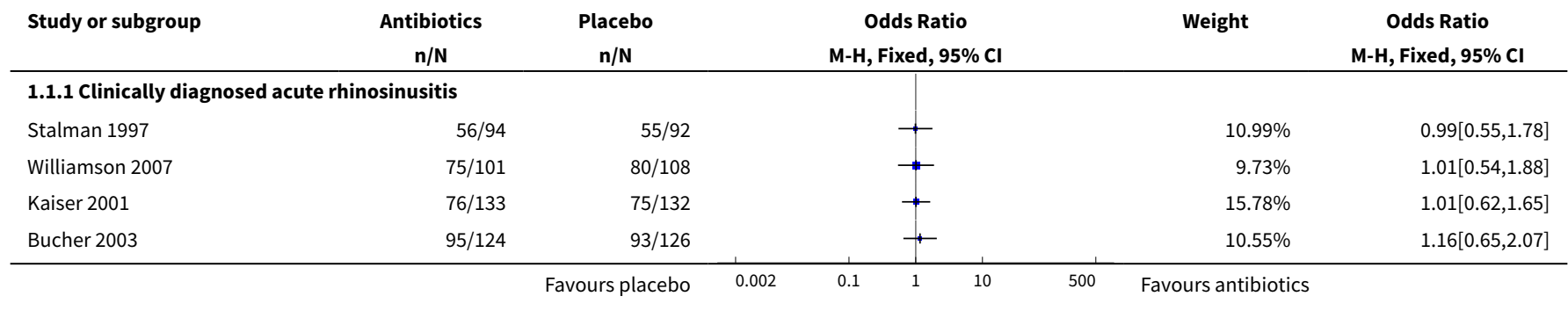




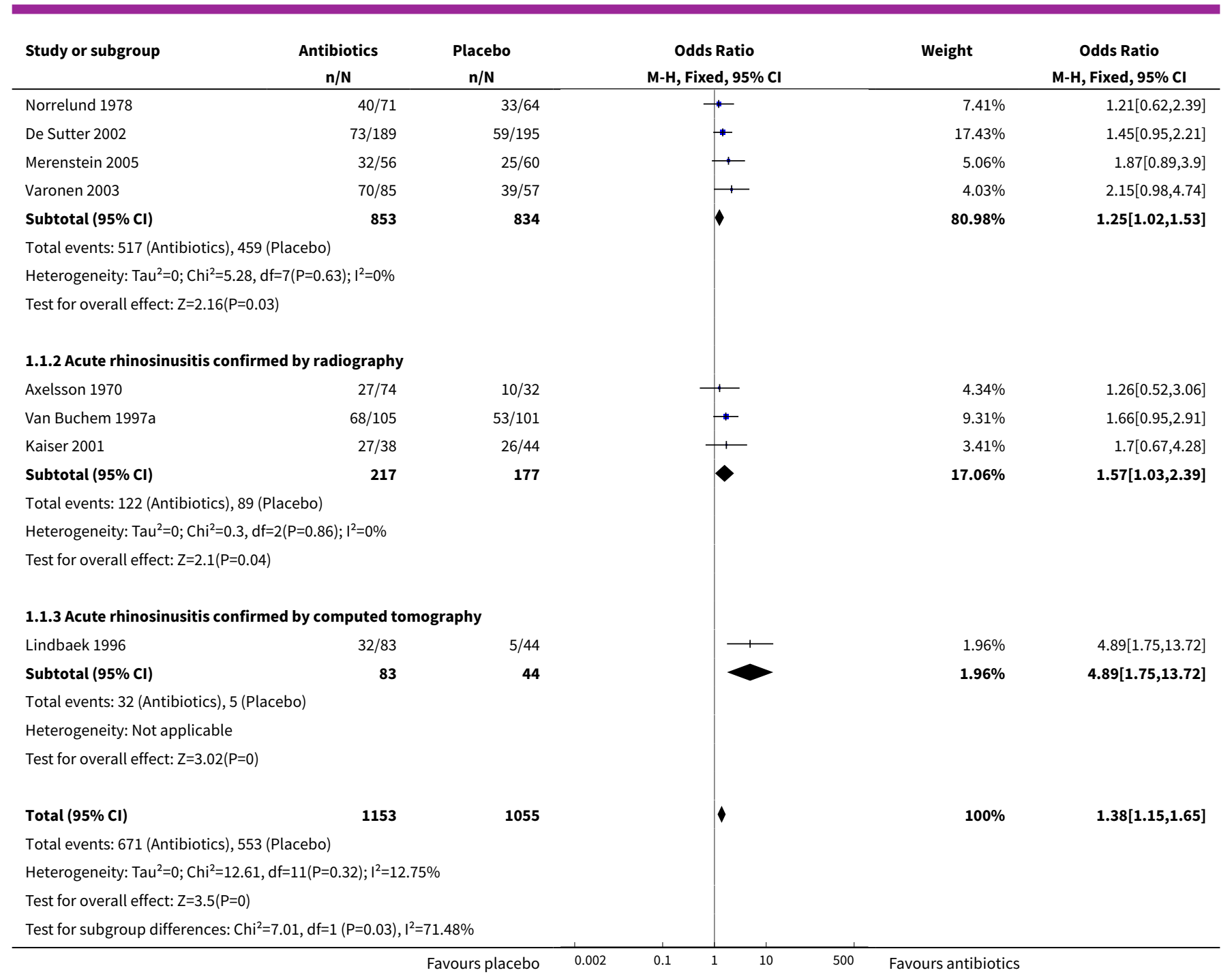

\section{Comparison 2. Antibiotics versus placebo in acute rhinosinusitis: secondary outcomes}

\begin{tabular}{lllll}
\hline Outcome or subgroup title & No. of studies & $\begin{array}{l}\text { No. of partici- } \\
\text { pants }\end{array}$ & Statistical method & Effect size \\
\hline $\begin{array}{l}1 \text { Severity or duration of different } \\
\text { clinical symptoms: resolution of pu- } \\
\text { rulent secretion }\end{array}$ & 3 & 660 & $\begin{array}{l}\text { Odds Ratio (M-H, Fixed, 95\% } \\
\text { Cl) }\end{array}$ & $1.58[1.13,2.22]$ \\
\hline $\begin{array}{l}2 \text { Side effects: total } \\
\text { is }\end{array}$ & 10 & 1816 & $\begin{array}{l}\text { Odds Ratio (M-H, Fixed, 95\% } \\
\text { Cl) }\end{array}$ & $2.21[1.74,2.82]$ \\
\hline $\begin{array}{l}2.1 \text { Clinically diagnosed rhinosinusi- } \\
\text { imaging }\end{array}$ & 7 & 1371 & $\begin{array}{l}\text { Odds Ratio (M-H, Fixed, 95\% } \\
\text { Cl) }\end{array}$ & $2.10[1.60,2.77]$ \\
\hline
\end{tabular}




\begin{tabular}{|c|c|c|c|c|}
\hline Outcome or subgroup title & No. of studies & $\begin{array}{l}\text { No. of partici- } \\
\text { pants }\end{array}$ & Statistical method & Effect size \\
\hline 3 Side effects: diarrhoea & 7 & 1210 & $\begin{array}{l}\text { Peto Odds Ratio (Peto, Fixed, } \\
95 \% \mathrm{Cl} \text { ) }\end{array}$ & $2.00[1.41,2.85]$ \\
\hline 4 Clinical failure & 12 & 2603 & $\begin{array}{l}\text { Peto Odds Ratio (Peto, Fixed, } \\
95 \% \mathrm{Cl} \text { ) }\end{array}$ & $0.48[0.36,0.63]$ \\
\hline $\begin{array}{l}4.1 \text { Clinically diagnosed rhinosinusi- } \\
\text { tis }\end{array}$ & 8 & 2101 & $\begin{array}{l}\text { Peto Odds Ratio (Peto, Fixed, } \\
95 \% \mathrm{Cl} \text { ) }\end{array}$ & $0.49[0.36,0.67]$ \\
\hline $\begin{array}{l}\text { 4.2 Rhinosinusitis confirmed by ra- } \\
\text { diography }\end{array}$ & 2 & 312 & $\begin{array}{l}\text { Peto Odds Ratio (Peto, Fixed, } \\
95 \% \mathrm{Cl} \text { ) }\end{array}$ & $2.09[0.52,8.35]$ \\
\hline $\begin{array}{l}\text { 4.3 Rhinosinusitis confirmed by } \\
\text { computed tomography }\end{array}$ & 2 & 190 & $\begin{array}{l}\text { Peto Odds Ratio (Peto, Fixed, } \\
95 \% \mathrm{Cl} \text { ) }\end{array}$ & $0.25[0.11,0.55]$ \\
\hline
\end{tabular}

\section{Analysis 2.1. Comparison 2 Antibiotics versus placebo in acute rhinosinusitis: secondary outcomes, Outcome 1 Severity or duration of different clinical symptoms: resolution of purulent secretion.}

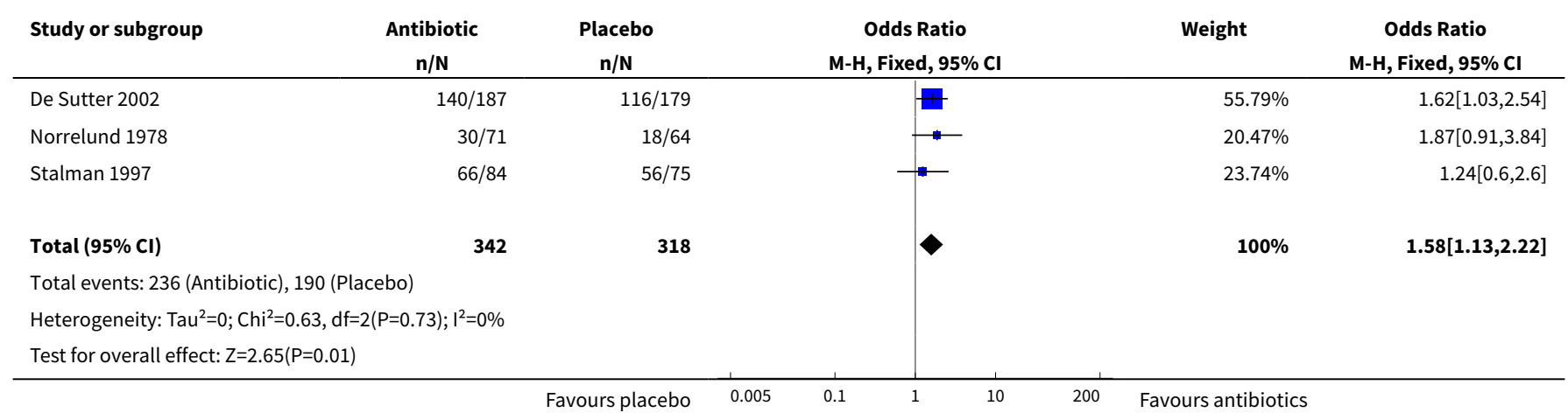

Analysis 2.2. Comparison 2 Antibiotics versus placebo in acute rhinosinusitis: secondary outcomes, Outcome 2 Side effects: total.

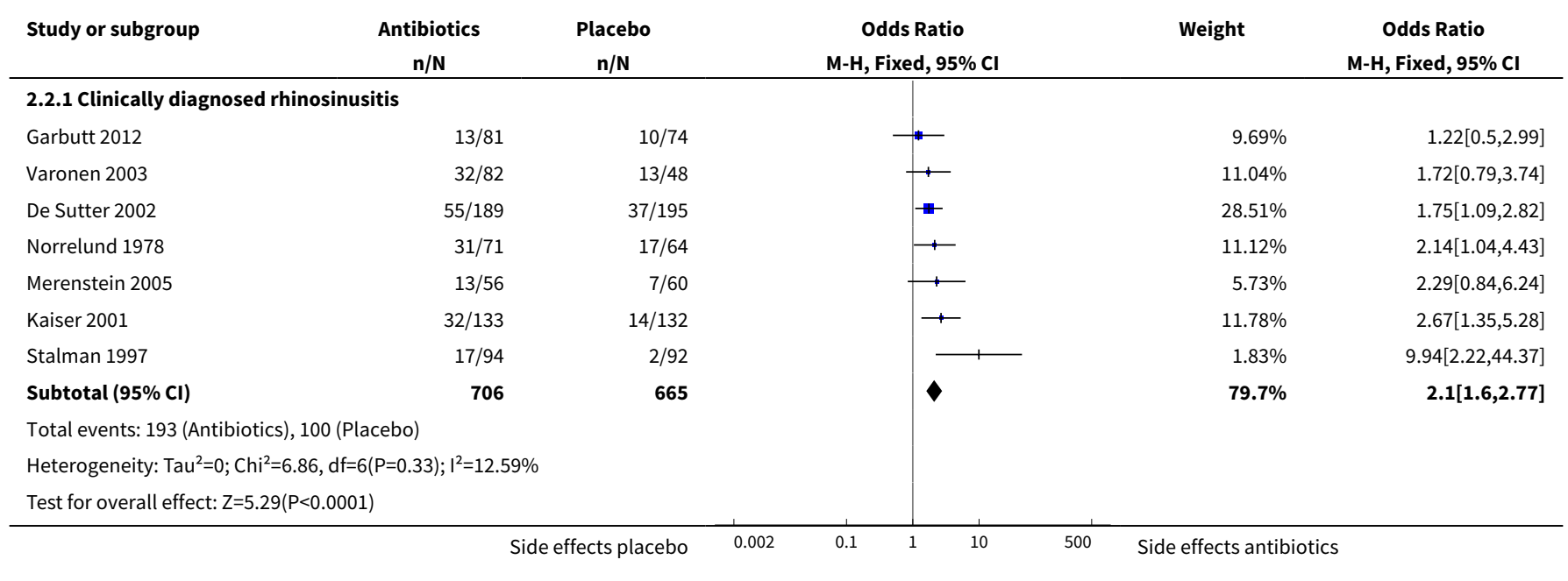




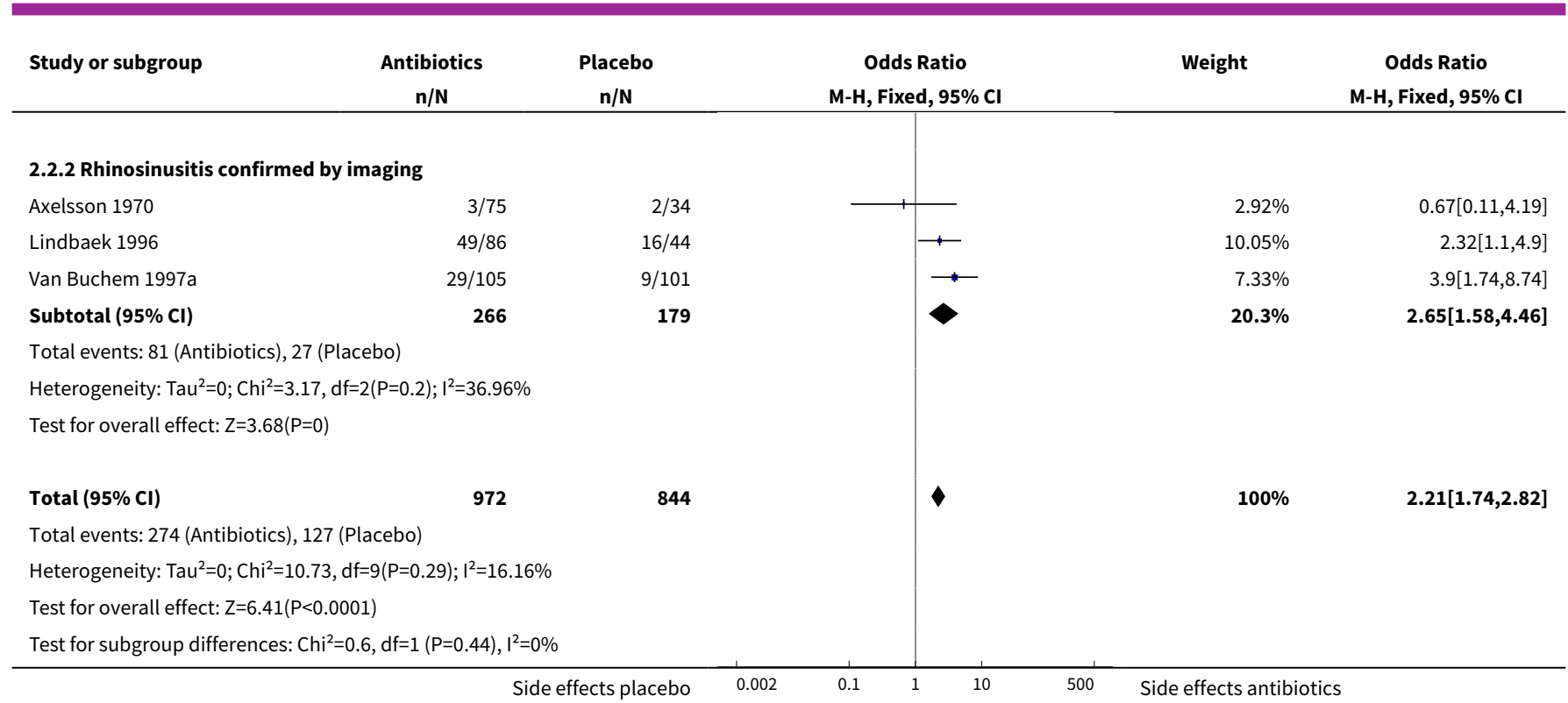

Analysis 2.3. Comparison 2 Antibiotics versus placebo in acute rhinosinusitis: secondary outcomes, Outcome 3 Side effects: diarrhoea.

\begin{tabular}{|c|c|c|c|c|c|}
\hline Study or subgroup & $\begin{array}{c}\text { Experimental } \\
n / N\end{array}$ & $\begin{array}{c}\text { Control } \\
n / N\end{array}$ & $\begin{array}{c}\text { Peto Odds Ratio } \\
\text { Peto, Fixed, } 95 \% \mathrm{Cl}\end{array}$ & Weight & $\begin{array}{c}\text { Peto Odds Ratio } \\
\text { Peto, Fixed, } 95 \% \mathrm{Cl}\end{array}$ \\
\hline Axelsson 1970 & $1 / 75$ & $0 / 34$ & $\longrightarrow$ & $0.69 \%$ & $4.28[0.06,294.11]$ \\
\hline De Sutter 2002 & $55 / 189$ & $37 / 195$ & 7 & $56.65 \%$ & $1.74[1.09,2.78]$ \\
\hline Garbutt 2012 & $7 / 81$ & $7 / 74$ & $\longrightarrow$ & $10.33 \%$ & $0.91[0.3,2.71]$ \\
\hline Lindbaek 1996 & $36 / 86$ & $5 / 44$ & $\rightarrow$ & $20.47 \%$ & $4.06[1.86,8.85]$ \\
\hline Merenstein 2005 & $4 / 56$ & $1 / 60$ & +1 & $3.89 \%$ & $3.73[0.63,22.24]$ \\
\hline Varonen 2003 & $6 / 82$ & $3 / 48$ & $\longrightarrow$ & $6.35 \%$ & $1.18[0.29,4.77]$ \\
\hline Total $(95 \% \mathrm{Cl})$ & 663 & 547 & $\boldsymbol{\gamma}$ & $100 \%$ & $2[1.41,2.85]$ \\
\hline \multicolumn{6}{|c|}{ Total events: 111 (Experimental), 53 (Control) } \\
\hline \multicolumn{6}{|c|}{ Heterogeneity: $\mathrm{Tau}^{2}=0 ; \mathrm{Chi}^{2}=7.5, \mathrm{df}=6(\mathrm{P}=0.28) ; \mathrm{I}^{2}=19.99 \%$} \\
\hline Test for overall effec & & & & & \\
\hline
\end{tabular}

Analysis 2.4. Comparison 2 Antibiotics versus placebo in acute rhinosinusitis: secondary outcomes, Outcome 4 Clinical failure.

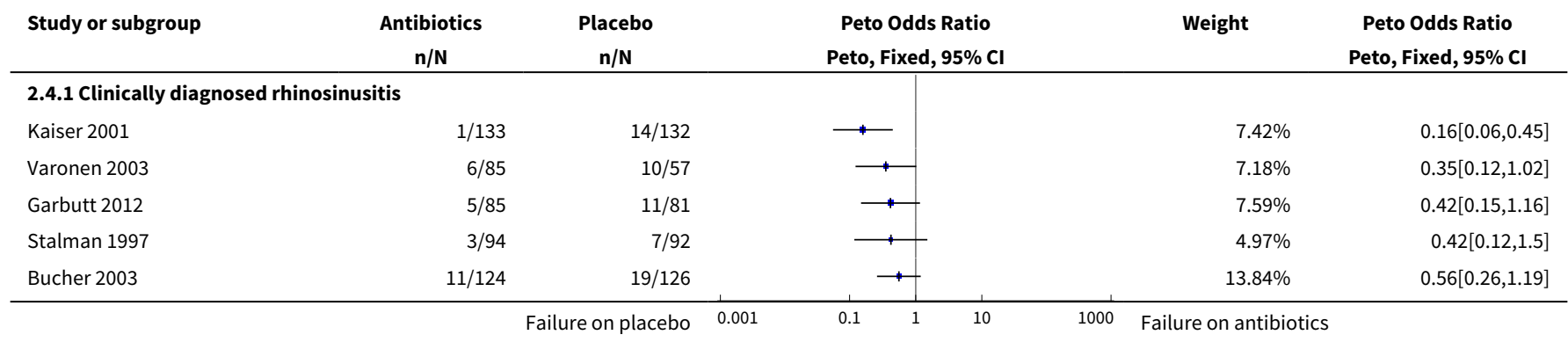




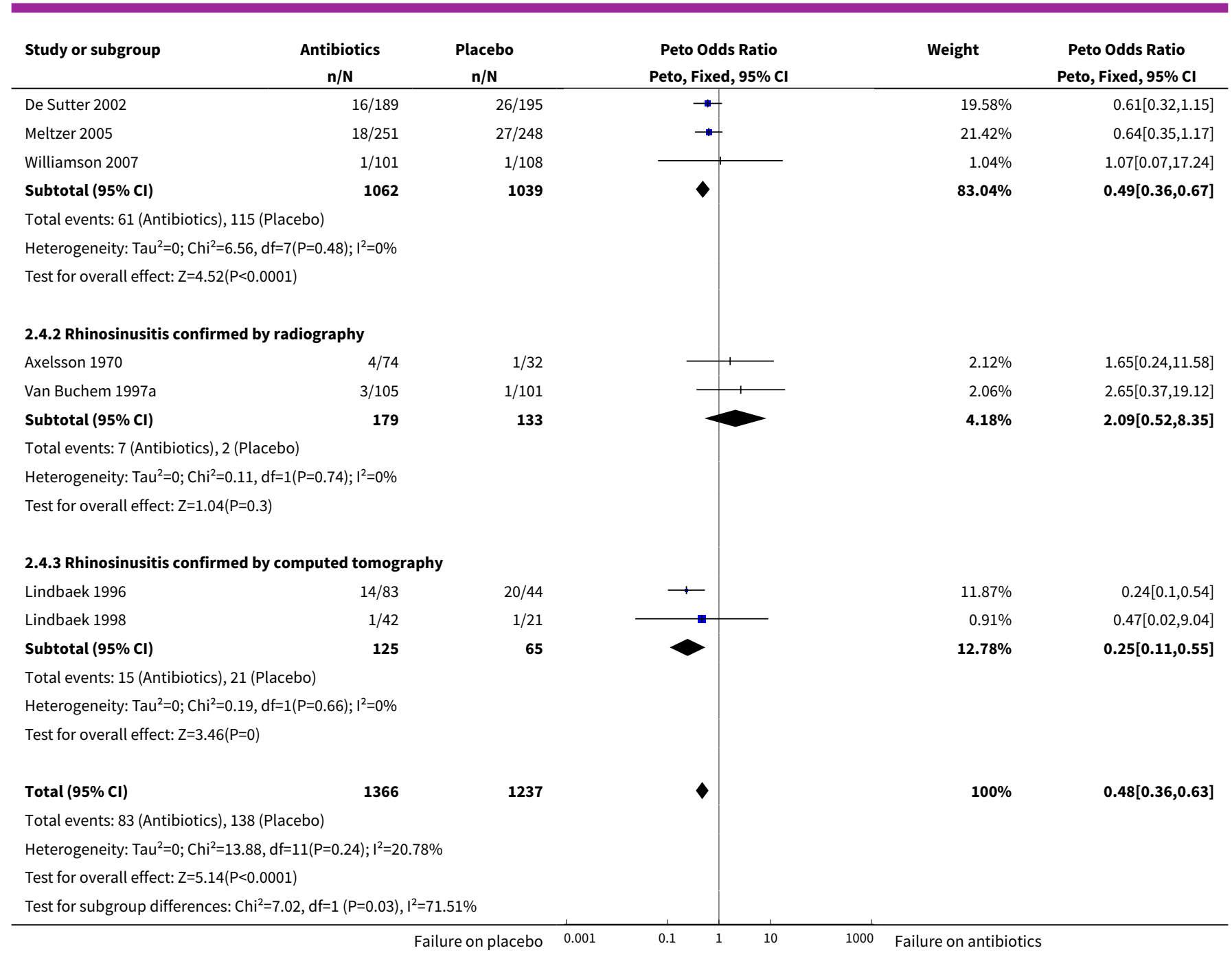

\section{Comparison 3. Sensitivity analyses}

\begin{tabular}{|c|c|c|c|c|}
\hline Outcome or subgroup title & No. of studies & $\begin{array}{l}\text { No. of partici- } \\
\text { pants }\end{array}$ & Statistical method & Effect size \\
\hline 1 Clinically diagnosed rhinosinusitis & 9 & 19409 & $\begin{array}{l}\text { Odds Ratio (M-H, Fixed, } \\
95 \% \mathrm{Cl})\end{array}$ & $1.22[1.14,1.29]$ \\
\hline 1.1 Cure at 1 week & 4 & 856 & $\begin{array}{l}\text { Odds Ratio (M-H, Fixed, } \\
95 \% \mathrm{Cl})\end{array}$ & $1.07[0.81,1.41]$ \\
\hline 1.2 Cure at 10 days & 4 & 1048 & $\begin{array}{l}\text { Odds Ratio (M-H, Fixed, } \\
95 \% \mathrm{Cl})\end{array}$ & $1.19[0.92,1.53]$ \\
\hline 1.3 Cure at 2 weeks & 4 & 717 & $\begin{array}{l}\text { Odds Ratio (M-H, Fixed, } \\
95 \% \mathrm{Cl})\end{array}$ & $1.37[0.98,1.91]$ \\
\hline 1.4 Cure at 1 week, with Garbutt data & 5 & 1011 & $\begin{array}{l}\text { Odds Ratio (M-H, Fixed, } \\
95 \% \mathrm{Cl})\end{array}$ & $1.20[0.93,1.54]$ \\
\hline
\end{tabular}




\begin{tabular}{|c|c|c|c|c|}
\hline Outcome or subgroup title & No. of studies & $\begin{array}{l}\text { No. of partici- } \\
\text { pants }\end{array}$ & Statistical method & Effect size \\
\hline 1.5 Cure at 10 days, with Garbutt data & 5 & 1203 & $\begin{array}{l}\text { Odds Ratio (M-H, Fixed, } \\
95 \% \mathrm{Cl})\end{array}$ & $1.16[0.91,1.47]$ \\
\hline $\begin{array}{l}1.6 \text { Influence of missing data: cure at any } \\
\text { time point if dropouts were successes }\end{array}$ & 8 & 1785 & $\begin{array}{l}\text { Odds Ratio (M-H, Fixed, } \\
95 \% \mathrm{Cl})\end{array}$ & $1.24[1.02,1.52]$ \\
\hline $\begin{array}{l}1.7 \text { Influence of missing data: cure at any } \\
\text { time point if dropouts were failures }\end{array}$ & 8 & 1785 & $\begin{array}{l}\text { Odds Ratio (M-H, Fixed, } \\
95 \% \mathrm{Cl})\end{array}$ & $1.24[1.02,1.51]$ \\
\hline $\begin{array}{l}1.8 \text { Influence of missing data: cure at any } \\
\text { time point if dropouts had the same cure } \\
\text { rate as control group }\end{array}$ & 8 & 1785 & $\begin{array}{l}\text { Odds Ratio (M-H, Fixed, } \\
95 \% \mathrm{Cl})\end{array}$ & $1.24[1.02,1.51]$ \\
\hline $\begin{array}{l}1.9 \text { Influence of missing data: cure at } 1 \\
\text { week if dropouts were successes }\end{array}$ & 4 & 901 & $\begin{array}{l}\text { Odds Ratio (M-H, Fixed, } \\
95 \% \mathrm{Cl})\end{array}$ & $1.03[0.79,1.35]$ \\
\hline $\begin{array}{l}1.10 \text { Influence of missing data: cure at } 1 \\
\text { week if dropouts were failures }\end{array}$ & 4 & 901 & $\begin{array}{l}\text { Odds Ratio (M-H, Fixed, } \\
95 \% \mathrm{Cl})\end{array}$ & $1.10[0.84,1.44]$ \\
\hline $\begin{array}{l}1.11 \text { Influence of missing data: cure at } 1 \\
\text { week if dropouts had the same cure rate as } \\
\text { control group }\end{array}$ & 3 & 632 & $\begin{array}{l}\text { Odds Ratio (M-H, Fixed, } \\
95 \% \mathrm{Cl})\end{array}$ & $1.09[0.79,1.50]$ \\
\hline $\begin{array}{l}1.12 \text { Influence of missing data: cure at } 10 \\
\text { days if dropouts were successes }\end{array}$ & 3 & 840 & $\begin{array}{l}\text { Odds Ratio (M-H, Fixed, } \\
95 \% \mathrm{Cl})\end{array}$ & $1.25[0.94,1.66]$ \\
\hline $\begin{array}{l}1.13 \text { Influence of missing data: cure at } 10 \\
\text { days if dropouts were failures }\end{array}$ & 3 & 840 & $\begin{array}{l}\text { Odds Ratio (M-H, Fixed, } \\
95 \% \mathrm{Cl})\end{array}$ & $1.25[0.94,1.65]$ \\
\hline $\begin{array}{l}1.14 \text { Influence of missing data: cure at } 10 \\
\text { days if dropouts had the same cure rate as } \\
\text { control group }\end{array}$ & 3 & 840 & $\begin{array}{l}\text { Odds Ratio (M-H, Fixed, } \\
95 \% \mathrm{Cl})\end{array}$ & $1.24[0.93,1.65]$ \\
\hline $\begin{array}{l}1.15 \text { Influence of missing data: cure at } 2 \\
\text { weeks if dropouts were successes }\end{array}$ & 4 & 1026 & $\begin{array}{l}\text { Odds Ratio (M-H, Fixed, } \\
95 \% \mathrm{Cl})\end{array}$ & $1.30[0.98,1.73]$ \\
\hline $\begin{array}{l}1.16 \text { Influence of missing data: cure at } 2 \\
\text { weeks if dropouts were failures }\end{array}$ & 4 & 776 & $\begin{array}{l}\text { Odds Ratio (M-H, Fixed, } \\
95 \% \mathrm{Cl})\end{array}$ & $1.35[0.99,1.84]$ \\
\hline $\begin{array}{l}1.17 \text { Influence of missing data: cure at } 2 \\
\text { weeks if dropouts had the same cure rate } \\
\text { as control group }\end{array}$ & 4 & 776 & $\begin{array}{l}\text { Odds Ratio (M-H, Fixed, } \\
95 \% \mathrm{Cl})\end{array}$ & $1.35[0.99,1.86]$ \\
\hline $\begin{array}{l}1.18 \text { Overall treatment effect (with Young } \\
2008 \text { data concerning Stalman) }\end{array}$ & 8 & 1687 & $\begin{array}{l}\text { Odds Ratio (M-H, Fixed, } \\
95 \% \mathrm{Cl})\end{array}$ & $1.27[1.04,1.56]$ \\
\hline 2 Rhinosinusitis confirmed by imaging & 5 & 1086 & $\begin{array}{l}\text { Odds Ratio (M-H, Fixed, } \\
95 \% \mathrm{Cl})\end{array}$ & $1.85[1.41,2.44]$ \\
\hline 2.1 Cure at any time point & 5 & 584 & $\begin{array}{l}\text { Odds Ratio (M-H, Fixed, } \\
95 \% \mathrm{Cl} \text { ) }\end{array}$ & $1.71[1.20,2.45]$ \\
\hline 2.2 Cure or improvement at any time point & 4 & 502 & $\begin{array}{l}\text { Odds Ratio (M-H, Fixed, } \\
95 \% \mathrm{Cl} \text { ) }\end{array}$ & $2.08[1.35,3.21]$ \\
\hline
\end{tabular}


Analysis 3.1. Comparison 3 Sensitivity analyses, Outcome 1 Clinically diagnosed rhinosinusitis.

\begin{tabular}{|c|c|c|c|c|c|}
\hline Study or subgroup & $\begin{array}{c}\text { Antibiotics } \\
\mathrm{n} / \mathrm{N}\end{array}$ & $\begin{array}{c}\text { Placebo } \\
\mathrm{n} / \mathrm{N}\end{array}$ & $\begin{array}{c}\text { Odds Ratio } \\
\text { M-H, Fixed, } 95 \% \mathrm{Cl}\end{array}$ & Weight & $\begin{array}{c}\text { Odds Ratio } \\
\text { M-H, Fixed, } 95 \% \mathrm{Cl}\end{array}$ \\
\hline \multicolumn{6}{|l|}{ 3.1.1 Cure at 1 week } \\
\hline Bucher 2003 & $36 / 122$ & $38 / 125$ & 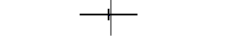 & $1.36 \%$ & $0.96[0.56,1.65]$ \\
\hline Kaiser 2001 & $76 / 133$ & $75 / 132$ & + & $1.65 \%$ & $1.01[0.62,1.65]$ \\
\hline Norrelund 1978 & $40 / 71$ & $33 / 64$ & $\rightarrow-$ & $0.78 \%$ & $1.21[0.62,2.39]$ \\
\hline Williamson 2007 & $53 / 101$ & $52 / 108$ & + & $1.22 \%$ & $1.19[0.69,2.05]$ \\
\hline Subtotal $(95 \% \mathrm{Cl})$ & 427 & 429 & & $5.01 \%$ & $1.07[0.81,1.41]$ \\
\hline \multicolumn{6}{|c|}{ Total events: 205 (Antibiotics), 198 (Placebo) } \\
\hline \multicolumn{6}{|c|}{ Heterogeneity: Tau $^{2}=0 ; \mathrm{Chi}^{2}=0.48, \mathrm{df}=3(\mathrm{P}=0.92) ; I^{2}=0 \%$} \\
\hline \multicolumn{6}{|c|}{ Test for overall effect: $Z=0.5(P=0.62)$} \\
\hline \multicolumn{6}{|c|}{ 3.1.2 Cure at 10 days } \\
\hline De Sutter 2002 & $73 / 189$ & $59 / 195$ & + & $1.83 \%$ & $1.45[0.95,2.21]$ \\
\hline Kaiser 2001 & $77 / 135$ & $76 / 134$ & $\leftarrow$ & $1.68 \%$ & $1.01[0.63,1.64]$ \\
\hline Stalman 1997 & $56 / 94$ & $55 / 92$ & 1 & $1.15 \%$ & $0.99[0.55,1.78]$ \\
\hline Williamson 2007 & $71 / 101$ & $71 / 108$ & + & $1.04 \%$ & $1.23[0.69,2.21]$ \\
\hline Subtotal $(95 \% \mathrm{Cl})$ & 519 & 529 & $\Rightarrow$ & $5.7 \%$ & $1.19[0.92,1.53]$ \\
\hline \multicolumn{6}{|c|}{ Total events: 277 (Antibiotics), 261 (Placebo) } \\
\hline \multicolumn{6}{|c|}{ Heterogeneity: Tau $^{2}=0 ; \mathrm{Chi}^{2}=1.66, \mathrm{df}=3(\mathrm{P}=0.65) ; \mathrm{I}^{2}=0 \%$} \\
\hline \multicolumn{6}{|c|}{ Test for overall effect: $Z=1.35(P=0.18)$} \\
\hline \multicolumn{6}{|c|}{ 3.1.3 Cure at 2 weeks } \\
\hline Bucher 2003 & $95 / 124$ & $93 / 126$ & $\leftarrow$ & $1.11 \%$ & $1.16[0.65,2.07]$ \\
\hline Merenstein 2005 & $32 / 56$ & $25 / 60$ & $\rightarrow$ & $0.53 \%$ & $1.87[0.89,3.9]$ \\
\hline Varonen 2003 & $70 / 85$ & $39 / 57$ & $\longrightarrow$ & $0.42 \%$ & $2.15[0.98,4.74]$ \\
\hline Williamson 2007 & $75 / 101$ & $80 / 108$ & - & $1.02 \%$ & $1.01[0.54,1.88]$ \\
\hline Subtotal $(95 \% \mathrm{Cl})$ & 366 & 351 & $\checkmark$ & $3.08 \%$ & $1.37[0.98,1.91]$ \\
\hline \multicolumn{6}{|c|}{ Total events: 272 (Antibiotics), 237 (Placebo) } \\
\hline \multicolumn{6}{|c|}{ Heterogeneity: $\mathrm{Tau}^{2}=0 ; \mathrm{Ch}^{2}=3.18, \mathrm{df}=3(\mathrm{P}=0.36) ; \mathrm{I}^{2}=5.78 \%$} \\
\hline \multicolumn{6}{|c|}{ Test for overall effect: $Z=1.86(P=0.06)$} \\
\hline \multicolumn{6}{|c|}{ 3.1.4 Cure at 1 week, with Garbutt data } \\
\hline Bucher 2003 & $36 / 122$ & $38 / 125$ & - & $1.36 \%$ & $0.96[0.56,1.65]$ \\
\hline Garbutt 2012 & $60 / 81$ & $41 / 74$ & $\longrightarrow$ & $0.57 \%$ & $2.3[1.17,4.52]$ \\
\hline Kaiser 2001 & $76 / 133$ & $75 / 132$ & - & $1.65 \%$ & $1.01[0.62,1.65]$ \\
\hline Norrelund 1978 & $40 / 71$ & $33 / 64$ & - & $0.78 \%$ & $1.21[0.62,2.39]$ \\
\hline Williamson 2007 & $53 / 101$ & $52 / 108$ & + & $1.22 \%$ & $1.19[0.69,2.05]$ \\
\hline Subtotal (95\% Cl) & 508 & 503 & 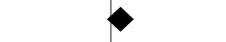 & $5.58 \%$ & $1.2[0.93,1.54]$ \\
\hline \multicolumn{6}{|c|}{ Total events: 265 (Antibiotics), 239 (Placebo) } \\
\hline \multicolumn{6}{|c|}{ Heterogeneity: Tau $^{2}=0 ; \mathrm{Chi}^{2}=4.68, \mathrm{df}=4(\mathrm{P}=0.32) ;\left.\right|^{2}=14.46 \%$} \\
\hline \multicolumn{6}{|c|}{ Test for overall effect: $Z=1.39(P=0.16)$} \\
\hline \multicolumn{6}{|c|}{ 3.1.5 Cure at 10 days, with Garbutt data } \\
\hline De Sutter 2002 & $73 / 189$ & $59 / 195$ & + & $1.83 \%$ & $1.45[0.95,2.21]$ \\
\hline Garbutt 2012 & $63 / 81$ & $59 / 74$ & - & $0.7 \%$ & $0.89[0.41,1.93]$ \\
\hline Kaiser 2001 & $77 / 135$ & $76 / 134$ & + & $1.68 \%$ & $1.01[0.63,1.64]$ \\
\hline Stalman 1997 & $56 / 94$ & $55 / 92$ & 1 & $1.15 \%$ & $0.99[0.55,1.78]$ \\
\hline Williamson 2007 & $71 / 101$ & $71 / 108$ & 1 & $1.04 \%$ & $1.23[0.69,2.21]$ \\
\hline Subtotal $(95 \% \mathrm{Cl})$ & 600 & 603 & $\leftrightarrow$ & $6.41 \%$ & $1.16[0.91,1.47]$ \\
\hline
\end{tabular}




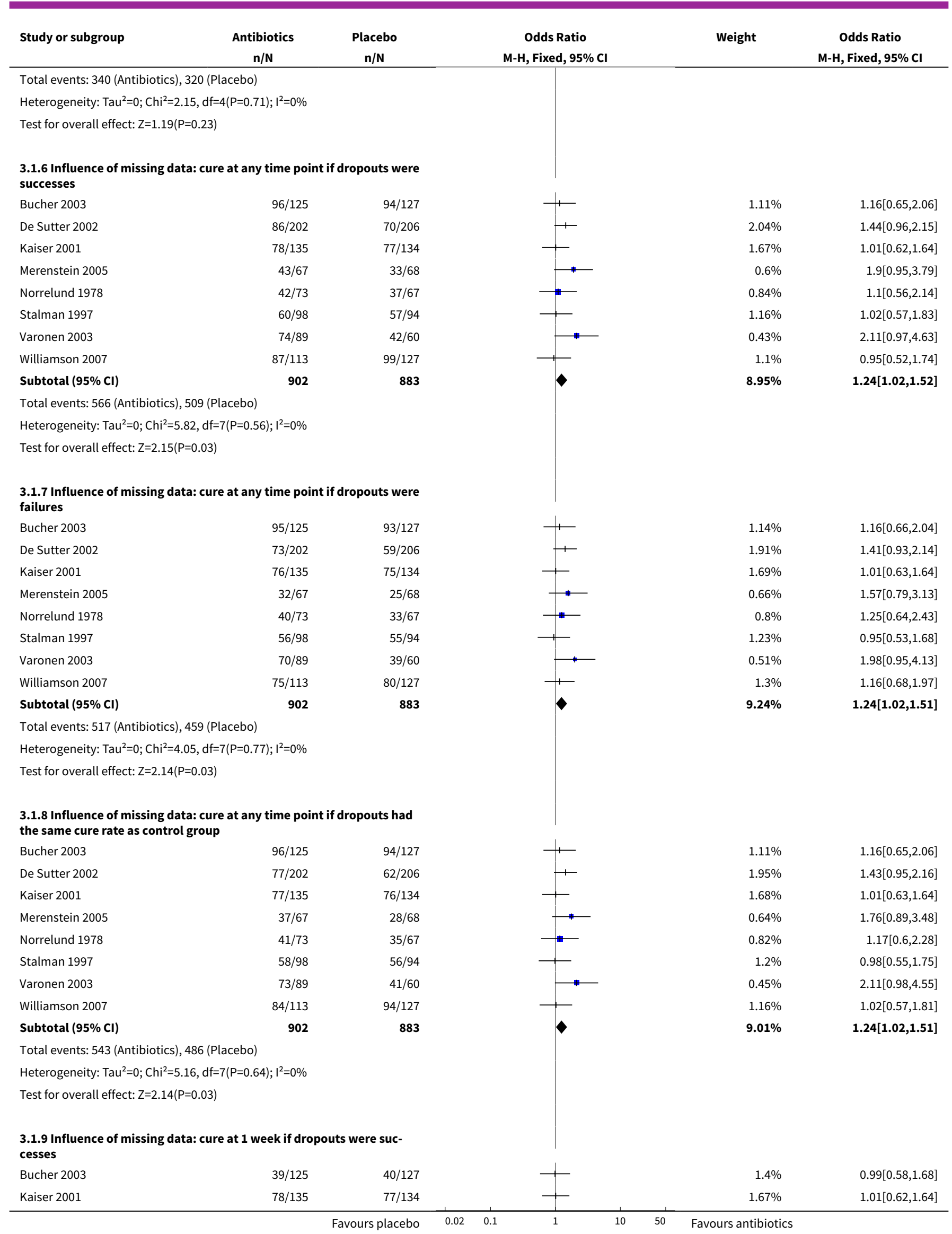




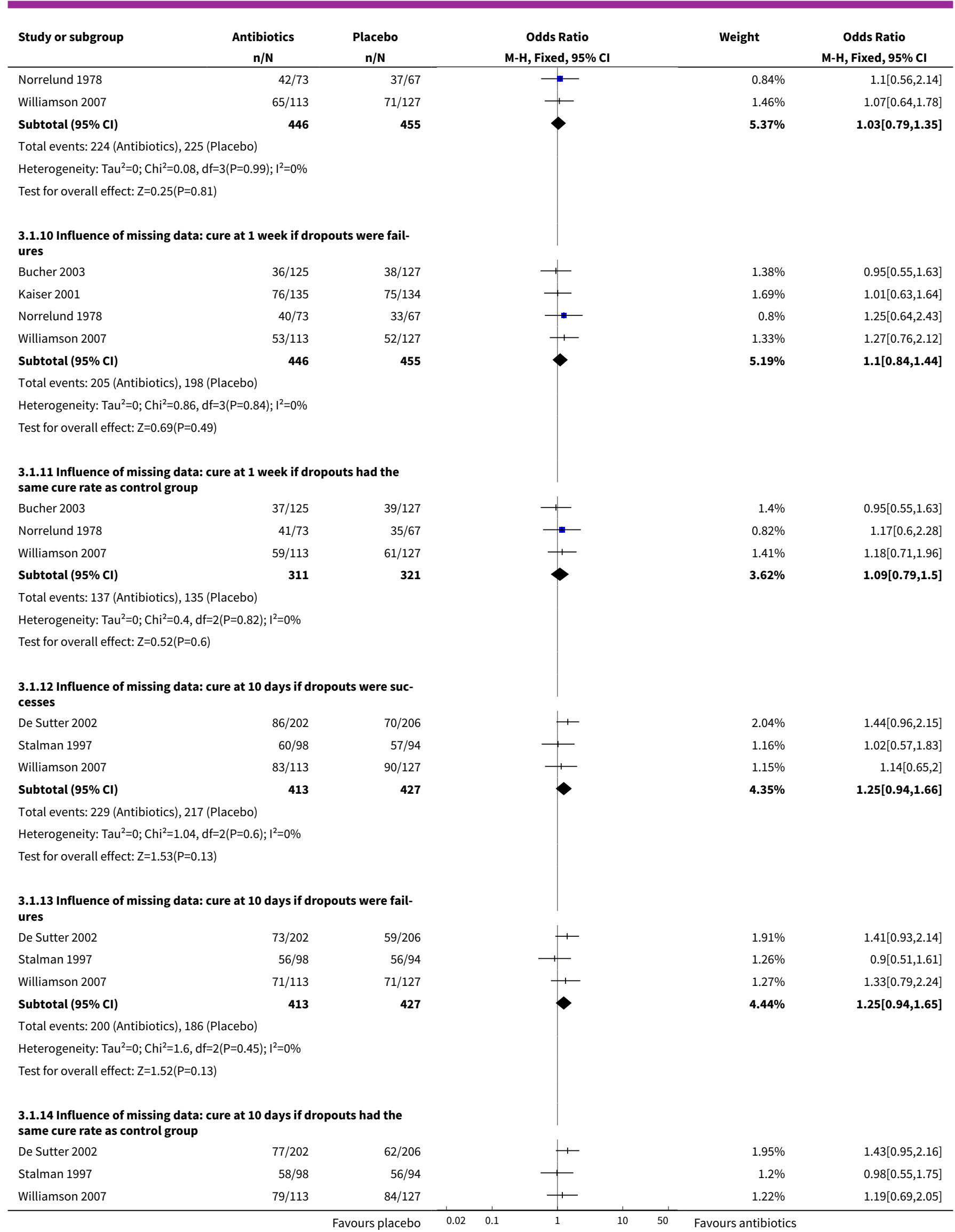




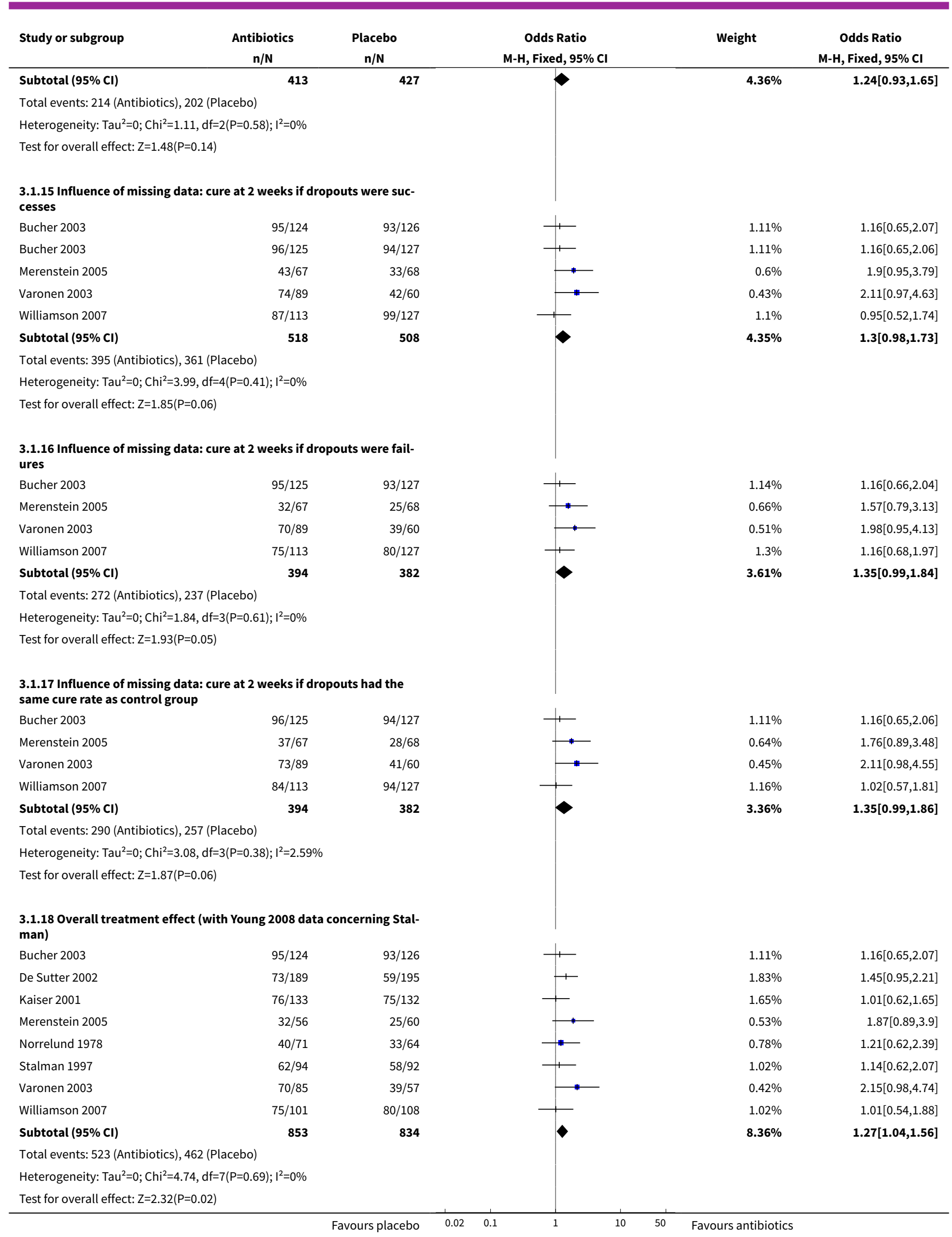




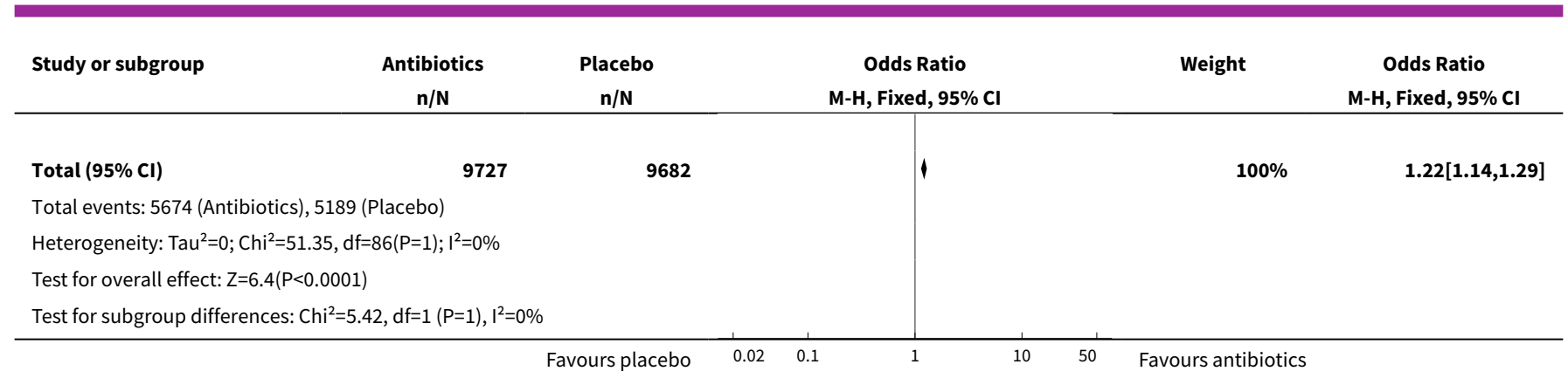

Analysis 3.2. Comparison 3 Sensitivity analyses, Outcome 2 Rhinosinusitis confirmed by imaging.

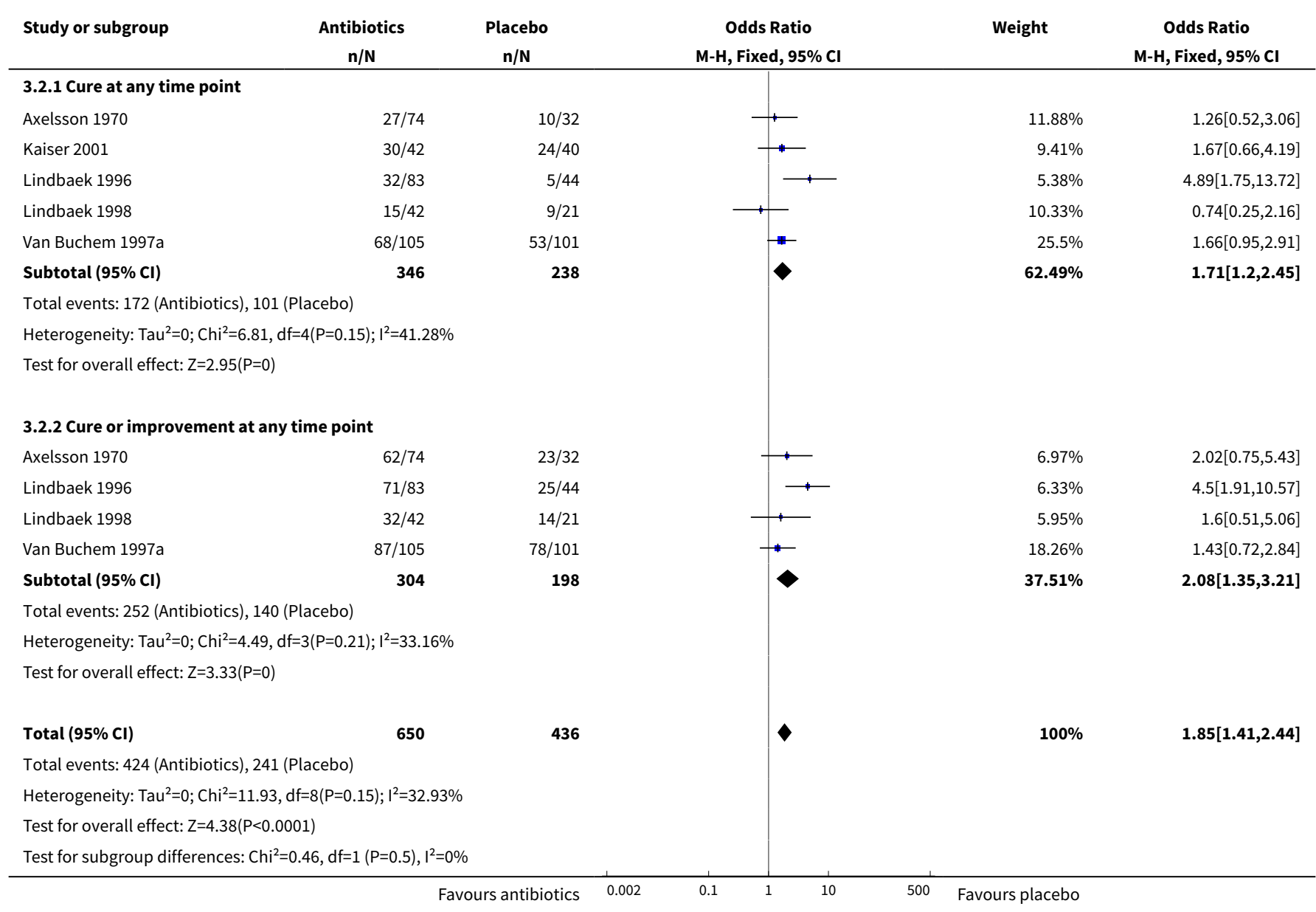

\section{APPENDICES}

\section{Appendix 1. MEDLINE and CENTRAL search strategy} MEDLINE (Ovid)

1 exp Sinusitis/

2 sinusit*.tw.

3 Rhinitis/ 
4 rhinit*.tw.

5 rhinosinusit*.tw.

6 nasosinusit*.tw.

7 ((suppurative or purulent) adj2 (nasal discharge or rhinitis or rhinorrhoea or rhinorrhoea)).tw.

8 or/1-7

9 exp Anti-Bacterial Agents/

10 antibacterial*.tw.

11 antibiotic ${ }^{*}$.tw.

$12 \exp$ Amoxicillin/

13 amoxicillin ${ }^{\star} . \mathrm{tw}, \mathrm{nm}$.

14 Ampicillin/

15 ampicillin*.tw,nm.

16 Azithromycin/

17 azithromycin.tw,nm.

18 Cefaclor/

19 cefaclor.tw,nm.

20 exp Cefadroxil/

21 cefadroxil.tw, nm.

22 cefatrizine.tw, nm.

23 Cefuroxime/

24 cefuroxim ${ }^{\star}$.tw,nm.

25 Cephalexin/

26 cephalexin ${ }^{\star} . t w, n m$.

27 Cephalosporins/

28 cephalosporin*.tw,nm.

29 Ciprofloxacin/

30 ciprofloxacin*.tw,nm.

31 Clarithromycin/

32 clarithromycin ${ }^{\star} . \mathrm{tw}, \mathrm{nm}$.

33 Clindamycin/

34 clindamycin*.tw,nm.

35 Doxycycline/

36 doxycyclin*.tw,nm.

37 Erythromycin/

38 erythromycin ${ }^{\star}$. tw, nm.

39 Fluoroquinolones/

40 fluoroquinolone ${ }^{\star} . \mathrm{tw}, \mathrm{nm}$.

41 levofloxacin.tw,nm.

42 Lincomycin/

43 lincomycin*.tw, nm.

44 Macrolides/

45 macrolide*.tw,nm.

46 Minocycline/

47 minocyclin*.tw,nm.

48 Miocamycin/

49 (miocamycin* or miokamycin ${ }^{\star}$ ).tw,nm.

50 moxifloxacin*.tw,nm.

51 norfloxacin.tw,nm.

52 Norfloxacin/

53 Ofloxacin/

54 ofloxacin.tw, nm.

55 Penicillins/

56 penicillin* $^{*}$ tw, nm.

57 Quinolones/

58 quinolone ${ }^{\star} . \mathrm{tw}, \mathrm{nm}$.

59 Spiramycin/

60 spiramycin.tw, nm.

61 telithromycin.tw, nm.

62 tetracyclines/ or tetracycline/

63 tetracycline ${ }^{\star} . \mathrm{tw}, \mathrm{nm}$.

64 Trimethoprim-Sulfamethoxazole Combination/

65 trimethoprim-sulfamethoxazole combination.tw, nm.

Antibiotics for acute rhinosinusitis in adults (Review)

Copyright $\odot 2018$ The Cochrane Collaboration. Published by John Wiley \& Sons, Ltd. 
66 cotrimoxazole ${ }^{\star} . \mathrm{tw}, \mathrm{nm}$.

67 or/9-66

688 and 67

\section{Appendix 2. Embase (Elsevier) search strategy}

\#21 \#12 AND \#20

\#20 \#15 NOT \#19

\#19 \#16 NOT \#18

\#18 \#16 AND \#17

\#17 'human'/de

\#16 'animal'/de OR 'nonhuman'/de OR 'animal experiment'/de

\#15 \#13 OR \#14

\#14 crossover*:ab,ti OR 'cross-over':ab,ti OR 'cross over':ab,ti OR placebo*:ab,ti OR (doubl* NEXT/1 blind*):ab,ti OR allocat*:ab,ti OR random*:ab,ti OR trial:ti

\#13 'randomized controlled trial'/exp OR 'single blind procedure'/exp OR 'double blind procedure'/exp OR 'crossover procedure'/exp

\#12 \#6 AND \#11

\#11 \#7 OR \#8 OR \#9 OR \#10

\#10 amoxicillin:ab,ti OR ampicillin*:ab,ti OR azithromycin:ab,ti OR cefaclor:ab,ti OR cefadroxil:ab,ti OR cefatrizine:ab,ti OR cefuroxim:ab,ti OR cephalexin*:ab,ti OR cephalosporin*:ab,ti OR ciprofloxacin*:ab,ti OR clarithromycin*:ab,ti OR clindamycin:ab,ti OR doxycyclin*:ab,ti OR erythromycin*:ab,ti OR fluoroquinolone*:ab,ti OR levofloxacin*:ab,ti OR lincomycin*:ab,ti OR macrolide*:ab,ti OR minocyclin*:ab,ti OR miocamycin*:ab,ti OR miokamycin*:ab,ti OR moxifloxacin*:ab,ti OR norfloxacin*:ab,ti OR ofloxacin*:ab,ti OR penicillin*:ab,ti OR quinolone*:ab,ti OR spiramycin*:ab,ti OR telithromycin*:ab,ti OR tetracyclin*:ab,ti OR trimethoprim*:ab,ti OR cotrimoxazol*:ab,ti

\#9 'amoxicillin'/de OR 'ampicillin'/de OR 'azithromycin'/de OR 'cefaclor'/de OR 'cefadroxil'/de OR 'cefuroxime'/de OR 'cefalexin'/ de OR 'cephalosporin'/de OR 'ciprofloxacin'/de OR 'clarithromycin'/de OR 'clindamycin'/de OR 'doxycycline'/de OR 'erythromycin'/de OR 'lincomycin'/de OR 'macrolide'/de OR 'quinolone derivative'/de OR 'minocycline'/de OR 'miokamycin'/exp OR 'norfloxacin'/de OR 'ofloxacin'/de OR 'penicillin derivative'/de OR 'spiramycin'/de OR 'tetracycline derivative'/de OR 'cotrimoxazole'/de

\#8 antibiotic $: a b, t i$

$\# 7$ 'antibiotic agent'/exp

\#6 \#1 OR \#2 OR \#3 OR \#4 OR \#5

\#5 ((suppurative OR purulent) NEAR/2 ('nasal discharge' OR rhinitis OR rhinorrhea OR rhinorrhoea)):ab,ti

\#4 rhinit $^{\star}$ :ab,ti OR rhinosinusit*a ab,ti OR nasosinusit*:ab,ti

\#3 'rhinitis'/de OR 'rhinosinusitis'/de

\#2 sinusit*:ab,ti

\#1 'sinusitis'/exp

\section{Appendix 3. WHO International Clinical Trials Registry Platform (ICTRP) search strategy}

sinusit $^{*}$ AND antibacterial ${ }^{*}$

OR rhinit* AND antibacterial*

OR rhinosinusit* AND antibacterial*

OR nasosinusit* AND antibacterial ${ }^{\star}$

OR suppurative nasal discharge AND antibacterial*

OR purulent nasal discharge AND antibacterial ${ }^{\star}$

OR suppurative rhinorrhoea AND antibacterial*

OR purulent rhinorrhoea AND antibacterial ${ }^{*}$

OR suppurative rhinorrhea AND antibacterial*

OR purulent rhinorrhea AND antibacterial*

OR sinusit* AND antibiotic*

OR rhinit* AND antibiotic*

OR rhinosinusit* AND antibiotic*

OR nasosinusit* AND antibiotic*

OR suppurative nasal discharge AND antibiotic*

OR purulent nasal discharge AND antibiotic*

OR suppurative rhinorrhoea AND antibiotic*

OR purulent rhinorrhoea AND antibiotic*

OR suppurative rhinorrhea AND antibiotic*

OR purulent rhinorrhea AND antibiotic*

\section{Appendix 4. ClinicalTrials.gov search strategy}

(sinusitis OR rhinitis OR rhinosinusitis OR nasosinusitis OR ((suppurative OR purulent) AND nasal discharge OR rhinorrhoea OR rhinorrhea)) AND (antibacterial OR anti-bacterial OR antibiotic OR antibiotics) 
WHAT'S NEW

\begin{tabular}{lll}
\hline Date & Event & Description \\
\hline 18 January 2018 & $\begin{array}{l}\text { New citation required but conclusions } \\
\text { have not changed }\end{array}$ & $\begin{array}{l}\text { Two Cochrane Reviews, 'Antibiotics for acute maxillary sinusitis } \\
\text { in adults' (Ahovuo-Saloranta 2014) and 'Antibiotics for clinical- } \\
\text { ly diagnosed acute rhinosinusitis in adults' (De Sutter 2012), de- } \\
\text { scribed the effect of antibiotics for acute rhinosinusitis. Although } \\
\text { both reviews studied the same condition, they studied different }\end{array}$ \\
& $\begin{array}{l}\text { populations: people diagnosed according to clinical signs, con- } \\
\text { firmed or not by imaging or bacterial culture (Ahovuo-Saloran- }\end{array}$ \\
& $\begin{array}{l}\text { ta 2014), and people diagnosed according to clinical signs and } \\
\text { symptoms (De Sutter 2012). Different approaches resulted in dif- } \\
\text { ferent conclusions, which was confusing for clinicians. We there- } \\
\text { fore merged these Cochrane Reviews whilst maintaining the rele- } \\
\text { vant distinction between populations diagnosed by clinical signs } \\
\text { and symptoms, or imaging. }\end{array}$ \\
&
\end{tabular}

18 January $2018 \quad$ New search has been performed

Searches updated. As a consequence of merging two Cochrane Reviews, we incorporated five trials from Ahovuo-Saloranta 2014 in the analyses (Axelsson 1970; Lindbaek 1996; Lindbaek 1998; Rantanen 1973; Van Buchem 1997a). The comparison between antibiotics, as published by Ahovuo-Saloranta 2014, was omitted. Instead of clinical trials, local up-to-date antibiotic resistance patterns should guide clinicians in making the best choice for the appropriate antibiotic and dose in the subgroup of people with suspected bacterial rhinosinusitis. No new studies were added as a result of the update.

\section{HIST O RY}

Protocol first published: Issue 3, 2006

Review first published: Issue 10, 2012

\begin{tabular}{lll}
\hline Date & Event & Description \\
\hline 2 April 2014 & New search has been performed & Searches updated. \\
\hline 7 April 2008 & Amended & Converted to new review format \\
\hline
\end{tabular}

\section{CONTRIBUTIONS OF AUTHORS}

An De Sutter (ADS) wrote the first draft of the protocol.

Marieke Lemiengre (ML) wrote the first draft of the amalgamation of the separate reviews Ahovuo-Saloranta 2014 and De Sutter 2012. ADS, Mieke van Driel (MVD), Dan Merenstein (DM), Helena Liira (HL), and Marjukka Mäkelä (MM) commented on the draft and suggested changes that consequently led to a new version.

\section{DECLARATIONSOF INTEREST}

Marieke B Lemiengre: none known.

Mieke L van Driel: Co-author of De Sutter 2002. No other conflicts of interest known.

Dan Merenstein: Main investigator of Merenstein 2005. No other conflicts of interest known.

Helena Liira: Main investigator of Varonen 2003. No other conflicts of interest known.

Marjukka Mäkelä: Co-author of Varonen 2003. No other conflicts of interest known.

An IM De Sutter: Main investigator of De Sutter 2002. No other conflicts of interest known. 


\section{SOURCES OF SUPPORT}

\section{Internal sources}

- Ghent University, Belgium.

Salary

\section{External sources}

- No sources of support supplied

\section{DIFFERENCES BETWEEN PROTOCOL AND REVIEW}

Two Cochrane Reviews, 'Antibiotics for acute maxillary sinusitis in adults' and 'Antibiotics for clinically diagnosed acute rhinosinusitis in adults' (Ahovuo-Saloranta 2014; De Sutter 2012), described the effects of antibiotics for acute rhinosinusitis. Although both reviews studied the same condition, they evaluated different populations, namely participants who were diagnosed by imaging (Ahovuo-Saloranta 2014), versus participants who were diagnosed by clinical signs and symptoms (De Sutter 2012). Different approaches resulted in different conclusions, which was confusing for clinicians. We therefore merged these Cochrane Reviews while maintaining the relevant distinction between both populations. The comparison between antibiotics, as published by Ahovuo-Saloranta 2014, was omitted. Instead of clinical trials, local up-to-date antibiotic resistance patterns should guide clinicians in making the best choice regarding which antibiotic and dose in the subgroup of people with suspected bacterial rhinosinusitis should be prescribed.

\section{NDEX TERMS}

\section{Medical Subject Headings (MeSH)}

Acute Disease; Anti-Bacterial Agents [ ${ }^{\star}$ therapeutic use]; Radiography; Randomized Controlled Trials as Topic; Rhinitis [diagnostic imaging] [ ${ }^{*}$ drug therapy]; Sinusitis [diagnostic imaging] [*drug therapy]; Time Factors

\section{MeSH check words}

Adult; Humans 